\title{
The Choice of Valuation Techniques in Practice: Education Versus Profession
}

\author{
Mukhlynina, Liliya ; Nyborg, Kjell G
}

\begin{abstract}
We use a survey approach to learn about valuation professionals' choices and implementations of valuation techniques in practice. Most use both multiples and DCF, but implement DCF in a way that almost turns it into a multiples exercise. Confusion reigns with respect to interest tax shields and the WACC. Higher educational levels do not reduce the confusion. The survey design allows us to control for a respondent's professional subgroup(e.g., consulting), education, experience, and valuation-purpose characteristics. We find that profession matters more than education; different professions have different valuation cultures. Other factors are less important. The relative unimportance of education raises questions about the role, benefit, and optimal mode of higher level finance education.
\end{abstract}

DOI: https://doi.org/10.1561/104.00000088

Posted at the Zurich Open Repository and Archive, University of Zurich ZORA URL: https://doi.org/10.5167/uzh-190474

Journal Article

Accepted Version

Originally published at:

Mukhlynina, Liliya; Nyborg, Kjell G (2020). The Choice of Valuation Techniques in Practice: Education Versus Profession. Critical Finance Review, 9(1-2):201-265.

DOI: https://doi.org/10.1561/104.00000088 


\section{The Choice of Valuation Techniques in Practice: Education versus Profession ${ }^{1}$}

\author{
Lilia Mukhlynina \\ University of Zurich \\ University of Zurich, \\ Swiss Finance Institute, \\ and CEPR
}

September 2018

\footnotetext{
${ }^{1}$ We would like to thank Pamela Ghilardi for assistance with the implementation of the survey on which this paper is based as well as all those who participated in the survey. We would also like to express our gratitude for comments from Michel Habib, Stefano Lugo, and Ivo Welch as well as participants at a brown bag seminar at the University of Zurich, December 2014, the European Financial Management Association Annual Meeting, Basel June 2016, the European Finance Association Annual Meeting, Oslo August 2016, and the EACVA Annual Meeting, Munich, October 2017. Nyborg (corresponding author): Department of Banking and Finance, University of Zurich, Plattenstrasse 14, CH-8032 Zurich, Switzerland; Swiss Finance Institute and CEPR. Email: kjell.nyborg@bf.uzh.ch. Mukhlynina: lilia.mukhlynina@bf.uzh.ch.
} 


\section{Abstract \\ The Choice of Valuation Techniques in Practice: Education versus Profession}

We use a survey approach to learn about valuation professionals' choices and implementations of valuation techniques in practice. Most use both multiples and DCF, but implement DCF in a way that almost turns it into a multiples exercise. Confusion reigns with respect to interest tax shields and the WACC. Higher educational levels do not reduce the confusion. The survey design allows us to control for a respondent's professional subgroup (e.g., consulting), education, experience, and valuation-purpose characteristics. We find that profession matters more than education; different professions have different valuation cultures. Other factors are less important. The relative unimportance of education raises questions about the role, benefit, and optimal mode of higher level finance education.

Keywords: Valuation, survey, sociological hypothesis, multiples, DCF.

JEL: G31, G32, G24, G02, A11, A14, A20. 


\section{Introduction}

"There seem to be lots of academics asking how analysts in the real world use CAPM or calculate the cost of capital. The answer is, people don't waste time on this. No one ever lost/made money because they calculated the WACC better than consensus. You accademic [sic] guys are wasting your time."

- A consultant ${ }^{1}$

The valuation of firms, projects, and transactions is a core topic in business and finance. How it is carried out in practice directly affects investment decisions and the allocation of resources in the economy. As a result, there is much academic work on the topic, with the main messages communicated in textbooks and widely taught. Yet, as illustrated in the quote above, it is no secret that those that do valuation for a living - the valuation professionals - do not always concur with academic wisdom. However, there is little systematic knowledge that informs on how valuation professionals actually go about the business of valuation. What are their favored techniques and what are the factors that affect their choices in practice? This matters because valuation professionals function as intermediaries in the capital allocation process.

In this paper, we use a survey approach to fill that gap. The survey design allows us to control for a respondent's professional subgroup (e.g., consulting), education, experience, and valuation-purpose characteristics. In broad terms, we find support for the "sociological hypothesis" that profession matters more than education; different professions have different valuation cultures. Thus, in practice, the values attached to different firms and projects and, ultimately, resource allocation may depend on "where" the valuation is carried out.

The two most established methods to value a project or a company are relative valuation ("multiples") and multiperiod models. Finance textbooks tend to emphasize the latter and especially the technique of discounted cash flows (DCF). ${ }^{2}$ These approaches differ on several levels: by the inputs one needs to consider, by the caveats one has to be aware of, and, most crucially, by the results one gets. Multiples are often referred to as

\footnotetext{
${ }^{1}$ Comment by a survey respondent working in the consulting industry.

2 See, e.g., the leading textbooks by Berk and DeMarzo (2017), Brealey, Myers, and Allen (2017), Ross, Westerfield, and Jaffe (2015), and Welch (2017). Only the last of these has a separate chapter dedicated to multiples.
} 
delivering market-based valuation in addition to being relatively easy to implement. Conversely, as hinted at in the quote above, DCF is sometimes viewed as more of an academic method with less practical relevance. However, it is unclear how widely held this belief is or how popular multiples really are. Our paper sheds light on these issues.

The paper works on two levels. First, it maps out how the professionals go about valuation. What are the methods they use and how do they implement them? This basic analysis is then used to address the deeper question as to what factors affect a valuation professional's choice of method and implementation approach. Some of the survey questions are also designed to investigate potential confusion, especially with respect to interest rate tax shields and the weighted average cost of capital (WACC).

The survey respondents represent an international cross-section of consultants, investment bankers, private equity professionals, and asset managers. Their educational levels range from $\mathrm{BA}$ to $\mathrm{PhD}$, with many having MBAs and some being CFAs. Most are males between 30 and 50 years of age with more than 10 years of experience. The respondents are involved in a variety of roles (buy-side, sell-side, advisory) and transactions (mergers, IPOs, going private), dealing with both listed and unlisted firms. They cover a wide range of industries, with a predominant regional focus on Western Europe. Around 25\% and 18\%, respectively, state that their geographic focus includes North America and Asia.

The majority of the survey respondents employ both relative valuation and multiperiod models, with those having a preference for one or the other being close to evenly divided in the population. By far the most popular multiple is EV/EBITDA, with $84 \%$ in our sample stating they use this multiple always or almost always when they use multiples. ${ }^{3}$ Respondents favor using 12-month forward estimates of earnings and, on average, employ eight comparables picked primarily from rivals in the same industry, also paying attention to size and expected growth.

The most popular multiperiod model is DCF. Respondents typically discount expected cash flows at the WACC, with the cost of debt being estimated by the riskfree rate plus a spread and the cost of equity being estimated by the CAPM. Multifactor models are rarely used. The riskfree rate is most commonly taken to be the yield on a long-term Treasury security. Cash flows are typically projected for only five years. Terminal values

\footnotetext{
${ }^{3} \mathrm{EV}$ is enterprise value. EBITDA is earnings before interest, depreciation, and amortization.
} 
are calculated using the Gordon growth model, with the most popular choices of growth rates being $2 \%$ and the expected GDP growth.

With these choices and with realistic assumptions on the discount rate and forecasting horizon growth rates, we show by way of examples that the fraction of the total gross value of a project that can be attributed to the terminal value is around $70 \%$. This underscores the practical significance of the forecasting horizon and the terminal value. It also implies that the way the technique of DCF is implemented in practice means that it collapses to being almost just another multiples exercise, with the majority of the estimated value being attributable to the forecasted cash flow in the first year after the forecasting horizon multiplied by one over the discount rate less the growth rate.

While respondents discount cash flows at the WACC, it is clear from their answers to other questions that confusion reigns with respect to the well known result, articulated in most textbooks, that the WACC is sensitive to leverage because of interest tax shields. On the whole, respondents do not exhibit a deep understanding of how to deal with tax shields in a DCF analysis. Incorrectly implemented valuation methodologies by valuation professionals are important to the extent that the valuations they come up with affect the allocation of resources in the economy. The valuation professionals' confusion therefore points to a challenge for finance academics to improve the effectiveness of their teaching.

This leads us to the second contribution of this paper; namely, the question as to what factors affect a respondent's dominant choice of valuation method. We frame this analysis as a contest between educational background versus a respondent's professional subgroup (consulting, investment banking, private equity, or asset management). We also investigate and control for other respondent characteristics such as the type of investment (project finance, listed firms, unlisted firms, real estate) that the respondent is typically involved in, the type of transaction (mergers and acquisitions, investment decisions, going public or private), and whether the respondent tends to be on the buy or sell side or in an advisory role. For succinctness, we refer to these three sets of characteristics collectively as describing "the purpose of the valuation" for a respondent.

Intuitively, one may expect those with a more advanced degree to use more sophisticated methods and to implement them with fewer conceptual mistakes. But it is also plausible that different cultural norms within professional subgroups affect preferred valuation approaches. Sociology and social psychology have long recognized that professions 
have identifiable cultures and that individuals are prone to influence from peers and groups (see, e.g., Asch 1955, Greenwood 1957). In the finance literature, Bob Shiller was an early proponent of some of these ideas (see, e.g., Shiller 1984). Hvide and Östberg (2015) document that individuals are prone to adopting the investment biases prevalent in their place of work. Our comparison of the influence of education versus professional subgroup is fundamentally motivated by the pioneering work of Harris $(1995,1998)$, who demonstrates that nurture effects (in our case, education) may be dominated by peer effects (in our case, work environment). The hypothesis we test is that valuation professionals' approaches to valuation are influenced more by their peers at work than their educational background; that they adopt the "valuation culture" of the professional subgroup they are enlisted into. The test examines differences in valuation approaches across professional subgroups. In contrast to a potential education level effect, there is no a priori reason as to why one profession should use more sophisticated valuation methods than another.

We find that there are distinct differences across professions with respect to some elements of the choice of valuation technique. Furthermore, these differences are not related to "sophistication." In contrast, education levels hardly matter. This supports the sociological hypothesis. It also suggests that higher-level finance education may have the most impact if carried out in the workplace.

A possible explanation for the importance of the professional subgroups is that they have different emphases with respect to the purpose of the valuation. While there is nothing by way of theory that says that different purposes call for different valuation methods, it is nevertheless possible that this is relevant in practice. In our sample, there are distinct differences in valuation-purpose characteristics across the professional subgroups. For example, consultants tend to be in an advisory role, investment bankers report they typically are on the sell-side, while private equity professionals and asset managers are for the most part on the buy-side. Cluster analysis based on our eleven valuation-purpose characteristics yield clusters drawn largely along professional subgroup lines. Therefore, to examine the effect of the valuation purpose, we employ within-profession clusters. ${ }^{4}$ We find that differences in valuation purpose have only a marginal effect on the choice of valuation technique. The evidence thus supports the sociological hypothesis that differences in

\footnotetext{
${ }^{4}$ Cluster analysis allows us to handle the high degree of correlation between the eleven valuation-purpose characteristics.
} 
valuation techniques across professional subgroups are driven by cultural factors.

The focus and depth of our survey distinguishes it from other surveys on valuation methods. The most prominent of these is that by Graham and Harvey (2001). This and other surveys we are aware of are directed at CFOs and focus on the capital budgeting process within firms. ${ }^{5}$ They ask questions about the broad methods firms employ, but, unlike our survey, do not go into depth with respect to implementation. They also do not explore the usage of multiples, but focus on multiperiod models. Our survey thus expands on this branch of the literature by focusing on valuation professionals as well as asking a broader set of questions. In the process, we contribute beyond providing basic survey descriptive statistics by presenting evidence that there are different valuation cultures within the distinct subgroups of the financial valuation profession. Thus, our survey differs both in terms of the richness of the questions we ask and in terms of the questions we can ask of the data.

The rest of this paper is organized as follows. Section 2 describes the survey and provides some basic statistics on response rates. Sections 3, 4, and 5 tabulate the survey's findings and compare the impact of educational level with that of respondents' profession subgroup, focusing on multiples and multiperiod models. Section 6 studies the purpose of the valuation and its relative importance using cluster analysis. Section 7 concludes.

\section{The survey}

\subsection{Questionnaire}

The are four parts to the questionnaire. The first part asks a series of background and personal questions that relate to the purpose of valuation, educational level achieved, experience, gender, regional focus, and so on. Full details are in the survey questionnaire itself (see Appendix B). The second and third parts focus on relative valuation and multiperiod models, respectively. Examples of the latter include discounted cash flows (DCF),

\footnotetext{
${ }^{5}$ Graham and Harvey (2001) also examine capital structure theories. Bancel and Mittoo (2004) and Brounen, de Jong, and Koedijk (2004) carry out similar surveys in Europe and obtain comparable results. Mohan, Ainina, Kaufman, and Winger (1991), Arnold and Hatzopoulos (2000), Ryan and Ryan (2002), and Mukherjee, Kiymaz, and Baker (2004) also focus on CFOs and firms.
} 
economic value added (EVA), and the dividend discount model (DDM). The fourth part concludes with some general questions that further elucidate a respondent's preferred valuation approach. The survey contains thirty-three numbered sets of questions, with six of these having labeled subsets of further questions. Most questions are multiple choice, where answers can be given on a scale from "Never" (0) to "Always" (4). Four questions are open-ended, fifteen questions are single-choice ("yes/no"), and four are multiple-choice questions where more than one answer is possible. Participants can provide additional details to individual questions if the set of listed choices is incomplete. There is also a possibility to leave further comments in a space at the end of the survey. The main analysis in this paper revolves around 98 questions from parts two, three, and four of the survey.

\subsection{Delivery, response rates, and final sample}

The survey was conducted online with the help of the LimeSurvey tool. ${ }^{6}$ Email invitations with the link to the survey were sent to 4,500 valuation professionals, identified through a search on the Web, between May 15 and June 6, 2012. These were divided up into 1,132 consultants, 1,176 investment bankers, 1,377 private equity professionals, and 815 asset managers, predominantly based in Western Europe. ${ }^{7}$ Recipients had access to the survey for three weeks following the day the email invitations were sent. In total, 329 responses were recorded (not counting 49 completely blank records). Thirty of these had duplicate names. We kept only one record per respondent, giving preference to the latest and most complete record. This resulted in a sample of 299 records, which represents a response rate of $6.6 \%$. In comparison, the response rates in Graham and Harvey (2001) and Brounen et al. (2004) are $8.8 \%$ and $4.8 \%$, respectively.

The 299 response records were examined for completeness. Because of our interest in learning about what multiples valuation professionals use, we kept all records with at least two questions answered (out of five) in the relative valuation part of the questionnaire. Only one name who had less than two questions answered in the relative valuation part had responded to the third and the fourth parts of the questionnaire. This respondent had

\footnotetext{
${ }^{6}$ LimeSurvey is a free software for conducting online surveys. See www.limesurvey.org.

${ }^{7}$ Individuals were classified into professional subgroups based on their place of work.
} 
answered $66 \%$ of the entire survey and was kept in the final sample. We dropped one record that had blanks everywhere except for the section on relative valuation, where the person responded " 0 " on everything. This left us with a final sample of 272 records (individual names). ${ }^{8}$ All individuals in the final sample answered at least $30 \%$ of all questions.

\section{Insert Table 1 here.}

Table 1 presents an overview of response rates, survey completeness, and the final sample, by profession. Consultants have the highest response rate (10.0\%) and make up the largest professional subgroup among respondents (41.5\%). This is followed by investment bankers $(6.1 \%$ and $26.5 \%)$, private equity (4.2\% and $21.3 \%)$, and asset managers $(3.6 \%$ and $10.7 \%$ ). Statistics on educational background are provided in the next section.

\section{Analysis: Preliminaries}

This section provides preliminary information on the general choice between multiples versus the more textbook oriented discounted cash flows (DCF) multiperiod approach. We tabulate responses by profession, educational background, and experience and test for the extent to which these respondent characteristics influence respondents' preferred valuation approaches. The basic structure of the analysis in this section is adopted in Sections 4 and 5, which study the details of respondents' specific approaches to valuation using multiples and multiperiod models, respectively. In particular, the basic layout of Table 2 in this section, which contains the results on the overall choice of valuation approach, is repeated in the tables in the next two sections. We therefore start by describing the general structure of these tables, before turning to the specifics of the results.

\subsection{General structure and basic results}

We describe the general structure of the survey response tables and our analysis in Sections 3 to 5 by focusing on Table 2. The table consists of several panels bound together by a common theme, namely the overall, broad approach to valuation and, in particular, the choice between using multiples versus DCF. Each panel summarizes the answers to specific

\footnotetext{
${ }^{8}$ The 272 survey respondents in the final sample come from 125 different firms, making an average of 2.17 respondents per firm.
} 
survey questions with answers on the 0 ("never") to 4 ("always") scale. An example is Panel A, Table 2, which we can think of as our generic "response panel." Where answer choices are not on the 0-4 scale, response panels are slightly different. These are discussed in the more specific context of the analysis of the results. The last panel in Table 2 is a "regression panel" that will be described below as well.

\section{Insert Table 2 here.}

The generic response panel (Table 2, Panel A) is comprised of four subpanels, or blocks, with each row going across the subpanels corresponding to a specific survey question. Going from left to right, the first subpanel provides overall statistics for each question on: (i) the number of respondents; (ii) the percent of replies that are 1 to 4, indicating that the respondent uses the method (for example) in question at least sometimes; (iii) the percent of replies that are 3 or 4, indicating a response of almost always or always; and (iv) the average response across respondents on the 0-4 scale. For example, 194 respondents answered the question as to whether they use both multiples and multiperiod models, with the average strength of response (on the 0-4 scale) being 2.97 and $76 \%$ reporting that they use both methods almost always (3) or always (4). Thus, as a rule, valuation professionals tend to use both methods.

The second subpanel, labeled "Profession," provides the mean (on the 0-4 scale) response per question for each professional subgroup; Consulting (Cons.), Investment Banking (IB), Private Equity (PE), and Asset Management (AM).

The third subpanel, labeled "Education," does the same for five different educational groups; Bachelor (BA), Master (MA), Doctoral degree (PhD), Master of Business Administration (MBA), and Chartered Financial Analyst (CFA). Respondents are classified into one of these educational groups according to the following hierarchical rule: Respondents with a CFA diploma (who may have other education as well) are labeled "CFA;" else, respondents with an MBA (who also may have a BA, MA or PhD) are labeled "MBA;" else, respondents are labeled according to their highest degree in the following order, $\mathrm{PhD}, \mathrm{MA}$, BA. We are especially interested in MBAs as this is a flagship degree in business schools. Students coming out of such programs would be expected to have a solid understanding of basic valuation techniques, such as what we examine in this survey. For this reason, we classify respondents with doctoral degrees as MBAs if they have that qualification. 
CFAs are singled out first according to our classification algorithm as this is a specialized financial analyst qualification. As seen in Table 2, in the full sample of 272 respondents, the distribution across educational levels is as follows:

\begin{tabular}{lllll} 
BA & MA & PhD & MBA & CFA \\
\hline 52 & 37 & 17 & 123 & 36
\end{tabular}

The fourth subpanel, labeled "Experience," provides mean (on the 0-4 scale) responses for two experience subgroups; those with less, alternatively more, than ten years of experience. In the full sample of 272 respondents, 168 report that they have more than ten years of experience.

For each group in each subpanel, the choice with the highest mean (or percentage) is indicated in bold. For example, in Table 2, Panel A the strength of the response for experienced valuation professionals is strongest for "Both multiples and DCF," being 3.09 on average.

Within each of the last three (rightmost) subpanels, we test for significant effects from profession, education, or experience by carrying out means tests of each individual group against the complement population (all other groups). Statistical significance is reported on the $1 \%$ (a), $5 \%$ (b), and $10 \%$ (c) levels. These tests allow us to gauge the importance of profession, education, or experience with respect to respondents' choice of valuation approach. A higher count of statistically different means within the profession subpanels as compared with the education subpanels, for example, would be support for the sociological hypothesis that there are valuation cultures within different professional subgroups that override educational influences. This is examined in the next subsection.

The means tests are supplemented by regression analysis that is reported on in the bottom panel. In particular, for each individual survey question (except "other"), $j$, in the response panels, we run the following two regression specifications:

$$
y_{i j}=\beta_{0 j}+\beta_{1 j} \text { Cons }_{i}+\beta_{2 j} P E_{i}+\beta_{3 j} A M_{i}+\beta_{4 j} M B A_{i}+\beta_{5 j} H E x p_{i}+\beta_{6 j} L S_{i}+\varepsilon_{i j},
$$

and

$$
\begin{aligned}
y_{i j}= & \beta_{0 j}+\beta_{1 j} \text { Cons }_{i}+\beta_{2 j} P E_{i}+\beta_{3 j} A M_{i}+\beta_{4 j} B A_{i}+\beta_{5 j} M A_{i} \\
& +\beta_{6 j} P_{i} D_{i}+\beta_{7 j} C_{F}+\beta_{8 j} H E_{i} p_{i}+\beta_{9 j} L S_{i}+\varepsilon_{i j},
\end{aligned}
$$

where $y_{i j}$ is respondent $i$ 's answer to question $j$. The RHS variables of the regression equation are indicator variables for different professional groups and educational levels, 
as described above. In addition, HExp is an indicator variable for having more than ten years of experience and $L S$ (Large Size) is an indicator variable for respondent $i$ having focus on firms with more than EUR 5 billion of assets. Whereas the first specification focuses on MBAs versus all other education levels, the second specification takes MBAs as the baseline education level and introduces dummy variables for the other levels. For each specification, the regression panel reports the number of statistically significant coefficients (at the $10 \%$ level or better) per variable across all regressions. A dash indicates that a variable is not part of the regression.

These regressions are thus designed to examine the extent to which respondents' educational levels or professions affect their approach to valuation. The regressions control for experience and size focus, but we note up front that the results without these two controls are not different in a noteworthy way. With these preliminaries in place, we now turn to discussing the specific findings in Table 2 .

\subsection{Multiples versus DCF by profession and education}

As noted above, Table 2 shows that most respondents use both multiples and DCF. Consultants $\left(3.29^{a}\right)$ are more likely to use both approaches, while private equity professionals $\left(2.03^{a}\right)$ are less likely. The numbers in brackets are the mean response strengths, with the superscript indicating the level of statistical significance (as described above), if any. Respondents whose highest degree is an MA $\left(3.46^{a}\right)$ or are more experienced $\left(3.09^{c}\right)$ are relatively more likely to use both approaches, while MBAs $\left(2.71^{a}\right)$ are less likely.

We have also asked whether respondents who use both multiples and DCF favor one or the other method. Forty-seven percent of respondents declare that they use both, but primarily multiples, almost always or always. Forty-six percent use both, but primarily DCF. On the four point scale, the averages to these two choices are 2.18 and 2.12, respectively. The scores for "multiples only" and "DCF only" are much lower; 1.59 and 1.28, respectively.

Reading down through the table, we see that most respondents use sensitivity (68\%) or scenario (57\%) analysis at least almost always, but only $39 \%$ use a sum of parts valuation almost always or always. We also see in Panel D that the main reason for not using multiperiod models such as DCF is the uncertainty behind cash flows. This holds for all 
professions and education levels, except for PhDs, whose most popular answer is that it is too time-consuming(!).

Comparing the impact of profession versus education, the table shows that there is more variation in terms of statistically significant means within the profession block as compared with the education block. The number being 15 versus 10 over all panels. That profession is more important with respect to differences in valuation approach is supported by the regression results in Panel E. In Specification 2, which is the specification that has dummy variables for all education levels, there are 11 statistically significant coefficients on the profession side, as compared with 4 on the education side. While there are differences across professions, a glance at the numbers in Table 2 also shows that there are substantial similarities. So a reasonable hypothesis may be that basic bachelor level finance education forms a baseline on which different professions innovate in their own different ways. We

will see whether this continues to be the case when looking more deeply into how the respondents report that they carry out valuations using multiples and multiperiod models.

\section{Multiples}

There is an often heard claim among practitioners that multiples are better, more marketoriented, and a less tedious method of valuation than DCF. One often hears that people use multiples first and then back up the results with DCF. This is supported by the survey finding that about half of the respondents use both methods, but favor multiples (Table 2). In this section, we study the usage of multiples in more detail by reporting on which multiples survey respondents favor and how they use them.

The first set of findings are in Table 3, which presents responses by profession, educational background, and experience in the same manner as Table 2 did for the general choice of valuation approach.

\section{Insert Table 3 here.}

As seen in Panel A, the most popular multiple is EV/EBITDA (enterprise value to EBITDA). Eighty-four percent of respondents answer that they use this multiple always or almost always (conditional on using multiples). The average response strength for this choice is 3.34 overall in the sample. For consultants and private equity professionals it is 
$3.62^{a}$ and 3.41, respectively. Its usage is lowest among asset managers $\left(2.75^{b}\right)$ whose most popular choice of multiple is $\mathrm{P} / \mathrm{E}$ (price/earnings, $2.93^{a}$ ). Investment bankers are also heavy users of $\mathrm{P} / \mathrm{E}$ (3.11). This may reflect that investment bankers and asset managers are more focused on listed firms. The role of the purpose of the valuation is studied in more detail in Section 6. In the sample overall, $\mathrm{P} / \mathrm{E}$ (2.26) and industry specific multiples (2.27) are the most popular choices after EV/EBITDA, EV/EBITA, and EV/EBIT. Industry specific multiples are more popular among consultants $\left(2.45^{c}\right)$ than among other valuation professionals. EV/EBITDA is also the most popular choice across all education levels and both experience levels, with $\mathrm{P} / \mathrm{E}$ being the second highest choice for those with education levels of BA, MA, and CFA. MBAs and PhDs second highest choices are EV/EBIT and $\mathrm{EV} / \mathrm{S}$ (sales). More means are statistically significantly different from their respective (complement) norms in the profession block (28) than the education block (6).

An important element of the implementation of the multiples approach to valuation is whether to use trailing or forward looking earnings (or other relevant denominators) when calculating the multiple. Respondents use both forward looking and trailing multiples, but favor the former. Panel B shows that $80 \%$ of respondents always or almost always use 12-month forward multiples, with $55 \%$ always or almost always using trailing multiples. ${ }^{9}$ Twenty-four month forward multiples are rarely used. The average strength of response for the 12-month forward multiple is 3.13. There is some variation among the different professions, but little across the different education levels. Private equity professionals favor trailing multiples $\left(3.05^{a}\right)$, while mean responses for each education level show a uniform preference for 12-month forward multiples.

In response to the question as to what firm or project characteristics affect the choice of multiple (Panel C), 89\% of respondents answered that "industry sector" almost always or always does so. All professions and education levels have this as their most popular choice, with the average strength of response being 3.44 and the individual profession and education means sitting in a tight band from 3.35 (asset managers) to 3.56 (PhDs), with no statistical significance in the means. Earnings and margin stability (70\%) and capital intensity (59\%) are the next two most impactful factors overall and for each individual profession, education, and experience level.

\footnotetext{
${ }^{9}$ In the literature, forward multiples are typically found to perform better than trailing multiples (Alford 1992, Kim and Ritter 1999, Lie and Lie 2002, and Liu, Nissim, and Thomas 2002).
} 


\section{Summary: Education vs Profession (Table 3)}

Across all three panels, there are 43 significant means in the profession block and 10 in the education block. This difference in impact is backed up by the regressions in Panel D. Under specification 2, there are 23 significant profession coefficients across all 20 regressions, as compared with only 7 significant education coefficients. For experience, there is none.

\subsection{Example: The choice of multiple matters}

One may ask how important the findings in Table 3 are. Even if some professionals prefer one set of multiples over the other, does it matter? Below we answer this question by way of an example of a simple multiples valuation exercise using a randomly chosen company on two randomly chosen dates. The idea of the exercise is to see how well multiples would perform in a setting where we happen to have the enterprise value of a company as assessed in the market.

The company is Green Mountain Coffee Roasters, which changed its name to Keurig Green Mountain on March 10, 2014. ${ }^{10}$ The valuation dates are February 14, 2014 (Green Mountain) and February 24, 2015 (Keurig). All data is taken from Bloomberg on these two dates.

We use both 12-month forward and trailing EV/EBITDA, EV/EBIT, P/E, P/B (book), and $\mathrm{P} / \mathrm{CF}$ (cash flows). ${ }^{11}$ The comparables set is important in any valuation. So as not to inject any biases we personally may have into the exercise, for each date we took a comparables set generated automatically on the Bloomberg system on the respective date. ${ }^{12}$

\footnotetext{
${ }^{10}$ Keurig was a subject to a takeover bid by JAB Holding on December 7, 2015. See, e.g., "JAB grows coffee empire with $\$ 13.9$ bn Keurig Green Mountain deal," by Massoudi, Fontanella-Khan, and Daneshkhu, Financial Times, December 7, 2015. This is well after our two sample dates.

${ }^{11}$ For $\mathrm{P} / \mathrm{B}$, we only use current book value.

${ }^{12}$ On February 14, 2014 (Green Mountain), the comparables were Nestlé, Coca-Cola, PepsiCo, Mondelēz International, Danone, Associated British Foods, and General Mills in the "Large" group and Kerry Group, ConAgra Foods, Monster Beverage, Lindt\&Sprüngli, Dr Pepper Snapple Group, Smucker's, Tata Global Beverages, and Dean Foods in the "Small" group. On February 24, 2015, (Keurig), the comparables were Nestlé, Coca-Cola, PepsiCo, Mondelēz International, Danone, Associated British Foods, General Mills, and Monster Beverage in the "Large" group and Dr Pepper Snapple Group, ConAgra Foods, Lindt\&Sprüngli, Kerry Group, Smucker's, Tata Global Beverages, and Dean Foods in the "Small" group.
} 
To investigate the effect of the comparables set, we subdivide the two sets of "Bloomberg comparables" into the $50 \%$ largest and smallest, by market capitalization. Thus, for each date, the exercise is carried out on three sets of comparables (small cap, large cap, all Bloomberg comparables).

For each comparables set, we calculate the average multiple and then apply it to the relevant earnings etc. of Green Mountain/Keurig. So estimating enterprise value using the $\mathrm{EV} / \mathrm{EBIT}(\mathrm{DA})$ multiples is done in the obvious, trivial way. Using price ratios involves two steps. For example, to estimate the enterprise value with the $\mathrm{P} / \mathrm{E}$ ratio, we first

calculate an estimated price, $\widehat{\text { Price }}$, of Green Mountain/Keurig by multiplying its EPS by the average $\mathrm{P} / \mathrm{E}$ for each set of comparables and then, calculate an estimated enterprise value of Green Mountain by using the definition in Bloomberg:

$$
\begin{aligned}
\widehat{E V}= & \widehat{\text { Price }} \times N_{\text {Sh }}+\text { Pref.Equity }+ \text { Minority Int. }+ \text { Tot.Debt } \\
& \text {-CashछMarktb.Securities }- \text { Other non-cash Adj. },
\end{aligned}
$$

where $N_{S h}$ is the number of shares of Green Mountain/Keurig.

Table 4 reports the valuation errors in absolute value terms, i.e., $\left|E V_{\text {true }}-\widehat{E V}\right|$ in USD mill. The true enterprise value of Green Mountain on February 14, 2014 (Panel A) was USD 15,900 mill, and for Keurig on February 24, 2015 (Panel B) it was USD 18,672. In each panel, the highest and the lowest valuation errors are indicated in bold.

\section{Insert Table 4 here.}

We see that the valuation error is sensitive to the choice of multiple and on the set of comparables. In Panel $\mathrm{A}$, the closest value arises from using trailing $\mathrm{P} / \mathrm{CF}$ on the small market cap comparables set. The valuation error is a mere USD 563 million, or $3.5 \%$ of Green Mountain's enterprise value. However, using the large comparables set, the valuation error from the trailing $\mathrm{P} / \mathrm{CF}$ multiple is a whopping 5,423 , or $34.1 \%$. The 12-month forward $\mathrm{P} / \mathrm{CF}$ multiple performs even worse and is the worst performer of all on the large comparables set. For this set, the best performing multiple is 12-month forward EV/EBIT, with a valuation error of 2,434 , or $15.3 \%$.

While this is only one example, we have done other examples as well, with the best performing multiple varying from company to company and across comparables sets. This lesson is brought home by the results in Panel B. Here, the trailing $\mathrm{P} / \mathrm{CF}$ multiple on the small comparables set has gone from the best to being the worst performing multiple, with 
a valuation error of USD 8,632 mill, or 46.2\%. The smallest valuation error now is found by using trailing EV/EBIT and is a remarkably small USD 25 mill, or $0.1 \%$. But this is a lucky strike rather than an example of consistent performance. The overall lesson is that there does not seem to be a general rule as to what the best performing multiple actually is. It is unclear as to why EV/EBITDA is so popular among valuation professionals.

The example in Table 4 illustrates that the best performing multiple depends on the choice of comparables. Thus, it is not only the multiple itself that matters, but how it is used. There is very little academic research on this topic, yet it is very important in practice. One does not learn much about multiples in University, but at the workplace. As one investment banker commented: "A lot depends on experience of what "works'." This refers not only to the choice of multiple, but to the implementation of the valuation. From what we can see from this example, obtaining accurate valuations with multiples is neither simple nor necessarily market based - perhaps unless you master the art of choosing the right multiple for the right comparables set - unlike what is expressed in the anecdotal claim we started this section with.

\subsection{Choosing comparables}

As we have seen, the comparables set is crucial with respect to the performance of a multiples valuation. Table 5 reports on how survey respondents choose comparables. In contrast to our example, valuation professionals do not tend to simply pick the Bloomberg comparables; while $60 \%$ use it some of the time, only $16 \%$ use this set almost always or always. Still, the two most popular choices include factors that presumably enter into Bloomberg's algorithm. These are rivals (3.48) and firms in the same industry (3.45), which $91 \%$ and $89 \%$, respectively, of respondents use almost always or always.

\section{Insert Table 5 here.}

A second tier of characteristics are formed by size (2.49) and expected growth (2.34). Taking account of these two characteristics makes sense from a conventional discounting perspective. The mathematical effect of positive growth is equivalent to lowering the cost of capital (consider, e.g., the formula for a growing perpetuity), and thus raising value. ${ }^{13}$

\footnotetext{
${ }^{13}$ As seen in (5) with the WACC as the discount rate.
} 
Furthermore, the empirical asset pricing literature has found that expected equity returns (cost of equity) are inversely related to size and the market-to-book (or $\mathrm{P} / \mathrm{B}$ ) ratio, with the latter increasing in growth, ceteris paribus, as we just observed (Fama and French 1993). In addition, we also know that large firms have more liquid stocks and often better access to credit markets, both of which help reduce the cost of capital and thus raise value.

These broad findings on the choice of comparables hold for all professions, education, and experience levels. But investment bankers have a stronger strength of response on placing emphasis on rivals in the comparables set $\left(3.68^{a}\right)$ than others, while, with respect to the second tier of characteristics, private equity professionals place more emphasis on expected growth $\left(2.60^{c}\right)$. Finally, Panel B reports that around eight comparables are used on average, with the range of the means within the four professions going from $6.76^{a}$ for private equity to $9.13^{a}$ for consultants. No means are statistically different from their respective (complement) norm for any of the education groups.

Eight comparables may seem like a small number when compared with the academic literature where the performance of multiples-based valuation is typically assessed using very large comparables sets (e.g., all firms in the same "industry," see, e.g., Liu, Nissim, and Thomas 2002). However, Cooper and Cordeiro (2008) show that using simple, but smarter, one-factor selection rules, one can do just as well with around ten comparables. ${ }^{14}$ As seen from our findings in Table 5, valuation professionals typically take several factors into account in practice. We know that practitioners pay close attention to the comparables. A common saying is that the most important thing in valuation is the set of comparables. The eight or so comparables typically used in practice presumably reflects learned wisdom that with a good selection rule, this is enough.

\section{Summary: Education vs Profession (Table 5)}

There are 17 significant means in the profession subpanels and 3 in the education subpanels. In the regressions in Panel $\mathrm{C}$ (specification 2), the profession block has 10 statistically significant coefficients; whereas, the education block has only 1. In terms of significant regression coefficients in our two multiples tables (3 and 5), the score therefore adds up to: profession 33, education 8 , experience 1 . The conclusion thus far is therefore that education

\footnotetext{
${ }^{14}$ See also Alford (1992), Bhojraj and Lee (2002), Vismara, Signori, and Paleari (2015), and DeFranco, Hope, and Larocque (2015) for studies on the selection of comparables.
} 
beyond the Bachelor level does not seem to matter much in terms of the preferred multiples valuation approach of valuation professionals. The only factor that modifies the baseline to any large extent is the profession an individual belongs to. Thus, our findings so far support the sociological hypothesis that there are cultural variations in the approach to valuation across professions.

\section{$5 \quad$ Multiperiod models}

This section starts by reporting on the usage of different multiperiod models before studying more closely how the particular technique of discounted cash flows (DCF) is implemented by survey respondents. With respect to DCF, the survey contains questions about forecasting horizons and terminal values, the calculation of the cost of capital, and the usage of the weighted average cost of capital (WACC). In addition, a number of questions are designed to investigate respondents' understanding of the effects of the tax shields that arise from the tax deductibility of interest payments. As before, we are also interested in examining the influence of respondents' professions and educational levels with respect to what methods they prefer and how they implement them.

\subsection{Basics}

The top panel in Table 6 reports on the popularity of DCF, residual income models (RIM), economic value added (EVA), dividend discounting models (DDM), and the internal rate of return (IRR). As seen, DCF is by far the most popular method, with an overall strength of response of 3.20. Seventy-six percent of respondents report that they use DCF almost always or always (conditional on using a multiperiod model). With one exception (private equity), DCF is also the most popular method among all professions and educational levels and both experience levels. Private equity professionals' preference is for using the internal rate of return $\left(3.10^{a}\right)$. In the sample as a whole, the IRR is the second most popular choice, with an overall score of 2.25 .

\section{Insert Table 6 here.}

Panels B and C ask more specific questions about DCF. The main finding in Panel B is that people overwhelmingly report that they calculate net present value (NPV, 3.17) 
rather than adjusted present value (APV, 1.09). Furthermore, they do so by discounting cash flows at the WACC (3.25). As shown by Miles and Ezzell (1980), the WACC is a tax adjusted discount rate; it implicitly accounts for the interest tax shield. Given a constant leverage ratio, Miles and Ezzell show that discounting at the WACC gives a levered valuation that is equivalent to that of a correct implementation of the two-step APV procedure. ${ }^{15}$ In other words, the "NPV" one gets by discounting at the WACC can also be viewed as an "APV" that is calculated in one step rather than two. The survey responses suggest that this is not necessarily well understood.

Panel $\mathrm{C}$ takes a closer look at how well survey respondents understand valuation using the WACC. Because it contains an adjustment for the interest tax shield, the WACC is sensitive to leverage. ${ }^{16}$ Thus, unless the project or firm that is being valued will maintain a constant debt to value ratio, one needs to recalculate the WACC every year in the "DCF spreadsheet" based on projected debt levels and project (or firm) values. This is difficult to do correctly. Respondents exhibit a limited understanding of this problem. Only $48 \%$ of respondents say that they always or almost always take debt policy into account when using DCF, with the average strength of response being 2.19. Interestingly, valuation professionals with higher education levels are not different in this respect. However, there is some variation among the professions. In particular, private equity professionals are less inclined to let debt policy affect their choice of DCF approach $\left(1.79^{b}\right)$. That only around half of the survey respondents seem to recognize the importance of debt policy in the implementation of a DCF valuation suggests a less than perfect understanding of the effect of tax shields. Potential confusion among survey respondents regarding the WACC,

\footnotetext{
${ }^{15}$ To be clear, we are referring to the standard "textbook" formula: WACC $=(E / V) r_{e}+(D / V) r_{d}(1-$ $T_{c}$ ), where $E$, is the market value of equity, $D$ is the market value of debt, $V=E+D, r_{e}$ is the "cost of equity," $r_{d}$ is the "cost of debt," and $T_{c}$ is the corporate tax rate. The factor $\left(1-T_{c}\right)$ reflects the tax deductibility of interest payments. Adjusted present value is: APV $=$ NPV + PV(TS), where PV(TS) is the present value of the tax shield arising from the tax deductibility of interest payments. This is analogous to the expression $V_{L}=V_{U}+\mathrm{PV}(\mathrm{TS})$, where $V_{L}$ is levered (actual) firm or project value and $V_{U}$ is the unlevered value. See, for example, Miles and Ezzell (1980), Cooper and Nyborg (2007 or 2008), or one of the corporate finance textbooks listed in footnote 2 .

${ }^{16}$ Except in the trivial case that the net tax advantage to debt is zero, as in Miller's (1977) famous equilibrium. See, e.g., Miles and Ezzell (1980), Taggart (1991), Cooper and Nyborg (2006, 2007, or 2008) for further discussion.
} 
debt policies, and tax shields is studied in more detail in Subsection 5.4.

\section{Summary: Education vs Profession (Table 6)}

With respect to the impact of profession versus education level, there are 21 significant means in the profession subpanels as compared with 7 in the education subpanels in Table 6. In addition, Panel D shows that for regression specification 2, there are 12 significant coefficients in the profession block as compared with 4 in the education block. This is in line with our findings in previous sections that profession matters more than the level of education.

\subsection{Forecasting horizon and terminal value}

Anyone using DCF to value projects or firms would be expected to be familiar with the importance of the forecasting horizon and the terminal value. In this subsection, we take a look at this. Using DCF and discounting at the WACC, the gross (levered) present value of a project can be written

$$
V=V_{H}+V_{T} \equiv \sum_{t=1}^{T} \frac{C_{t}}{(1+\mathrm{WACC})^{t}}+V_{T},
$$

where $C_{t}$ is the all-equity after corporate tax cash flow in year, or period, $t, T$ is the forecasting horizon, $V_{H}$, is value of cash flows up to and including the forecasting horizon, and $V_{T}$ is the terminal value, that is, the present value of cash flows materializing after date $T$. For illustrative purposes we are assuming that $D / V$ is constant over time so that we can discount at a single, time invariant WACC. ${ }^{17}$

\section{Insert Table 7 here.}

Table 7 shows valuation professionals' choices of $T$ and method for estimating $V_{T}$. We see in Panel A that the most common choice of forecasting horizon is five years, with 122 of 222 respondents naming this as their favored option. Only investment bankers favor a longer horizon, namely ten years. With respect to calculating $V_{T}$, Panel B reveals that the overwhelmingly most popular method for estimating $V_{T}$ is the Gordon growth model. Seventy-eight percent of respondents use this method almost always or always, with the average strength of response on our 0-4 point scale being 2.99. This is the favored

\footnotetext{
${ }^{17}$ This ignores term structure effects and forecastable time varying risk premia.
} 
choice among all professions (except private equity) and educational levels. Private equity professionals prefer using multiples.

Using the Gordon growth model, $V_{T}$ in (4) can be written

$$
V_{T}=\frac{C_{T}(1+g)}{\mathrm{WACC}-g}
$$

where $g$ is the growth rate of cash flows in perpetuity. ${ }^{18}$ The growth rate is thus a crucial input into a valuation using DCF in practice. Panel C reports that the most popular choice of $g$ is $2 \%$, with an overall strength of response of 2.29 . Fifty-six percent set $g=2 \%$ almost always or always. The next most popular choice is the rate of inflation (2.16). There is some variation across the different subpopulations. For example, private equity professionals prefer the inflation rate, while CFAs prefer the GDP growth rate.

\section{Summary: Education vs Profession (Table 7)}

With respect to the relative importance of profession versus education, the "score" in Table 7 is as follows. Significant means: profession 19, education 12. Significant regression coefficients (specification 2): profession 11, education 5. Thus, the overall picture is still that profession matters more than education with respect to deviations from the norm.

We close this subsection with an example illustrating the practical significance of the forecasting horizon and terminal value. In particular, we are interested in the contribution of the terminal value, $V_{T}$, to the total gross value, $V$, in (4), as a function of the forecasting horizon, $T$, and terminal value growth rate, $g$. To do this, we first simplify the expression for the forecasting horizon value, $V_{H}$, in (4), by assuming a constant growth rate over this period. In a DCF valuation in practice, analysts typically assume that cash flows grow over the forecasting horizon. ${ }^{19}$ We allow the forecasting horizon and terminal value growth rates to differ. Typically one might think that cash flows grow at a larger rate initially, as the firm or project is in its first growth spurt. Eventually, as competitive advantage is reduced, growth rates would be expected to subside. The fraction $V_{T} / V$ is then

$$
\frac{V_{T}}{V}=\frac{P V(\text { Growing perpetuity starting in T years })}{P V(\text { Growing T-year annuity })+P V(\text { Growing perpetuity starting in T years })} .
$$

\footnotetext{
${ }^{18}$ For simplicity, in (5) we are assuming that $D / V$, and, therefore, WACC, is constant in perpetuity. Possible time variation in the WACC arising from the term structure of interest rates or time varying risk premia is ignored.

${ }^{19}$ This statement is based on our experience. We did not include questions about this in the survey.
} 
Using (5) and the formula for an annuity growing at a rate of $h,(6)$ can be written ${ }^{20}$

$$
\frac{V_{T}}{V}=\frac{1}{1+\frac{1+h}{1+g} \frac{\mathrm{WACC}-g}{\mathrm{WACC}-h}\left[\left(\frac{1+\mathrm{WACC}}{1+h}\right)^{T}-1\right]} .
$$

Table 8 lists values for the percentage of the total gross value that is attributable to the terminal value as a function of forecasting horizon, $T$, forecasting period growth rate, $h$, WACC, and terminal value growth rate, $g$. We consider forecasting horizons of five and ten years, $g$ 's of zero, two, and four percent, WACCs of eight and ten percent, and $h$ 's of two, four, and six percent. The numbers in bold indicate the values for the most commonly used scenario in practice as found by our survey, namely a five year forecasting horizon and a $2 \%$ terminal value growth rate.

\section{Insert Table 8 here.}

Using the parameter values in Table 8, the terminal value accounts for $69-77 \%$ of the total value. If we were to reduce the WACC to reflect today's low interest rates, this would be even larger. An implication is that in the hands of valuation professionals, $D C F$ is almost reduced to being just another multiples exercise; roughly seventy percent of the value is given by the forecasted cash flow in six years multiplied by $1 /(\mathrm{WACC}-g)$. As seen in Table 8, the multiples interpretation of DCF fits less well using a longer forecasting horizon. However, even setting this to ten years, the terminal value accounts for 47-61\% of the total value (for $g=2 \%$ ). The examples in Table 8 thus underscore the great significance of the forecasting horizon and terminal value. The way DCF is implemented by valuation professionals means that this technique is, in practice, not far from being just another multiples method.

\subsection{Cost of capital}

Table 9 reports on how respondents calculate cost of capital. Starting with the cost of debt in Panel A, we see that the most popular approach is a riskfree rate plus a spread (based on

\footnotetext{
${ }^{20}$ Using the WACC as the discount rate, the present value of a T-year annuity growing at the rate of $h$ and with a year 1 cash flow of $C_{1}$ is

$$
C_{1}\left[\frac{1}{\mathrm{WACC}-h}-\frac{(1+h)^{T}}{(\mathrm{WACC}-h)(1+\mathrm{WACC})^{T}}\right] .
$$

Note also that, in this scenario, $C_{T}=C_{1}(1+h)^{T-1}$.
} 
rating and/or duration). This is used by $72 \%$ of respondents almost always or always, with the overall strength of response being 2.77. With respect to the cost of equity, Panel B reveals that $76 \%$ of respondents use the CAPM almost always or always, the overall score being 2.98. No other method comes close. Notably, only $4 \%$ of respondents use the Fama and French (1993) three-factor model that is so popular in academic research. The cost of equity is typically viewed as being represented by a riskfree rate plus a risk premium (as in the CAPM). Panel $\mathrm{C}$ shows that valuation professionals typically use longer term treasury securities as their riskfree rate. Only asset managers differ in this respect, having a preference for using swap rates $\left(2.71^{a}\right)$.

\section{Insert Table 9 here.}

While not tabulated, the survey also asked about what market risk premium respondents typically use. The average is $5.4 \%$, with little variation across subpopulations with different regional foci. There is some variation among the professions. The highest average is among private equity professionals (5.7\%), while the lowest is among asset managers $(4.6 \%) .{ }^{21}$

\section{Summary: Education vs Profession (Table 9)}

There is a fair amount of "harmony" across the different profession and education groups with respect to their favored approach to calculating the cost of capital. There are only 6 and 4 significant regression coefficients (specification 2) in the profession and education blocks, respectively. With respect to significant means coefficients, the respective numbers are 16 and 20, but the most popular choices are consistent across professions and educational levels. There are only two cases in the profession block and one case in the education block where these differ.

\footnotetext{
${ }^{21}$ But the number of asset managers responding to this question is small. Also not tabulated are responses regarding the calculation of equity betas (when using the CAPM). Among survey respondents, $50 \%$ calculate betas in house. Among those that do not, $56 \%$ get betas from Bloomberg. Return frequencies: monthly, 50\%; weekly, 23\%, daily, 27\%. Estimation period: 3 or 5 years, 74\%; 1 year, 19\%. "Market portfolio": national index, 64\%; world index, 13\%. Shrinkage techniques: $27 \%$. These practices stand in contrast to the recommendations of Levi and Welch (2017).
} 


\subsection{WACC and tax shields: Implementation and confusion}

As seen in Subsection 5.1, there appears to be some confusion among survey respondents with respect to the topic of WACC and interest tax shields. As noted, when there is a net tax advantage to debt, WACC is sensitive to leverage. Ceteris paribus, WACC is decreasing in leverage because it incorporates the interest tax shield. In this subsection, we explore the depth of survey respondents' understanding of this basic result. This matters because, empirically, interest tax shields are arguably economically significant. Graham (2000) estimates that they account for around 5-10\% of firm value.

The survey asks three specific questions to examine whether respondents properly adjust the WACC for leverage when discounting project cash flows. We first ask whether survey respondents use market or target weights when calculating WACCs of comparables. Then we ask the same question regarding the WACC they use to discount project cash flows. The idea behind these two questions is that it is necessary to releverage comparables' WACCs to reflect the debt policy that applies to the to-be-valued project. This may be done, for example, using the Miles and Ezzell (1980) formula for tax-adjusted discount rates and its extensions to investor taxes in Taggart (1991), risky debt in Cooper and Nyborg (2008), and positive default recovery rates in Molnár and Nyborg (2013). ${ }^{22}$ These specific formulas assume constant leverage ratios. Tax adjusted discount rate formulas that assume other debt policies can be found in Modigliani and Miller (1963) and Cooper and Nyborg (2018). However, we do not ask about any specific tax-adjusted discount rate formula. Our third question asks the more general question as to how survey respondents deal with expected future changes in the capital structure of the project.

\section{Insert Table 10 here.}

Table 10 reports the results. Panel A shows that 57 out of 201 respondents, or approximately $28 \%$, incorrectly use target weights when calculating the WACCs of comparables. Panel B reveals an even larger confusion, with half of the respondents incorrectly using market weights when calculating the WACC of the to-be-valued project or firm.

That there is a fair amount of confusion among valuation professionals regarding the WACC and tax shields is also apparent in Panel C. Only $31 \%$ of respondents report

\footnotetext{
${ }^{22}$ Under some specific assumptions, Miles and Ezzell (1980) show that the WACC is consistent with their tax-adjusted discount rate. See Cooper and Nyborg (2008) for further discussion.
} 
that they take future changes in capital structure into account when discounting using the WACC. The overall score is a mere 1.47. Forty percent never adjust WACC for anticipated changes in capital structure. With respect to the flows-to-equity method, where the discount rate is even more sensitive to capital structure (Esty 1999, Cooper and Nyborg 2018), only 15\% take future changes in capital structure into account almost always or always. Half of the respondents never take it into account. Surprisingly, respondents with MBAs, CFAs or PhDs are just as confused about the correct usage of the WACC as other respondents. However, investment bankers are marginally less confused than others, with their score for adjusting the WACC according to future capital structure being $1.96^{a}$.

While a WACC valuation is complicated to implement when capital structure is expected to vary over time, the two-step APV procedure is ideally suited to such a scenario since it does not require recalculating the cost of capital. Nevertheless, only $44 \%$ of respondents use this approach sometimes to deal with changes to capital structure - and only $15 \%$ do so almost always or always. The average strength of response is a mere 0.94. While there is some variation in this figure across professions, there is no statistically significant variation across education levels.

\section{Summary: Education vs Profession (Table 10)}

Overall, in the education block, there are no significant means or regression coefficients (specification 2) in Table 10. In the profession block, there are 9 significant means and 4 significant regression coefficients.

\subsubsection{Robustness}

As a robustness check on the findings in Table 10 and our conclusion that there is substantial confusion with respect to interest rate tax shields and the WACC, we have conducted a supplementary survey. This is comprised of (i) the same preliminary questions as in our main survey; (ii) a subset of the multiperiod model/DCF questions, including those in Table 10; and (iii) a new question, essentially a quiz, on the basics of implementing a valuation using the WACC. The quiz is designed to give additional insights into the kinds of mistakes the professionals might do. Given its role as a robustness check, the supplementary survey was sent to a relatively small set of valuation professionals. In total, there are twenty-four respondents. Thirteen of these attempted the quiz. Full details of the 
survey and all results are in a supplementary document. Here, we only summarize the key findings.

The results from the supplementary survey support our findings and conclusions above. The respondents' preferred multiperiod approach is DCF and they discount cash flows using the WACC. However, like the original respondents, they exhibit confusion with respect to whether and when to use market or target leverage ratios when computing WACCs. Furthermore, only about half of them report that they would recalculate the WACC almost always or always in response to projected changes in leverage ratios.

Respondents' answers on the quiz shed further light on their confusion. The quiz examines comprehension on three dimensions: (i) adjusting the WACC for leverage; (ii) not double counting tax shields; and (iii) discounting the right cash flows. We find that respondents are uniformly confused about how to adjust the WACC for leverage. In addition, approximately one third of the respondents double counts tax shields. However, almost all of them understand that the basic cash flows that should be discounted are the after-tax unlevered cash flows. In conclusion, the supplementary survey results support the view that a large fraction of valuation professionals have a less than perfect understanding of the WACC as a tax-adjusted discount rate and how to deal with its sensitivity to leverage.

\subsubsection{Adjusted Present Value}

While APV is not commonly used among the survey respondents, Table 11 nevertheless takes a look at how they deal with tax shields when they use the two-step APV procedure. The key issue that is being explored is whether respondents understand that the appropriate discount rate for the interest tax savings depends on debt policy (see, e.g., Brealey, Myers, and Allen 2017 or Cooper and Nyborg 2007). Under a constant debt to value ratio, the appropriate discount rate for future tax shields is the all equity opportunity cost of capital, $R_{u}$ (Miles and Ezzell 1980). Under a deterministic debt schedule, Cooper and Nyborg $(2008,2018)$ show that it is appropriate to discount tax shields at the debt's yield. This result is not incorporated in most textbooks. However, what is well communicated in textbooks is that when a project supports a constant amount of debt, $D$, interest tax savings should be discounted at the cost of debt, leaving the standard 
formula, $\mathrm{PV}(\mathrm{TS})=D T_{c}$ (assuming corporate taxes only). The questions reported on in Table 11 ask whether respondents typically discount interest tax savings at $R_{u}, R_{d}$ (cost of debt), or take into account debt policy in their choice of discount rate. We also ask whether respondents take into account the stability of the cash flows that will be used to service the debt. Highly variable cash flows may make the tax savings more risky.

\section{Insert Table 11 here.}

As seen in the table, there is little by way of conviction in survey participants' answers. The most popular choice is $R_{u}$, with an overall score of only 1.18. But the correct choice is that it depends on the debt policy of the firm (or project). ${ }^{23}$ The irony of $R_{u}$ being the most popular choice is that this is only correct if $D / V$ is constant, in which case it would be easier to incorporate the tax shields directly into the valuation in one step using the WACC. The answers here support the view that respondents do not fully understand tax shields or how to calculate APV correctly.

Panel B shows that valuation professionals almost never consider personal taxes when estimating the present value of the tax shield. Given how much confusion exists with respect to basic results relating to the interest tax shield, it is not surprising that more advanced issues such as the effect of personal taxes are not taken into account.

\section{Summary: Education vs Profession (Table 11 and all multiperiod tables)}

Once again, in Table 11 there is little by way of statistical significance in means and regression coefficients in either the profession or education blocks. For means, we have profession 9, education 3. For regression coefficients (specification 2), we have profession 3, education 1. Overall, for the multiperiod questions (Tables 6, 7, 9-11), the score is: Profession 73, Education 42 (means) and Profession 36, Education 14 (regression coefficients).

\subsection{Profession versus education: Overall review and summary}

Table 12 adds up the profession versus education scores over all tables thus far in all sections (Tables 2, 3, 5-7, 9-11). The results from the regressions, summarized in Panel A, shows that there is substantially more variation across the profession as compared with the education subgroups.

\footnotetext{
${ }^{23}$ See, e.g., Cooper and Nyborg (2006).
} 


\section{Insert Table 12 here.}

Focusing on regression specification 2, the educational subpopulation with the most significant regression coefficients (at conventional levels) is the BA group, with 10. By way of comparison, the private equity group have 33 significant coefficients, with consultants and asset managers having 25 and 22, respectively. Overall, there are 80 significant regression coefficients in the profession block as compared with only 26 in the education block. That profession matters more than educational level is borne out by the number of significant means. As seen in Panel B, there are 123 out of 372 in the profession block but only 54 out of 465 in the education block. It is almost surprising to see how inconsequential a valuation professional's educational level is.

Our findings support the sociological hypothesis that there are valuation cultures specific to different professions. This may also help explain respondents' confusion with respect to the WACC, APV, debt policies, and tax shields. It is difficult to break away from an ingrained culture with respect to how things are done. Dealing with tax shields correctly is relatively intricate and therefore easily forgotten if not regularly practiced.

The incorrect application of DCF is likely to lead to incorrect valuations and, as a consequence, a misallocation of capital in the economy. This is a challenge for finance education. Our survey findings suggest that the solution may require better teaching at valuation professionals' places of work.

\section{Valuation purpose and cluster analysis}

In this section, we examine the purpose of the valuation (as discussed in the Introduction) across professional subgroups and ask whether the importance of the profession documented above is driven by differences in valuation purposes. We examine this with the help of cluster analysis on the eleven valuation-purpose characteristics. ${ }^{24}$ Multicollinearity precludes us from using all eleven variables in the same regression. Cluster analysis circumvents this problem by creating clusters of respondents with similar valuation-purpose characteristics. It is also a useful tool in assessing whether the different professional sub-

\footnotetext{
${ }^{24}$ See questions 1, 2, and 3 in the "preliminary and personal" part of the survey and the discussion in the Introduction.
} 
groups have different valuation-purpose profiles.

\subsection{Valuation purposes across professions}

We start by looking at the replies to the eleven valuation purpose questions (in the "preliminary and personal" part of the survey) across and within the four professional subgroups. Table 13 summarizes the findings.

\section{Insert Table 13 here.}

Panel A reports on the type of investment; project finance, listed firms, unlisted firms, real estate, or "other." Most survey respondents are involved in valuing either listed or unlisted firms, with the overall strength of response for these two choices being 2.66 and 2.83, respectively. Respondents are to a much lesser extent involved with project finance (0.79), real estate $(0.72)$, or “other" (0.77). Consultants' and private equity professionals' most popular choice is unlisted firms $\left(3.38^{a}\right.$ and $3.67^{a}$, respectively), whereas that of investment bankers and asset managers is listed firms $\left(3.96^{a}\right.$ and $3.32^{a}$, respectively).

Panel B reports on the type of transaction; mergers and acquisitions, investment decisions, going public, going private, or other. The most popular choice in the population as a whole is investment decisions (3.12), followed by mergers and acquisitions (2.44) which is also the most popular choice among consultants $\left(3.27^{a}\right)$. For the less popular choices, investment bankers and asset managers are relatively more involved with going public transactions $\left(1.83^{a}\right.$ and 1.24 , respectively) than going private ones $\left(0.65^{a}\right.$ and $0.75^{b}$, respectively), while for consultants and private equity professionals, it is the reverse $\left(1.12^{b}\right.$ and $1.02^{c}$ versus $1.56^{a}$ and 1.51 , respectively).

Panel C reports on whether survey respondents are typically in an advisory role, on the buy side, on the sell side, or other. Consultants are most often in an advisory role $\left(3.09^{a}\right)$, investment bankers are on the sell-side $\left(3.99^{a}\right)$, and private equity professionals and asset managers are typically on the buy-side $\left(3.33^{a}\right.$ and $3.71^{a}$, respectively). However, consultants, for example, are also often on the buy or sell side $\left(1.93^{a}\right.$ and $2.30^{b}$, respectively).

In conclusion, Table 13 shows that there are both similarities and differences in valuation purposes across the professional subgroups. Next, we use cluster analysis to take a 
closer look at this.

\subsection{Cluster analysis: Valuation-purpose based clusters}

Cluster analysis reduces the valuation-purpose dimensionality through the formation of groups, or clusters, comprised of individual survey respondents with similar valuationpurpose characteristics. Different clusters will, therefore, also be distinct from each other with respect to valuation purpose. A feature of cluster analysis is that the data largely "speaks for itself" with respect to how individuals are assigned to different clusters. ${ }^{25}$ We first want to see whether clusters based on valuation-purpose characteristics are distinct from the professional subgroups.

To form clusters, each survey respondent is initially represented (as one observation) by an eleven-dimensional vector of his/her responses on our 0-4 point scale to the eleven valuation purpose questions. To measure the proximity between observations (and clusters), we use the Euclidean distance. ${ }^{26}$

From our full sample of 272 respondents, we drop observations with more than four missing characteristics, which leads to a new, reduced sample of 222. Missing values in this sample are substituted by the corresponding attribute value of the most similar complete object in the dataset (K-nearest-neighbor method with $\mathrm{K}=1) .{ }^{27}$

To form clusters, we use the hierarchical agglomerative clustering method (Rencher and Christensen 2012). This is a sequential approach where, in each step, the two closest clusters are merged to form a new, larger cluster. Thus the number of clusters shrinks with each step and the clusters grow larger.

Closeness is measured, and clusters are formed, using Ward's linkage method. This method calculates the dissimilarity between two clusters as the increase in the sum of squared distance (or, error), SSE, from the mean cluster vectors from joining two clusters. Specifically, if we combine two clusters $A$ and $B$ into a single cluster $A B$, then the increase, $I_{A B}$, is defined as:

$$
I_{A B}=\mathrm{SSE}_{A B}-\left(\mathrm{SSE}_{A}+\mathrm{SSE}_{B}\right)
$$

\footnotetext{
${ }^{25}$ See, e.g., Rencher and Christensen (2012) for a detailed exposition of cluster analysis.

${ }^{26}$ The Euclidean distance between two vectors $\mathbf{x}=\left(x_{1}, x_{2}, \ldots, x_{p}\right)^{\prime}$ and $\mathbf{y}=\left(y_{1}, y_{2}, \ldots, y_{p}\right)^{\prime}$ is defined as $d(\mathbf{x}, \mathbf{y})=\sqrt{(\mathbf{x}-\mathbf{y})^{\prime}(\mathbf{x}-\mathbf{y})}=\sqrt{\sum_{j=1}^{p}\left(x_{j}-y_{j}\right)^{2}}$.

${ }^{27}$ For a discussion of the nearest-neighbor method, see Hruschka, Hruschka Jr., and Ebecken (2003).
} 
where $\operatorname{SSE}_{A}=\sum_{i=1}^{n_{A}}\left(\mathbf{y}_{i}-\overline{\mathbf{y}}_{A}\right)^{\prime}\left(\mathbf{y}_{i}-\overline{\mathbf{y}}_{A}\right) ; \operatorname{SSE}_{B}=\sum_{i=1}^{n_{B}}\left(\mathbf{y}_{i}-\overline{\mathbf{y}}_{B}\right)^{\prime}\left(\mathbf{y}_{i}-\overline{\mathbf{y}}_{B}\right) ; \operatorname{SSE}_{A B}=$ $\sum_{i=1}^{n_{A B}}\left(\mathbf{y}_{i}-\overline{\mathbf{y}}_{A B}\right)^{\prime}\left(\mathbf{y}_{i}-\overline{\mathbf{y}}_{A B}\right) ; \overline{\mathbf{y}}_{A}=\sum_{i=1}^{n_{A}} \mathbf{y}_{i} / n_{A} ; \overline{\mathbf{y}}_{B}=\sum_{i=1}^{n_{B}} \mathbf{y}_{i} / n_{B} ; \overline{\mathbf{y}}_{A B}=\left(n_{A} \overline{\mathbf{y}}_{A}+\right.$ $\left.n_{B} \overline{\mathbf{y}}_{B}\right) /\left(n_{A}+n_{B}\right)$; and $n_{A}, n_{B}$, and $n_{A B}=n_{A}+n_{B}$ are the number of observations (individuals) in $A, B$, and $A B$ respectively. Thus, in each step, Ward's method joins the two clusters that minimize the increase in SSE.

We set the hierarchical agglomerative algorithm to produce four clusters. The reason is that there are four professional groups in our sample and we wish to examine the extent to which they also represent different valuation purposes. We are interested in the distribution of the four professions across the four clusters.

\section{Insert Figure 1 here.}

Figure 1 shows the dendrogram produced by the algorithm. Below each of the final four clusters, we list the number of individuals, by profession, that comprise the cluster. It turns out that survey respondents cluster by professions. From left to right: Cluster 1 consists of 46 (out of 50) investment bankers and one consultant. Cluster 2 consists of most private equity professionals and asset managers, joined by one consultant. Clusters 3 and 4 represent two consultant-dominated clusters. They also include the leftovers from Clusters 1 and 2 of the three other professions. The conclusion is, therefore, that the different professional subgroups have distinct valuation-purpose profiles.

Because the clusters shown in Figure 1 are so closely aligned with the different professional subgroups, they cannot be easily used to separate out profession from valuation purpose. Our approach is, therefore, to form within-profession valuation-purpose clusters, as this, by design, controls for professional subgroup.

\subsection{Within-profession clusters and regression analysis}

To examine the importance of the valuation purpose on the choice of valuation technique, in this subsection we carry out an analysis based on within-profession clusters. Asset managers are excluded because of their small number among the survey respondents. For the other three professions, we run, individually, the same hierarchical agglomerative cluster algorithm as in the previous subsection, but with the algorithm now set to produce two clusters per profession. The within-profession clusters are then used in two sets of 
regressions, as discussed below.

\section{Insert Table 14 here.}

For each pair of within-profession clusters, Table 14 lists the means of the eleven valuation-purpose characteristics and tests for differences. Starting with consultants, we see that the means are statistically significantly different ( $1 \%$ level) for nine of the eleven characteristics. Thus, the two populations produced by the cluster analysis are significantly different in terms of their valuation purpose. Cluster 1 can be viewed as consisting of generalists, with a high strength of response for a broad set of valuation purposes. Cluster 2 can be viewed as specialists, whose focus is on unlisted firms (3.51), mergers and acquisitions (3.18), and on being in an advisory role (2.87).

For investment bankers, the same pattern repeats; Cluster 1 consists of generalists and Cluster 2 of specialists. Seven of the eleven pairs of valuation purpose means are statistically significantly different (1\% level). The specialists focus on listed firms (3.93) and investment decisions (3.79) and are on the sell side (4.00).

Private equity professionals are also clustered into generalists (Cluster 1) and specialists (Cluster 2). The specialists focus on unlisted firms (3.58) and investment decisions (3.16) and are typically on the buy side (3.28).

To examine the importance of the purpose of valuation within each profession, next we run within-profession regressions on all 98 questions in Tables 2, 3, 5-7, and 9-11 as follows:

$$
y_{i j}=\beta_{0 j}+\beta_{1 j} \text { Clus }_{i}+\beta_{2 j} M B A_{i}+\beta_{3 j} \operatorname{HExp}_{i}+\beta_{4 j} L S_{i}+\varepsilon_{i j},
$$

where $y_{i j}$ is respondent $i$ 's answer to question $j$. Clus 1 is an indicator variable for Cluster 1 (within-profession generalists). The other explanatory variables are indicator variables as defined earlier. Because these regressions are within-profession regressions, they allow us to examine the importance of different valuation-purpose profiles while controlling for the profession.

The results are summarized in Table 15. For each profession, the table reports on the number of statistically significant coefficients (10\% or better) for each variable for all questions in Tables 2, 3, 5-7, and 9-11 on a table by table basis. The bottom line is that the valuation purpose is relatively unimportant with respect to explaining the choice (and implementation) of valuation technique. Clus 1 is significant in only 10, 16, and 9 
regressions for consulting, investment banking, and private equity, respectively. This is about a third to a half of the number of significant coefficients for the individual professions in the same kinds of regressions, as reported in Table 12. The findings summarized in Table 15 suggest that the importance of the professional subgroups with respect to the choice of valuation technique documented in previous sections is not driven by differences in the purpose of valuation.

As a robustness check, we also run regressions similar to those in Sections 3-5, but where we add indicator variables for the three specialist clusters, the Clus2's just described. In particular, we run

$$
y_{i j}=\beta_{0 j}+\beta_{1 j} \text { Cons }_{i}+\beta_{2 j} I B_{i}+\beta_{3 j} P E_{i}+\beta_{4 j} M B A_{i}+\beta_{5 j} H E x p_{i}+\beta_{6 j} L S_{i}+\beta_{7 j} C_{l u s} 2_{i}+\varepsilon_{i j},
$$

where Clus 2 refers to either consultants, investment bankers, or private equity professionals. In other words, (10) is run three times, one time for each of the three Clus2's. We do the same for the second specification:

$$
\begin{aligned}
y_{i j}= & \beta_{0 j}+\beta_{1 j} \text { Cons }_{i}+\beta_{2 j} I B_{i}+\beta_{3 j} P E_{i}+\beta_{4 j} B A_{i}+\beta_{5 j} M A_{i} \\
& +\beta_{6 j} \text { PhD }_{i}+\beta_{7 j} C_{F} A_{i}+\beta_{8 j} \operatorname{HExp}_{i}+\beta_{9 j} L S_{i}+\beta_{10 j} \text { Clus }_{i}+\varepsilon_{i j} .
\end{aligned}
$$

The findings are in Table 7. There are substantially more significant profession coefficients than Clus2 (valuation purpose) coefficients. For either specification, the ratios of significant profession to valuation-purpose coefficients are approximately: two to one (consulting), three to one (investment banking), and four to one (private equity). This is in line with the results above in Tables 12 and 15. It shows that the purpose of the valuation does not explain the inter-profession differences in valuation approach documented in Sections 3-5. Given the profession, the purpose of the valuation has a relatively small impact on the choice of valuation technique.

Our findings in this section support the view that the differences in valuation techniques between subgroups of valuation professionals are manifestations of different valuation cultures. Further work is required to understand how such cultures originate and evolve and what their impact may be on the allocation of capital and resources in the economy. 


\section{Concluding remarks}

In this paper, we have used a survey approach to learn about how valuation professionals go about valuing investment projects or firms. The survey asks questions relating to what methods the professionals use and how they implement these methods. Some questions are designed to tease out confusion that may exist, especially in the context of interest tax shields. Importantly, background questions on the survey respondents have allowed us to examine the impact of their professional subgroups, educational levels, experience, and typical valuation purposes on their approaches to valuation.

While we find, as one would expect, that there are substantial commonalities in the choice of valuation technique, there is also a fair amount of variation. In particular, the evidence is that: 1. Valuation approaches vary across professions. 2. There are not many differences across education levels. 3. Experience has almost no significant effect. 4. The purpose of the valuation has limited effect on the choice of valuation method. While different professions have different valuation-purpose characteristics, this does not explain the systematic differences we document across professions. 5. There is a fair amount of confusion with respect to interest tax shields and the WACC. Higher educational levels do not alleviate this confusion.

These findings support what we call the sociological hypothesis, namely that there are different valuation cultures within the different subgroups of valuation professionals. These apparent valuation cultures have only limited basis in the valuation purposes that dominate within the professions. Unfortunately, our survey can not shed light on the origin of such valuation cultures.

Our finding of systematic differences in valuation approaches across the professions contributes to the broader behavioral finance literature. There is substantial evidence of various behavioral biases across individual investors and other agents in the broader finance arena (see, e.g., Odean 1999, Barberis and Thaler 2003, or, for a review, Subrahmanyam 2007). There is also evidence that some of these biases may derive from interaction with others (Hong, Kubik, and Stein 2004, Hvide and Östberg 2015). What we call the sociological hypothesis expands on the standard peer effect hypothesis, since the influence is hypothesized to come from the profession as a whole. While it is beyond this paper to comment on the mechanism through which different valuation cultures sustain themselves 
or propagate, the finding that there are systematic differences across professions that are not related to differences in educational levels, experience, or valuation purposes is clear.

Our findings also relate to the sociology and social psychology literatures and, in particular, Harris (1998) who demonstrates the critical importance of sociological forces in shaping behavioral norms. Specifically, our findings suggest that valuation professionals' approach to valuation is more influenced by their peers at work and the standards of their profession than from what they learned as advanced students at University. One may, therefore, ask whether higher-level finance education beyond the bachelor level is merely a sideshow? A more positive perspective would be that higher-level finance education at University permeates to the workplace through peer effects, and this contributes to our finding of relatively small differences across educational levels. Alternatively, people with lower educational levels catch up through reading more advanced material on the job or on their own. ${ }^{28}$ Regardless of the interpretation, our findings suggest that it would be valuable to teach higher-level finance material in professional, work-related settings.

On a more basic and specific level, this paper contributes by documenting what the most popular valuation methodologies are among valuation professionals. Broadly speaking, we have seen that people use both multiples and discounted cash flows. While the theoretical foundation of the latter is highly developed - it is well explained in textbooks and substantially explored in the academic literature - there is much less work on multiples. That multiples are so popular in practice, across the professions and all educational levels, suggests that it would be useful to have more research into their performance and how best to use them in practice.

\footnotetext{
${ }^{28}$ We thank Ivo Welch for suggesting this possibility.
} 


\section{References}

Alford, A. W. (1992). The effect of the set of comparable firms on the accuracy of the price-earnings valuation method. Journal of Accounting Research 30, 94-108.

Arnold, G. C. and P. D. Hatzopoulos (2000). The theory-practice gap in capital budgeting: Evidence from the United Kingdom. Journal of Business Finance and Accounting 27, $603-626$.

Asch, S. E. (1955). Opinions and social pressure. Scientific American 193, 31-35.

Bancel, F. and U. R. Mittoo (2004). Cross-country determinants of capital structure choice: A survey of european firms. Financial Management 33, 103-132.

Barberis, N. and R. H. Thaler (2003). A survey of behavioral finance (Ch. 18 in Handbook of the Economics of Finance). Elsevier B.V., Amsterdam, Netherlands.

Berk, J. and P. DeMarzo (2017). Corporate Finance. Prentice Hall, Essex, UK.

Bhojraj, S. and C. M. Lee (2002). Who is my peer? A valuation-based approach to the selection of comparable firms. Journal of Accounting Research 40, 407-439.

Brealey, R. A., S. C. Myers, and F. Allen (2017). Principles of Corporate Finance. McGraw-Hill, New York, US.

Brounen, D., A. de Jong, and K. Koedijk (2004). Corporate Finance in Europe: Confronting theory with practice. Financial Management 33, 71-101.

Cooper, I. A. and L. Cordeiro (2008). Optimal equity valuation using multiples: The number of comparable firms. Working paper, London Business School, 2008.

Cooper, I. A. and K. G. Nyborg (2006). The value of tax shields is equal to the present value of tax shields. Journal of Financial Economics 81, 215-225.

Cooper, I. A. and K. G. Nyborg (2007). Valuing the debt tax shield. Journal of Applied Corporate Finance 19, 50-59.

Cooper, I. A. and K. G. Nyborg (2008). Tax-adjusted discount rates with investor taxes and risky debt. Financial Management 37, 365-379. 
Cooper, I. A. and K. G. Nyborg (2018). Consistent valuation of project finance and LBO's using the flows-to-equity method. European Financial Management 24, 34-52.

DeFranco, G., O. K. Hope, and S. Larocque (2015). Analysts' choice of peer companies. Review of Accounting Studies 20, 82-109.

Esty, B. C. (1999). Improved techniques for valuing large-scale projects. Journal of Project Finance 5, 9-25.

Fama, E. F. and K. R. French (1993). Common risk factors in the returns on stocks and bonds. Journal of Financial Economics 33, 3-56.

Graham, J. R. (2000). How big are the tax benefits of debt? Journal of Finance 55, 1901-1941.

Graham, J. R. and C. R. Harvey (2001). The theory and parctice of corporate finance: Evidence from the field. Journal of Financial Economics 60, 187-243.

Greenwood, E. (1957). Attributes of a profession. Social Work 2, 45-55.

Harris, J. R. (1995). Where is the child's environment? A group socialization theory of development. Psychological Review 102, 458-489.

Harris, J. R. (1998). The nurture assumption: Why children turn out the way they do. Free Press, New York, US.

Hong, H., J. D. Kubik, and J. C. Stein (2004). Social interaction and stock market participation. Journal of Finance 59, 137-163.

Hruschka, E. R., E. R. Hruschka Jr., and N. F. Ebecken (2003). Evaluating a nearestneighbor method to substitute continuous missing values. Advances in Artificial Intelligence 2903, 723-734.

Hvide, H. K. and P. Östberg (2015). Social interaction at work. Journal of Financial Economics 117, 628-652.

Kim, M. and J. R. Ritter (1999). Valuing IPO. Journal of Financial Economics 53, 409-437. 
Levi, Y. and I. Welch (2017). Best practice for cost-of-capital estimates. Journal of Financial and Quantitative Analysis 52, 427-463.

Lie, E. and H. J. Lie (2002). Multiples used to estimate corporate value. Financial Analysts Journal 58, 44-54.

Liu, J., D. Nissim, and J. Thomas (2002). Equity valuation using multiples. Journal of Accounting Research 40, 135-172.

Miles, J. and J. R. Ezzell (1980). The weighted average cost of capital, perfect capital markets and project life: A clarification. Journal of Financial and Quantitative Analysis 15, 719-730.

Modigliani, F. and M. H. Miller (1963). Corporate income taxes and the cost of capital: A correction. American Economic Review 53, 433-443.

Mohan, N., M. Ainina, D. Kaufman, and B. J. Winger (1991). Acquisition/divestiture valuation practices in major U.S. firms. Financial Practice and Education 1, 73-81.

Molnár, P. and K. G. Nyborg (2013). Tax-adjusted discount rates: A general formula under constant leverage ratios. European Financial Management 19, 419-428.

Mukherjee, T. K., H. Kiymaz, and H. Baker (2004). Merger motives and target valuation: A survey of evidence from CFOs. Journal of Applied Finance 14, 7-24.

Odean, T. (1999). Do investors trade too much? American Economic Review 89, 12791298.

Rencher, A. and W. Christensen (2012). Methods of multivariate analysis. Wiley, New Jersey, US.

Ross, S. A., R. W. Westerfield, and J. Jaffe (2015). Corporate Finance. McGraw-Hill, New York, US.

Ryan, P. A. and G. P. Ryan (2002). Capital budgeting practices of the fortune 1000: How have things changed? Journal of Business and Management 8, 355-364. 
Shiller, R. J. (1984). Stock prices and social dynamics. Brookings Papers on Economics Activity 2, 457-510.

Subrahmanyam, A. (2007). Behavioural finance: A review and synthesis. European Financial Management 14, 12-29.

Taggart, R. A. (1991). Consistent vavaluation and cost of capital expressions with corporate and personal taxes. Financial Management 20, 8-20.

Vismara, S., A. Signori, and S. Paleari (2015). Changes in underwriters' selection of comparable firms pre- and post-IPO: Same bank, same company, different peers. Journal of Corporate Finance 34, 235-250.

Welch, I. (2017). Corporate Finance, Volume 4th edition. Ivo Welch, Los Angeles, US. 


\section{Appendix A: Tables and figures}

\begin{tabular}{lcccccc}
\hline \multirow{2}{*}{ Profession } & Initial mailings & \multicolumn{3}{c}{ Selected responses } & \multirow{2}{*}{ Response rate } & \% of sample \\
\cline { 3 - 5 } & & Complete & Partly complete & Total & & \\
\hline Consulting & 1132 & 54 & 59 & $\mathbf{1 1 3}$ & $10.0 \%$ & $41.5 \%$ \\
Investment banking & 1176 & 29 & 43 & $\mathbf{7 2}$ & $6.1 \%$ & $26.5 \%$ \\
Private equity & 1377 & 18 & 40 & $\mathbf{5 8}$ & $4.2 \%$ & $21.3 \%$ \\
Asset management & 815 & 4 & 25 & $\mathbf{2 9}$ & $3.6 \%$ & $10.7 \%$ \\
\hline Total & 4500 & 105 & 167 & $\mathbf{2 7 2}$ & $6.0 \%$ & $100 \%$ \\
\hline
\end{tabular}

Table 1: Overview of responses and selected sample.

Description: Our final (selected) sample has 272 responses out of 4500 initial mailings. We drop all records which contain responses only for section 1 of the survey (preliminary questions) and keep all records with at least 2 (out of 5) questions completed in the Multiples section. "Complete" means at least $95 \%$ overall completeness across all 4 sections. "Partly complete" means a completeness rate of at least 30\%. "Response rate" is the "Total" column as a percent of "Initial mailings." "\% of sample" denotes the percentage of the indicated profession out of the total sample of 272 . 


\begin{tabular}{|c|c|c|c|c|c|c|c|c|c|c|c|c|c|c|c|}
\hline \multirow[b]{3}{*}{ Full sample } & \multirow{3}{*}{$\begin{array}{c}\text { Replies } \\
272\end{array}$} & \multirow[t]{3}{*}{$\% 1-4$} & \multirow[t]{3}{*}{$\% 3-4$} & \multirow[t]{3}{*}{ mean } & \multicolumn{4}{|c|}{ Profession } & \multicolumn{5}{|c|}{ Education } & \multicolumn{2}{|c|}{ Experience } \\
\hline & & & & & Cons. & IB & $\mathrm{PE}$ & $\mathrm{AM}$ & $\mathrm{BA}$ & MA & $\mathrm{PhD}$ & MBA & CFA & $\leq 10 \mathrm{y}$ & $>10 \mathrm{y}$ \\
\hline & & & & & 113 & 72 & 58 & 29 & 52 & 37 & 17 & 123 & 36 & 103 & 168 \\
\hline \multicolumn{16}{|c|}{ Panel A: Valuation approach: frequency of use } \\
\hline Both Mult. and DCF & 194 & $94 \%$ & $76 \%$ & 2.97 & $3.29^{a}$ & 3.12 & $2.03^{a}$ & 2.88 & 3.03 & $3.46^{a}$ & 3.36 & $2.71^{a}$ & 3.00 & $2.78^{c}$ & $3.09^{c}$ \\
\hline Both, primarily Mult. & 178 & $87 \%$ & $47 \%$ & 2.18 & 2.12 & 2.24 & 2.17 & 2.36 & $2.82^{a}$ & 2.04 & 2.08 & 2.09 & 1.92 & 2.16 & 2.19 \\
\hline Both, primarily DCF & 173 & $83 \%$ & $46 \%$ & 2.12 & $2.33^{c}$ & $2.61^{a}$ & $0.90^{a}$ & 1.75 & 1.97 & 2.50 & 2.27 & 1.96 & 2.19 & $1.80^{b}$ & $2.33^{b}$ \\
\hline Only Multiples & 164 & $80 \%$ & $26 \%$ & 1.59 & 1.67 & $1.24^{b}$ & 1.88 & 1.58 & $2.00^{b}$ & $1.05^{a}$ & 1.50 & 1.68 & 1.42 & 1.74 & 1.48 \\
\hline Only DCF & 160 & $70 \%$ & $17 \%$ & 1.28 & 1.36 & $1.58^{b}$ & $0.65^{a}$ & 1.25 & $1.73^{a}$ & $0.90^{b}$ & 1.75 & 1.15 & 1.19 & 1.22 & 1.32 \\
\hline Sensitivity & 182 & $95 \%$ & $68 \%$ & 2.82 & 2.82 & 2.69 & 2.97 & 2.93 & 2.76 & 2.57 & 3.18 & 2.78 & 2.97 & 2.78 & 2.85 \\
\hline Scenario & 175 & $92 \%$ & $57 \%$ & 2.46 & 2.42 & 2.32 & 2.75 & 2.58 & 2.25 & 2.21 & 2.73 & 2.55 & 2.52 & 2.51 & 2.43 \\
\hline Sum-of-parts & 180 & $91 \%$ & $39 \%$ & 2.08 & $1.89^{b}$ & $2.53^{a}$ & $1.71^{c}$ & 2.38 & 2.03 & 2.05 & 2.40 & 2.13 & 1.90 & 1.93 & 2.18 \\
\hline \multicolumn{16}{|c|}{ Panel B: Does industry affect valuation approach? } \\
\hline Yes & 199 & $92 \%$ & $50 \%$ & 2.33 & 2.37 & 2.31 & 2.21 & 2.44 & 2.46 & 2.56 & 2.36 & 2.28 & 2.14 & 2.38 & 2.30 \\
\hline \multicolumn{16}{|c|}{ Panel C: Does transaction type affect val. approach? } \\
\hline Yes & 190 & $93 \%$ & $34 \%$ & 1.97 & 1.95 & 2.02 & 2.03 & 1.79 & 2.14 & 1.88 & 2.15 & 1.88 & 2.17 & 2.04 & 1.93 \\
\hline \multicolumn{16}{|c|}{ Panel D: Reason for NOT using multi-period models } \\
\hline Time-consuming & 116 & $67 \%$ & $34 \%$ & 1.71 & 1.77 & $1.24^{b}$ & 2.00 & 2.14 & 1.73 & 1.21 & 1.83 & 1.87 & 1.53 & 1.79 & 1.65 \\
\hline CF uncertainty & 117 & $79 \%$ & $51 \%$ & 2.27 & 2.32 & $1.73^{b}$ & 2.57 & $3.13^{b}$ & 2.29 & 1.93 & 1.80 & 2.35 & 2.53 & 2.26 & 2.28 \\
\hline Cost of cap. unc. & 112 & $73 \%$ & $39 \%$ & 1.87 & 1.81 & 1.71 & 2.13 & 2.00 & 1.73 & 1.64 & 1.80 & 1.80 & $2.50^{c}$ & 2.14 & 1.69 \\
\hline Other & 41 & $29 \%$ & $17 \%$ & 0.85 & 1.55 & $0.15^{a}$ & 0.69 & 1.75 & 1.20 & $0.00^{a}$ & $0.00^{a}$ & 0.63 & 0.75 & 0.77 & 0.95 \\
\hline \multicolumn{16}{|c|}{ Panel E: Regressions. Significant coefficients. Stat. significant coefficients ( $\leq 10 \%)$ out of 13 : } \\
\hline Specification 1 & & & & & 3 & - & 6 & 2 & - & - & - & 1 & - & - & 0 \\
\hline Specification 2 & & & & & 3 & - & 6 & 2 & 2 & 1 & 0 & - & 1 & - & 0 \\
\hline
\end{tabular}

Table 2: Choice of valuation approach.

Description: This table reports results from the fourth part of the questionnaire (General questions on analysis approach). The row labeled "Full sample" provides the total number of respondents in the whole sample and the indicated subpopulations. Panels A - D correspond to sets of questions 30 - 33 . The first block of columns represents results for the total number of participants (272). The first column gives the number of replies to each question; the second column gives the percentage of the replies that are from 1 to 4 (where 0 is "never" and 4 is "always"); the third column gives the percentage of the replies that are 3 or 4 ("almost always" or "always"); the fourth column shows the mean across all replies (on the $0-4$ scale). The remaining columns are divided into three blocks, "Profession," "Education," and "Experience," within which each column provides the mean of the respective responses (on the 0 - 4 scale) for the indicated subpopulation (e.g., Consulting, Investment Banking, etc.). Within each panel, the highest number in each column is indicated in bold. Within each panel-block we check whether the mean of each subpopulation is statistically different from that of the complement population (e.g., Cons. vs. IB, PE, and AM together) and indicate statistical significance at the $1 \%, 5 \%$, and $10 \%$ level by $\boldsymbol{a}, \boldsymbol{b}$, and $\boldsymbol{c}$, respectively. Panel E reports the number of statistically significant coefficients at the $10 \%$ level or less from running the following regressions for each question in all preceding panels (except "Other")

Specification 1: $y_{i j}=\beta_{0 j}+\beta_{1 j}$ Cons $_{i}+\beta_{2 j} P E_{i}+\beta_{3 j} A M_{i}+\beta_{4 j} M B A_{i}+\beta_{5 j} H E x p_{i}+\beta_{6 j} L S_{i}+\varepsilon_{i j}$,

Specification 2: $y_{i j}=\beta_{0} j+\beta_{1 j}$ Cons $_{i}+\beta_{2 j} P E_{i}+\beta_{3 j} A M_{i}+\beta_{4 j} B A_{i}+\beta_{5 j} M A_{i}+\beta_{6 j} P_{h D}+\beta_{7 j} C F A_{i}+\beta_{8 j} H E_{x p}+\beta_{9 j} L S_{i}+\varepsilon_{i j}$,

where $y_{i j}$ is respondent $i$ 's answer to question $j$. The RHS variables in the regression are defined in the text after equations $(1,2)$. The numbers of statistically significant coefficients for the variable $L S$ are not provided in the table, but can be found as a summary for all regressions in Tables 2, 3, 5-7, 9-11 in Table 12. All significance tests are two-tailed.

"Cons.," "IB," "PE," and "AM" denote "Consulting," "Investment Banking," "Private Equity," and "Asset Management" respectively. "BA," "MA," "PhD," "MBA," and "CFA" denote "Bachelor," "Master," "Doctoral degree," "Master of Business Administration," and "Chartered Financial Analyst" respectively.

Interpretation: About $3 / 4$ of respondents use both multiples and DCF almost always or always. Respondents with a preference for multiples or DCF are evenly divided in the population. The main reason for not using DCF is cash flow uncertainty. There are more statistically significant response differences across the professional subgroups than across educational levels. 


\begin{tabular}{|c|c|c|c|c|c|c|c|c|c|c|c|c|c|c|c|}
\hline \multirow[b]{2}{*}{ Full sample } & \multirow{2}{*}{$\begin{array}{c}\text { Replies } \\
272\end{array}$} & \multirow[t]{2}{*}{$\% 1-4$} & \multirow[t]{2}{*}{$\% 3-4$} & \multirow[t]{2}{*}{ mean } & \multicolumn{4}{|c|}{ Profession } & \multicolumn{5}{|c|}{ Education } & \multicolumn{2}{|c|}{ Experience } \\
\hline & & & & & $\begin{array}{c}\text { Cons. } \\
113\end{array}$ & $\begin{array}{l}\text { IB } \\
72\end{array}$ & $\begin{array}{r}\mathrm{PE} \\
58\end{array}$ & $\begin{array}{r}\mathrm{AM} \\
29\end{array}$ & $\begin{array}{l}\mathrm{BA} \\
52\end{array}$ & $\begin{array}{r}\text { MA } \\
37\end{array}$ & $\begin{array}{c}\mathrm{PhD} \\
17\end{array}$ & $\begin{array}{c}\text { MBA } \\
123\end{array}$ & $\begin{array}{c}\mathrm{CFA} \\
36\end{array}$ & $\begin{array}{c}\leq 10 \mathrm{y} \\
103\end{array}$ & $\begin{array}{c}>10 y \\
168\end{array}$ \\
\hline \multicolumn{16}{|l|}{ Panel A: Multiples } \\
\hline $\mathrm{P} / \mathrm{E}$ & 266 & $85 \%$ & $49 \%$ & 2.26 & $2.02^{b}$ & $3.11^{a}$ & $1.30^{a}$ & $2.93^{a}$ & 2.42 & 2.30 & 2.44 & 2.12 & 2.42 & 2.14 & 2.33 \\
\hline PEG & 257 & $72 \%$ & $21 \%$ & 1.38 & $1.20^{b}$ & $1.90^{a}$ & $0.83^{a}$ & $1.85^{c}$ & 1.39 & 1.29 & 1.94 & 1.28 & 1.44 & 1.25 & 1.46 \\
\hline $\mathrm{P} / \mathrm{B}$ & 261 & $72 \%$ & $24 \%$ & 1.50 & $1.17^{a}$ & $1.93^{a}$ & $0.98^{a}$ & $2.64^{a}$ & 1.63 & 1.32 & 1.41 & 1.39 & $1.97^{b}$ & $1.30^{b}$ & $1.63^{b}$ \\
\hline $\mathrm{P} / \mathrm{S}$ & 257 & $60 \%$ & $14 \%$ & 1.09 & 1.08 & 1.16 & $0.72^{a}$ & $1.68^{a}$ & 0.94 & 1.36 & 1.53 & 0.99 & 1.22 & $0.91^{b}$ & $1.21^{b}$ \\
\hline $\mathrm{P} / \mathrm{CF}$ & 257 & $77 \%$ & $31 \%$ & 1.75 & $1.53^{b}$ & $2.01^{b}$ & 1.48 & $2.50^{a}$ & 1.69 & 1.83 & 1.94 & 1.67 & 1.92 & 1.60 & 1.87 \\
\hline $\mathrm{EV} / \mathrm{S}$ & 257 & $79 \%$ & $28 \%$ & 1.70 & $1.97^{a}$ & 1.68 & $1.23^{a}$ & 1.64 & 1.56 & 1.83 & $2.47^{a}$ & 1.67 & 1.54 & 1.70 & 1.70 \\
\hline EV/EBITDA & 267 & $95 \%$ & $84 \%$ & 3.34 & $3.62^{a}$ & $3.09^{b}$ & 3.41 & $2.75^{b}$ & 3.29 & 3.53 & 3.24 & 3.41 & 3.11 & 3.46 & 3.27 \\
\hline EV/EBITA & 259 & $82 \%$ & $51 \%$ & 2.32 & 2.40 & 2.09 & $2.77^{a}$ & $1.68^{a}$ & 2.12 & $1.86^{b}$ & 2.19 & $2.62^{a}$ & 2.29 & 2.36 & 2.28 \\
\hline $\mathrm{EV} / \mathrm{EBIT}$ & 258 & $88 \%$ & $59 \%$ & 2.55 & $2.84^{a}$ & $2.30^{c}$ & 2.67 & $1.71^{a}$ & 2.37 & 2.26 & 2.29 & $2.82^{a}$ & 2.29 & 2.59 & 2.51 \\
\hline Ind.-specific & 253 & $87 \%$ & $47 \%$ & 2.27 & $2.45^{c}$ & 2.06 & 2.24 & 2.19 & 2.39 & 2.11 & $1.67^{c}$ & 2.39 & 2.14 & $2.44^{c}$ & $2.15^{c}$ \\
\hline \multicolumn{16}{|c|}{ Panel B: Multiples. Time aspect } \\
\hline Trailing & 265 & $89 \%$ & $55 \%$ & 2.53 & $2.74^{b}$ & $1.87^{a}$ & $3.05^{a}$ & 2.29 & $2.90^{b}$ & 2.42 & 2.00 & 2.57 & 2.28 & $2.70^{c}$ & $2.42^{c}$ \\
\hline $12 \mathrm{~m}$ fwd & 268 & $96 \%$ & $80 \%$ & 3.13 & 3.11 & $3.44^{a}$ & $2.90^{c}$ & 2.89 & 3.02 & 3.03 & 3.12 & 3.20 & 3.28 & 3.20 & 3.08 \\
\hline $24 \mathrm{~m}$ fwd & 262 & $84 \%$ & $37 \%$ & 2.04 & 2.02 & $2.59^{a}$ & $1.38^{a}$ & 2.04 & 2.08 & 1.81 & 2.35 & 2.03 & 2.14 & 1.90 & 2.14 \\
\hline \multicolumn{16}{|c|}{ Panel $C:$ Impact of investment characteristics } \\
\hline Industry & 244 & $99 \%$ & $89 \%$ & 3.44 & 3.37 & 3.52 & 3.51 & 3.35 & 3.47 & 3.50 & 3.56 & 3.41 & 3.43 & 3.46 & 3.43 \\
\hline Size & 242 & $87 \%$ & $41 \%$ & 2.17 & $2.35^{b}$ & $1.77^{a}$ & 2.31 & 2.13 & 2.02 & 2.18 & 1.94 & 2.20 & 2.46 & 2.31 & 2.08 \\
\hline Transaction type & 238 & $88 \%$ & $38 \%$ & 2.10 & 2.24 & $1.87^{c}$ & 2.34 & $1.50^{b}$ & 2.05 & 2.00 & 2.18 & 2.10 & 2.34 & 2.13 & 2.08 \\
\hline Account. manip. & 239 & $92 \%$ & $42 \%$ & 2.17 & 2.14 & 2.26 & 1.92 & $2.57^{b}$ & 1.95 & 1.97 & 2.19 & 2.24 & $2.49^{c}$ & $1.97^{b}$ & $2.28^{b}$ \\
\hline Earn., marg. stab. & 243 & $97 \%$ & $70 \%$ & 2.84 & 2.82 & 2.92 & 2.84 & 2.70 & 2.93 & 2.71 & 3.06 & $2.69^{b}$ & $3.23^{a}$ & 2.84 & 2.84 \\
\hline Cap. intensity & 241 & $93 \%$ & $59 \%$ & 2.51 & 2.46 & 2.52 & 2.53 & 2.70 & 2.56 & 2.32 & 2.50 & 2.54 & 2.60 & 2.51 & 2.51 \\
\hline Stock liq. & 235 & $76 \%$ & $27 \%$ & 1.63 & $1.82^{b}$ & 1.57 & $1.26^{b}$ & 1.61 & 1.48 & 1.38 & 1.81 & 1.64 & 1.97 & 1.49 & 1.71 \\
\hline Other & 107 & $28 \%$ & $14 \%$ & 0.74 & $1.17^{c}$ & 0.56 & 0.52 & 0.73 & 0.50 & 0.50 & 0.38 & 0.84 & 1.08 & 0.59 & 0.86 \\
\hline \multicolumn{16}{|c|}{ Panel D: Regressions. Significant coefficients. Stat. significant coefficients ( $\leq 10 \%)$ out of 20 : } \\
\hline Specification 1 & & & & & 8 & - & 8 & 4 & - & - & - & 3 & - & - & 1 \\
\hline Specification 2 & & & & & 8 & - & 10 & 5 & 2 & 2 & 2 & - & 1 & - & 0 \\
\hline
\end{tabular}

Table 3: Multiples

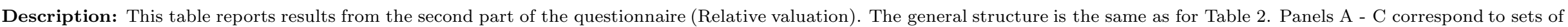

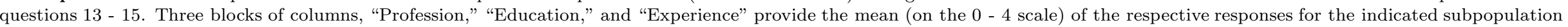

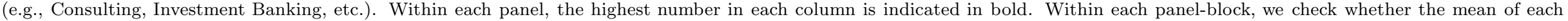

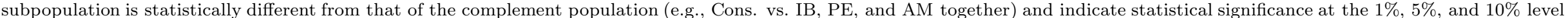

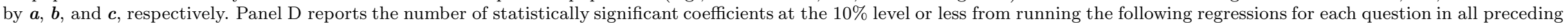
panels (except "Other")

Specification 1: $y_{i j}=\beta_{0 j}+\beta_{1 j}$ Cons $_{i}+\beta_{2 j} P E_{i}+\beta_{3 j} A M_{i}+\beta_{4 j} M B A_{i}+\beta_{5 j} H \operatorname{Exp}_{i}+\beta_{6 j} L S_{i}+\varepsilon_{i j}$,

Specification 2: $y_{i j}=\beta_{0 j}+\beta_{1 j}$ Cons $_{i}+\beta_{2 j} P E_{i}+\beta_{3 j} A M_{i}+\beta_{4 j} B A_{i}+\beta_{5 j} M A_{i}+\beta_{6 j} P h D_{i}+\beta_{7 j} C F A_{i}+\beta_{8 j} H E x p_{i}+\beta_{9 j} L S_{i}+\varepsilon_{i j}$,

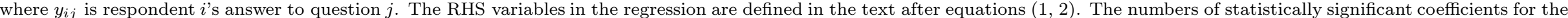
variable $L S$ are not provided in the table, but can be found as a summary for all regressions in Tables 2, 3, 5-7, 9-11 in Table 12. All significance tests are two-tailed.

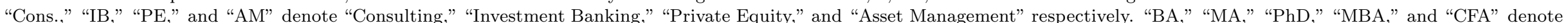
"Bachelor," "Master," "Doctoral degree," "Master of Business Administration," and "Chartered Financial Analyst" respectively.

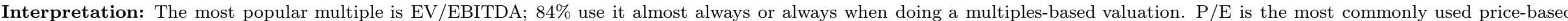

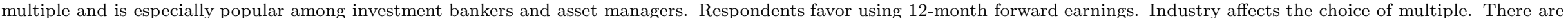
more statistically significant response differences across the professional subgroups than across educational levels. 
Enterprise value valuation errors (in \$mill)

\begin{tabular}{|c|c|c|c|c|c|c|c|c|c|}
\hline & \multicolumn{2}{|c|}{ EV/EBITDA } & \multicolumn{2}{|c|}{ EV/EBIT } & \multicolumn{2}{|c|}{$\mathbf{P} / \mathbf{E}$} & \multirow[t]{2}{*}{$\mathbf{P} / \mathbf{B}$} & \multicolumn{2}{|c|}{$\mathrm{P} / \mathrm{CF}$} \\
\hline & Trail. & Forw. & Trail. & Forw. & Trail. & Forw. & & Trail. & Forw. \\
\hline \multicolumn{10}{|c|}{ Panel A: Green Mountain at 14.02. 2014} \\
\hline Bloomberg & 3,280 & 3,199 & 3,665 & 2,887 & 5,536 & 6,189 & 5,725 & 2,430 & 7,204 \\
\hline Large & 3,289 & 2,865 & 3,601 & 2,434 & 5,788 & 6,398 & 6,498 & 5,423 & 7,765 \\
\hline Small & 3,272 & 3,490 & 3,720 & 3,282 & 5,315 & 6,007 & 5,049 & 563 & 6,642 \\
\hline \multicolumn{10}{|c|}{ Panel B: Keurig at 24.02.2015 } \\
\hline Bloomberg & 1,487 & 1,116 & 1,171 & 818 & 5,299 & 3,904 & 2,524 & 8,499 & 4,553 \\
\hline Large & 1,606 & 182 & 2,069 & 315 & 4,793 & 3,535 & 831 & 8,383 & 3,142 \\
\hline Small & 1,352 & 2,600 & 25 & 2,328 & 5,975 & 4,307 & 6,358 & 8,632 & 6,433 \\
\hline
\end{tabular}

Table 4: Multiples. Example.

Description: This table represents an example of valuation with multiples for Green Mountain Coffee Roasters (later known as Keurig). The valuation is carried out for three sets of comparables: (i) the Bloomberg comparables set (as of 14.02.2014 and 24.02.2015), (ii) the 50\% largest in (i), by enterprise value, and (iii) the $50 \%$ smallest. For each comparables set, we calculate the average of each multiple and then apply it to the relevant earnings or cash flow figure of Keurig Green Mountain. For example, to estimate the enterprise value with a $\mathrm{P} / \mathrm{E}$ multiple we first calculate an estimated price, $\widehat{\text { Price, }}$ of Keurig Green Mountain by multiplying its EPS by the average $\mathrm{P} / \mathrm{E}$, for each set of comparables, and then calculating an estimated enterprise value of Keurig Green Mountain by using the definition in Bloomberg: $\widehat{E V}=$ $\widehat{\text { Price }} \times N_{S h}+$ Pref.Equity + Minority Int. + Tot.Debt - Cash83Marktb.Securities - Other non-cash Adj., where $N_{S h}$ is the number of shares of Keurig Green Mountain. The table reports valuation errors in absolute terms, i.e., $\left|E V_{\text {true }}-\widehat{E V}\right|$ in $\$$ mill. The true enterprise value of Keurig Green Mountain was 15,900 \$mill on 14.02.2014 and 18,672 \$mill on 24.02.2015. Similar procedures are applied to all multiples presented in the table, all except $\mathrm{P} / \mathrm{B}$ with trailing and forward earnings (or cash flows). The numbers in bold represent the highest and the lowest valuation errors (in absolute terms).

On February 14, 2014 (Green Mountain), the comparables were Nestlé, Coca-Cola, PepsiCo, Mondelēz International, Danone, Associated British Foods, and General Mills in the "Large" group and Kerry Group, ConAgra Foods, Monster Beverage, Lindt\&Sprüngli, Dr Pepper Snapple Group, Smucker's, Tata Global Beverages, and Dean Foods in the "Small" group. On February 24, 2015 (Keurig), the comparables were Nestlé, Coca-Cola, PepsiCo, Mondelēz International, Danone, Associated British Foods, General Mills, and Monster Beverage in the "Large" group and Dr Pepper Snapple Group, ConAgra Foods, Lindt\&Sprüngli, Kerry Group, Smucker's, Tata Global Beverages, and Dean Foods in the "Small" group.

Interpretation: The best performing multiple is sensitive to the comparables set and varies over time. 


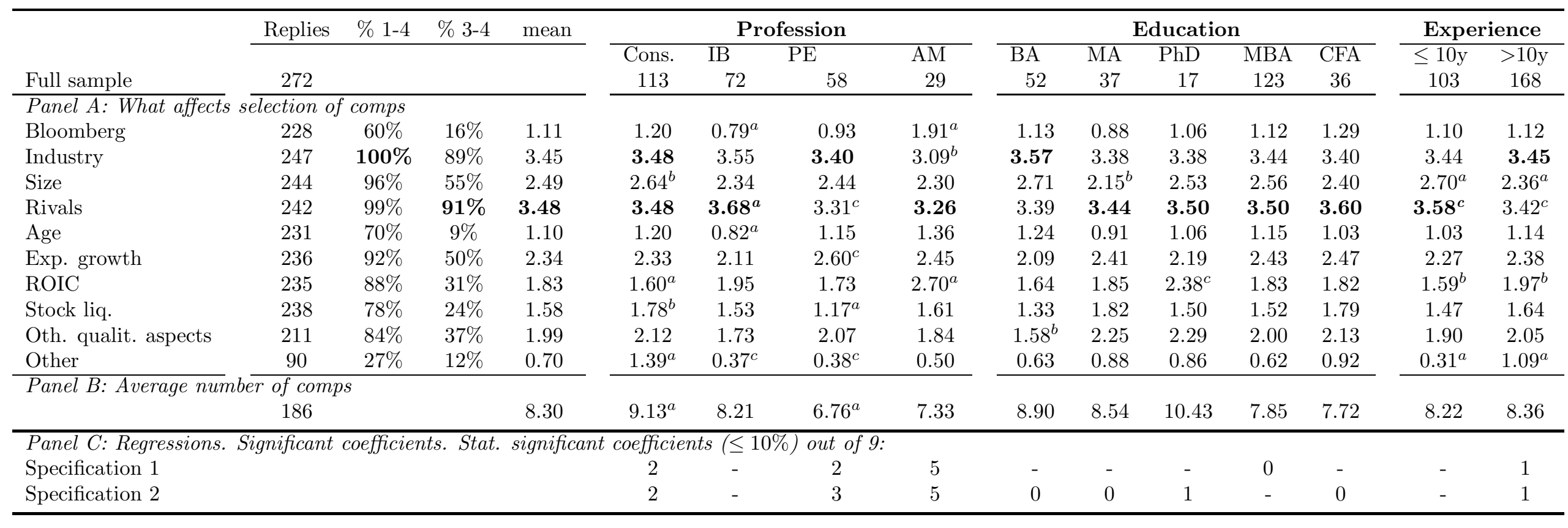

Table 5: Multiples. Comparables selection.

Description: This table reports results from the second part of the questionnaire (Relative valuation). The general structure is the same as for Table 2. Panels A, B correspond to sets of questions 16, 17. Three blocks of columns, "Profession," "Education," and "Experience" provide the mean (on the 0 - 4 scale) of the respective responses for the indicated subpopulation (e.g., Consulting, Investment Banking, etc.). Within each panel, the highest number in each column is indicated in bold. Within each panel-block, we check whether the mean of each subpopulation is statistically different from that of the complement population (e.g., Cons. vs. IB, PE, and AM together) and indicate statistical significance at the $1 \%, 5 \%$, and $10 \%$ level by $\boldsymbol{a}$, $\boldsymbol{b}$, and $\boldsymbol{c}$, respectively. Panel $\mathrm{C}$ reports the number of statistically significant coefficients at the $10 \%$ level or less from running the following regressions for each question in all preceding panels (except "Other")

Specification 1: $y_{i j}=\beta_{0 j}+\beta_{1 j}$ Cons $_{i}+\beta_{2 j} P E_{i}+\beta_{3 j} A M_{i}+\beta_{4 j} M B A_{i}+\beta_{5 j} H \operatorname{Exp}_{i}+\beta_{6 j} L S_{i}+\varepsilon_{i j}$,

Specification 2: $y_{i j}=\beta_{0} j+\beta_{1 j}$ Cons $_{i}+\beta_{2 j} P E_{i}+\beta_{3 j} A M_{i}+\beta_{4 j} B A_{i}+\beta_{5 j} M A_{i}+\beta_{6 j} P h D_{i}+\beta_{7 j} C F A_{i}+\beta_{8 j} \operatorname{HExp}_{i}+\beta_{9 j} L S_{i}+\varepsilon_{i j}$,

where $y_{i j}$ is respondent $i$ 's answer to question $j$. The RHS variables in the regression are defined in the text after equations $(1,2)$. The numbers of statistically significant coefficients for the variable $L S$ are not provided in the table, but can be found as a summary for all regressions in Tables 2, 3, 5-7, 9-11 in Table 12. All significance tests are two-tailed.

"Cons.," "IB," "PE," and "AM" denote "Consulting," "Investment Banking," "Private Equity," and "Asset Management" respectively. "BA," "MA," "PhD," "MBA," and "CFA" denote "Bachelor," "Master," "Doctoral degree," "Master of Business Administration," and "Chartered Financial Analyst" respectively.

Interpretation: Respondents use eight comparables on average, predominantly picked from rivals in the same industry. Size and expected growth are also important factors. There are more statistically significant response differences across the professional subgroups than across educational levels. 


\begin{tabular}{|c|c|c|c|c|c|c|c|c|c|c|c|c|c|c|c|}
\hline \multirow[b]{3}{*}{ Sample } & \multirow{2}{*}{ Replies } & \multirow{3}{*}{$\% 1-4$} & \multirow{3}{*}{$\% 3-4$} & \multirow{3}{*}{ mean } & \multicolumn{4}{|c|}{ Profession } & \multicolumn{5}{|c|}{ Education } & \multicolumn{2}{|c|}{ Experience } \\
\hline & & & & & Cons. & IB & $\mathrm{PE}$ & $\mathrm{AM}$ & $\mathrm{BA}$ & MA & $\mathrm{PhD}$ & $\mathrm{MBA}$ & CFA & $\leq 10 \mathrm{y}$ & $>10 y$ \\
\hline & 272 & & & & 113 & 72 & 58 & 29 & 52 & 37 & 17 & 123 & 36 & 103 & 168 \\
\hline \multicolumn{16}{|c|}{ Panel A: Different models } \\
\hline DCF & 239 & $95 \%$ & $76 \%$ & 3.20 & $3.57^{a}$ & $3.45^{b}$ & $2.06^{a}$ & 3.18 & 3.20 & $3.52^{c}$ & 3.18 & $3.02^{c}$ & 3.43 & 3.08 & 3.28 \\
\hline RIM & 228 & $52 \%$ & $9 \%$ & 0.87 & 0.93 & 0.87 & $0.50^{a}$ & $1.36^{b}$ & 0.89 & 0.74 & 0.88 & 0.85 & 1.06 & 0.75 & 0.94 \\
\hline EVA & 232 & $69 \%$ & $19 \%$ & 1.35 & 1.26 & $1.77^{a}$ & $0.68^{a}$ & $2.00^{b}$ & 1.34 & 1.16 & 1.18 & 1.36 & 1.61 & $0.96^{a}$ & $1.60^{a}$ \\
\hline DDM & 232 & $66 \%$ & $18 \%$ & 1.31 & 1.37 & 1.48 & $0.66^{a}$ & $1.91^{b}$ & 1.39 & 1.26 & 1.53 & $1.16^{c}$ & $1.71^{c}$ & $1.07^{b}$ & $1.46^{b}$ \\
\hline IRR & 233 & $87 \%$ & $47 \%$ & 2.25 & 2.31 & $1.51^{a}$ & $3.10^{a}$ & 2.27 & $2.64^{b}$ & 1.94 & 2.12 & 2.29 & 2.00 & 2.29 & 2.23 \\
\hline \multicolumn{16}{|c|}{ Panel B: Approaches within DCF } \\
\hline NPV & 230 & $91 \%$ & $80 \%$ & 3.17 & 3.16 & 3.34 & 2.89 & 3.30 & 3.42 & 3.45 & 3.29 & $2.88^{a}$ & 3.47 & 3.10 & 3.21 \\
\hline $\mathrm{APV}$ & 216 & $56 \%$ & $15 \%$ & 1.09 & 1.13 & 1.08 & 0.90 & 1.30 & 1.02 & 1.00 & 1.40 & 1.08 & 1.09 & $0.86^{b}$ & $1.24^{b}$ \\
\hline $\mathrm{CCF}$ & 219 & $53 \%$ & $14 \%$ & 1.00 & 1.03 & 0.94 & 0.88 & 1.26 & 1.05 & 0.87 & 1.19 & 0.98 & 0.97 & 0.99 & 1.00 \\
\hline Flows to Equity & 220 & $60 \%$ & $23 \%$ & 1.29 & 1.38 & 1.21 & 1.15 & 1.40 & 1.43 & $0.87^{c}$ & 1.00 & 1.34 & 1.58 & 1.18 & 1.36 \\
\hline WACC & 229 & $94 \%$ & $82 \%$ & 3.25 & $3.44^{b}$ & 3.41 & $2.77^{b}$ & 2.85 & 3.09 & 3.26 & 3.44 & 3.25 & 3.29 & 3.23 & 3.26 \\
\hline \multicolumn{16}{|c|}{ Panel C: What affects choice of DCF approach (in Panel B) } \\
\hline Debt Policy & 216 & $82 \%$ & $48 \%$ & 2.19 & 2.25 & 2.39 & $1.79^{b}$ & 2.20 & 2.22 & 2.17 & 2.20 & 2.27 & 2.09 & 2.19 & 2.20 \\
\hline Tax shield risk & 212 & $73 \%$ & $15 \%$ & 1.32 & 1.38 & 1.33 & $1.05^{c}$ & 1.61 & $1.63^{c}$ & 1.14 & 1.43 & 1.28 & 1.24 & 1.33 & 1.31 \\
\hline Credit rating & 211 & $74 \%$ & $17 \%$ & 1.43 & 1.42 & 1.36 & 1.34 & $1.84^{b}$ & 1.56 & 1.10 & 1.73 & 1.45 & 1.44 & 1.27 & 1.53 \\
\hline Transaction type & 209 & $79 \%$ & $37 \%$ & 1.97 & $2.42^{a}$ & $1.26^{a}$ & 1.90 & $\begin{array}{c}1.07 \\
2.00\end{array}$ & 2.10 & 2.10 & 1.93 & 1.89 & $\begin{array}{l}1.07 \\
2.06\end{array}$ & 1.84 & 2.06 \\
\hline Other & 96 & $24 \%$ & $13 \%$ & 0.66 & $1.30^{a}$ & $0.21^{a}$ & 0.38 & 1.10 & 0.65 & 0.50 & 1.38 & 0.57 & 0.42 & $0.23^{a}$ & $1.02^{a}$ \\
\hline \multicolumn{16}{|c|}{ Panel D: Regressions. Significant coefficients. Stat. significant coefficients $(\leq 10 \%)$ out of 14: } \\
\hline Specification 1 & & & & & 3 & - & 7 & 2 & - & - & - & 1 & - & - & 1 \\
\hline Specification 2 & & & & & 3 & - & 7 & 2 & 2 & 1 & 0 & - & 1 & - & 2 \\
\hline
\end{tabular}

Table 6: Multiperiod models.

Description: This table reports results from the second part of the This table reports results from the third part of the questionnaire (Multiperiod models). The general structure is the same as for Table 2. Panels A - C correspond to sets of questions 18 - 19a. Three blocks of columns, "Profession," "Education," and "Experience" provide the mean (on the 0 - 4 scale) of the respective responses for the indicated subpopulation (e.g., Consultants, Investment Bankers, etc.). Within each panel, the highest number in each column is indicated in bold. Within each panel-block, we check whether the mean of each subpopulation is statistically different from that of the complement population (e.g., Cons. vs. IB, PE, and AM together) and indicate statistical significance at the $1 \%$, $5 \%$, and $10 \%$ level by $\boldsymbol{a}, \boldsymbol{b}$, and $\boldsymbol{c}$, respectively. Panel D reports the number of statistically significant coefficients at the $10 \%$ level or less from running the following regressions for each question in all preceding panels (except "Other")

Specification 1: $y_{i j}=\beta_{0 j}+\beta_{1 j}$ Cons $_{i}+\beta_{2 j} P E_{i}+\beta_{3 j} A M_{i}+\beta_{4 j} M B A_{i}+\beta_{5 j} H \operatorname{Exp}_{i}+\beta_{6 j} L S_{i}+\varepsilon_{i j}$,

Specification 2: $y_{i j}=\beta_{0} j+\beta_{1 j}$ Cons $_{i}+\beta_{2 j} P E_{i}+\beta_{3 j} A M_{i}+\beta_{4 j} B A_{i}+\beta_{5 j} M A_{i}+\beta_{6 j} P_{h D}+\beta_{7 j} C F A_{i}+\beta_{8 j} H_{E x p}+\beta_{9 j} L S_{i}+\varepsilon_{i j}$,

where $y_{i j}$ is respondent $i$ 's answer to question $j$. The RHS variables in the regression are defined in the text after equations $(1,2)$. The numbers of statistically significant coefficients for the variable $L S$ are not provided in the table, but can be found as a summary for all regressions in Tables 2, 3, 5-7, 9-11 in Table 12. All significance tests are two-tailed.

"Cons.," "IB," "PE," and "AM" denote "Consulting," "Investment Banking," "Private Equity," and "Asset Management" respectively. "BA," "MA," "PhD," "MBA," and "CFA" denote "Bachelor," "Master," "Doctoral degree," "Master of Business Administration," and "Chartered Financial Analyst" respectively.

Interpretation: DCF is the most popular multiperiod model; $76 \%$ use it almost always or always when using multiperiod models. Private equity professionals favor IRR, which is the second most popular approach overall. Within DCF, respondents report that they calculate NPV (rather than APV) and they discount cash flows at the WACC. While WACC is sensitive to leverage because of tax shields, only $48 \%$ take debt policy into account at least almost always. This fraction does not increase with more advanced educational levels. There are more statistically significant response differences across the professional subgroups than across educational levels. 


\begin{tabular}{|c|c|c|c|c|c|c|c|c|c|c|c|c|c|c|c|}
\hline \multirow[b]{3}{*}{ Sample } & \multirow{3}{*}{$\begin{array}{c}\text { Replies } \\
272\end{array}$} & \multirow[t]{3}{*}{$\% 1-4$} & \multirow[t]{3}{*}{$\% 3-4$} & \multirow[t]{3}{*}{ mean } & \multicolumn{4}{|c|}{ Profession } & \multicolumn{5}{|c|}{ Education } & \multicolumn{2}{|c|}{ Experience } \\
\hline & & & & & Cons. & IB & $\mathrm{PE}$ & $\mathrm{AM}$ & $\mathrm{BA}$ & MA & PhD & MBA & $\mathrm{CFA}$ & $\leq 10 \mathrm{y}$ & $>10 y$ \\
\hline & & & & & 113 & 72 & 58 & 29 & 52 & 37 & 17 & 123 & 36 & 103 & 168 \\
\hline \multicolumn{5}{|c|}{ Panel A: CF forecasting horizon } & \multicolumn{4}{|c|}{ Count } & \multicolumn{5}{|c|}{ Count } & \multicolumn{2}{|c|}{ Count } \\
\hline 5 years & 122 & - & - & - & 61 & 20 & 32 & 9 & 22 & 24 & 6 & 52 & 16 & 47 & 75 \\
\hline 8 years & 28 & - & - & - & 14 & 7 & 5 & 2 & 4 & 1 & 3 & 16 & 4 & 12 & 16 \\
\hline 10 years & 47 & - & - & - & 11 & 26 & 5 & 5 & 12 & 2 & 4 & 19 & 9 & 20 & 27 \\
\hline Other & 25 & - & - & - & 8 & 9 & 4 & 4 & 4 & 1 & 3 & 13 & 4 & 7 & 18 \\
\hline \multicolumn{16}{|c|}{ Panel B: Approach for terminal value } \\
\hline Gordon growth & 217 & $89 \%$ & $78 \%$ & 2.99 & $3.31^{a}$ & $3.54^{a}$ & $1.73^{a}$ & 2.50 & 3.07 & 2.86 & $3.43^{b}$ & 2.85 & 3.12 & 2.83 & 3.08 \\
\hline $\mathrm{P} / \mathrm{B}$ & 194 & $45 \%$ & $13 \%$ & 0.91 & 0.82 & 0.90 & 0.74 & $1.82^{a}$ & 1.11 & 0.83 & 0.82 & 0.76 & 1.25 & $0.68^{b}$ & $1.08^{b}$ \\
\hline Other mult. & 200 & $72 \%$ & $46 \%$ & 1.98 & 2.15 & $1.12^{a}$ & $2.60^{a}$ & 2.13 & 2.34 & 2.00 & 2.00 & 1.80 & 2.13 & 1.94 & 2.01 \\
\hline Liq.value & 192 & $55 \%$ & $9 \%$ & 0.91 & 0.84 & 0.80 & 0.92 & $1.50^{b}$ & 1.19 & 0.96 & 1.08 & $0.72^{b}$ & 0.93 & 0.80 & 0.98 \\
\hline Repl.cost & 192 & $46 \%$ & $6 \%$ & 0.69 & $0.55^{b}$ & $0.92^{c}$ & 0.56 & 0.94 & 0.83 & 0.72 & 1.08 & $0.51^{b}$ & 0.77 & $0.49^{a}$ & $0.82^{a}$ \\
\hline Invested cap. & 194 & $46 \%$ & $13 \%$ & 0.89 & $0.54^{a}$ & $1.38^{a}$ & 0.80 & $1.35^{c}$ & 0.78 & 0.69 & $1.71^{b}$ & 0.88 & 0.93 & $0.71^{c}$ & $1.02^{c}$ \\
\hline Other & 99 & $23 \%$ & $16 \%$ & 0.71 & 1.00 & $0.33^{b}$ & 0.81 & 1.00 & 0.53 & 0.80 & 0.50 & 0.79 & 0.75 & 0.67 & 0.75 \\
\hline \multicolumn{16}{|c|}{ Panel C: Gordon growth: which growth rate } \\
\hline$-2 \%$ & 127 & $22 \%$ & $2 \%$ & 0.29 & 0.33 & 0.28 & 0.18 & 0.33 & $0.62^{c}$ & $0.13^{c}$ & 0.13 & 0.21 & 0.33 & 0.23 & 0.34 \\
\hline$-1 \%$ & 125 & $30 \%$ & $2 \%$ & 0.40 & 0.38 & 0.47 & 0.30 & 0.60 & $0.81^{b}$ & $0.13^{a}$ & $0.25^{b}$ & 0.25 & 0.59 & 0.34 & 0.45 \\
\hline $0 \%$ & 136 & $65 \%$ & $21 \%$ & 1.40 & 1.43 & $1.78^{b}$ & $0.71^{a}$ & 1.57 & $1.87^{b}$ & 1.00 & 1.00 & 1.24 & 1.45 & 1.27 & 1.51 \\
\hline $1 \%$ & 145 & $77 \%$ & $46 \%$ & 1.95 & 2.10 & 2.05 & 1.58 & 1.38 & 2.07 & $1.37^{b}$ & 2.40 & 2.00 & 1.95 & 1.98 & 1.93 \\
\hline $2 \%$ & 162 & $83 \%$ & $56 \%$ & 2.29 & 2.31 & 2.53 & 1.93 & 2.00 & 2.42 & 1.85 & 2.83 & 2.38 & 2.12 & 2.41 & 2.20 \\
\hline $3 \%$ & 141 & $61 \%$ & $30 \%$ & 1.42 & 1.61 & 1.23 & 1.04 & 1.88 & 1.69 & 1.12 & 1.56 & 1.33 & 1.61 & 1.55 & 1.31 \\
\hline $4 \%$ & 128 & $30 \%$ & $11 \%$ & 0.66 & 0.61 & 0.86 & 0.35 & 1.17 & 0.69 & 0.71 & 0.67 & 0.64 & 0.68 & 0.56 & 0.73 \\
\hline Inflation & 157 & $78 \%$ & $54 \%$ & 2.16 & 2.23 & $1.83^{c}$ & 2.36 & 2.42 & 2.03 & 2.00 & 1.78 & 2.27 & 2.29 & 2.17 & 2.15 \\
\hline GDP growth & 161 & $74 \%$ & $47 \%$ & 1.96 & 1.96 & 1.67 & 2.11 & $2.62^{b}$ & 1.73 & 1.82 & 1.90 & 1.99 & 2.38 & 1.77 & 2.09 \\
\hline Other & 82 & $32 \%$ & $18 \%$ & 0.93 & $1.44^{b}$ & 0.77 & $0.28^{a}$ & 1.33 & 0.71 & $2.08^{b}$ & 1.00 & 0.84 & 0.36 & $0.45^{a}$ & $1.38^{a}$ \\
\hline \multicolumn{16}{|c|}{ Panel D: Regressions. Significant coefficients. Stat. significant coefficients $(\leq 10 \%)$ out of 16 : } \\
\hline Specification 1 & & & & & 3 & - & 4 & 5 & - & - & - & 1 & - & - & 0 \\
\hline Specification 2 & & & & & 2 & - & 5 & 4 & 4 & 1 & 0 & - & 0 & - & 0 \\
\hline
\end{tabular}

Table 7: DCF. Forecasting horizon and terminal value.

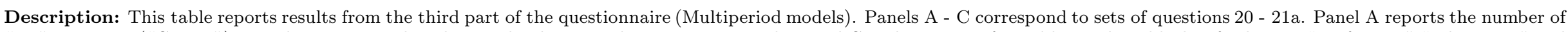

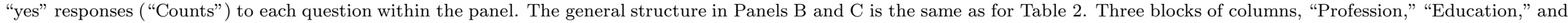

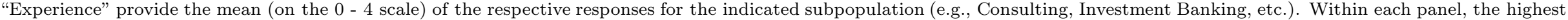

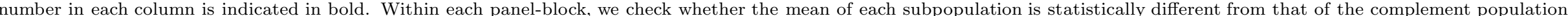

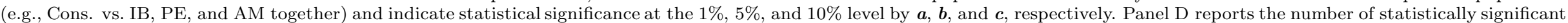

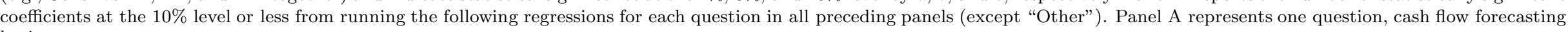
horizon.

Specification 1: $y_{i j}=\beta_{0 j}+\beta_{1 j}$ Cons $_{i}+\beta_{2 j} P E_{i}+\beta_{3 j} A M_{i}+\beta_{4 j} M B A_{i}+\beta_{5 j} H \operatorname{Exp}_{i}+\beta_{6 j} L S_{i}+\varepsilon_{i j}$

Specification 2: $y_{i j}=\beta_{0 j}+\beta_{1 j}$ Cons $_{i}+\beta_{2 j} P E_{i}+\beta_{3 j} A M_{i}+\beta_{4 j} B A_{i}+\beta_{5 j} M A_{i}+\beta_{6 j} P h D_{i}+\beta_{7 j} C F A_{i}+\beta_{8 j} H E_{x p}+\beta_{9 j} L S_{i}+\varepsilon_{i j}$,

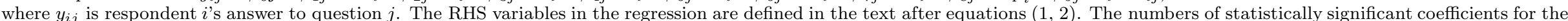
variable $L S$ are not provided in the table, but can be found as a summary for all regressions in Tables 2, 3, 5-7, 9-11 in Table 12. All significance tests are two-tailed.

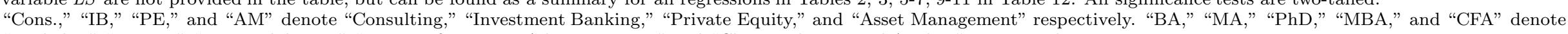
"Bachelor," "Master," "Doctoral degree," "Master of Business Administration," and "Chartered Financial Analyst" respectively.

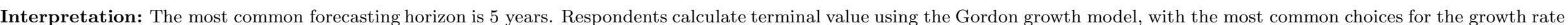
being $2 \%$ and the rate of inflation. 


\begin{tabular}{|c|c|c|c|c|c|c|c|c|c|c|c|c|}
\hline & & & & \multicolumn{9}{|c|}{ Forecasting horizon } \\
\hline & & & & \multicolumn{3}{|c|}{5 years } & \multicolumn{3}{|c|}{8 years } & \multicolumn{3}{|c|}{10 years } \\
\hline & & & & \multicolumn{9}{|c|}{ Forecasting period growth rate } \\
\hline & & & & $2 \%$ & $4 \%$ & $6 \%$ & $2 \%$ & $4 \%$ & $6 \%$ & $2 \%$ & $4 \%$ & $6 \%$ \\
\hline \multirow{6}{*}{ 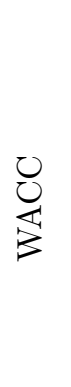 } & \multirow{4}{*}{$8 \%$} & \multirow{6}{*}{ 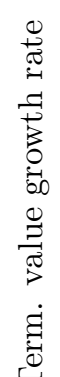 } & $0 \%$ & $69 \%$ & $70 \%$ & $71 \%$ & $56 \%$ & $58 \%$ & $59 \%$ & $49 \%$ & $51 \%$ & $53 \%$ \\
\hline & & & $2 \%$ & $75 \%$ & $76 \%$ & $77 \%$ & $63 \%$ & $65 \%$ & $67 \%$ & $56 \%$ & $59 \%$ & $61 \%$ \\
\hline & & & $4 \%$ & $82 \%$ & $83 \%$ & $83 \%$ & $73 \%$ & $74 \%$ & $75 \%$ & $66 \%$ & $69 \%$ & $70 \%$ \\
\hline & & & $0 \%$ & $63 \%$ & $64 \%$ & $65 \%$ & $49 \%$ & $50 \%$ & $52 \%$ & $41 \%$ & $43 \%$ & $46 \%$ \\
\hline & \multirow[t]{2}{*}{$10 \%$} & & $2 \%$ & $69 \%$ & $69 \%$ & $70 \%$ & $55 \%$ & $57 \%$ & $58 \%$ & $47 \%$ & $49 \%$ & $52 \%$ \\
\hline & & & $4 \%$ & $75 \%$ & $76 \%$ & $76 \%$ & $62 \%$ & $64 \%$ & $65 \%$ & $55 \%$ & $57 \%$ & $59 \%$ \\
\hline
\end{tabular}

Table 8: Terminal value. Example.

Description: This table shows values (in \%) of the expression

$P V$ (Growing perpetuity starting in T years)

$\overline{P V(\text { Growing T-year annuity })+P V(\text { Growing perpetuity starting in } T \text { years })}$

i.e. terminal value as a percent of total value under the most standard implementation of the DCF technique (which uses the Gordon growth model) to calculate terminal values. The numbers in bold represent the values for the most commonly used scenario, namely a 5 year forecasting horizon and a $2 \%$ terminal value growth rate.

Interpretation: The way DCF is implemented in practice means that it is almost just another multiples approach. For example, at a WACC of $10 \%$, terminal value is around $70 \%$ of total value using a the most common choice of forecasting horizon ( 5 years) and perpetual growth rate $(2 \%)$. 


\begin{tabular}{|c|c|c|c|c|c|c|c|c|c|c|c|c|c|c|c|}
\hline \multirow[b]{3}{*}{ Sample } & \multirow[t]{2}{*}{ Replies } & \multirow[t]{3}{*}{$\% 1-4$} & \multirow[t]{3}{*}{$\% 3-4$} & \multirow[t]{3}{*}{ mean } & \multicolumn{4}{|c|}{ Profession } & \multicolumn{5}{|c|}{ Education } & \multicolumn{2}{|c|}{ Experience } \\
\hline & & & & & Cons. & IB & $\mathrm{PE}$ & $\mathrm{AM}$ & $\mathrm{BA}$ & MA & $\mathrm{PhD}$ & MBA & CFA & $\leq 10 \mathrm{y}$ & $>10 \mathrm{y}$ \\
\hline & 272 & & & & 113 & 72 & 58 & 29 & 52 & 37 & 17 & 123 & 36 & 103 & 168 \\
\hline \multicolumn{16}{|c|}{$\overline{\text { Panel A: Calculating }}$ cost of debt } \\
\hline Yield & 150 & $73 \%$ & $38 \%$ & 1.77 & 1.76 & 1.57 & 1.73 & $2.64^{b}$ & 1.59 & 1.77 & 1.29 & 1.71 & 2.19 & $1.42^{b}$ & $2.02^{b}$ \\
\hline Coupon & 151 & $68 \%$ & $32 \%$ & 1.61 & 1.52 & 1.63 & 1.66 & 2.00 & 2.04 & 1.29 & 2.00 & 1.66 & $1.16^{b}$ & 1.73 & 1.52 \\
\hline Rf rate & 146 & $57 \%$ & $25 \%$ & 1.34 & 1.32 & 1.34 & 1.09 & $2.44^{b}$ & $1.89^{b}$ & $0.80^{b}$ & 2.29 & 1.39 & $0.73^{a}$ & 1.49 & 1.23 \\
\hline Rf+spread & 172 & $89 \%$ & $72 \%$ & 2.77 & 2.83 & 2.78 & 2.57 & 3.00 & 2.77 & 2.68 & 2.00 & 2.79 & 2.93 & 2.70 & 2.82 \\
\hline CAPM & 150 & $69 \%$ & $41 \%$ & 1.80 & 1.99 & 1.79 & $1.28^{b}$ & 2.33 & 2.19 & 1.33 & $3.00^{b}$ & $1.51^{b}$ & 2.17 & 1.65 & 1.92 \\
\hline Other & 60 & $17 \%$ & $7 \%$ & 0.37 & $0.83^{c}$ & 0.21 & 0.16 & $0.00^{a}$ & 0.73 & 0.60 & $0.00^{a}$ & 0.34 & $0.00^{a}$ & 0.41 & 0.32 \\
\hline \multicolumn{16}{|c|}{$\overline{\text { Panel B: Calculating }}$ cost of equity } \\
\hline CAPM & 193 & $87 \%$ & $76 \%$ & 2.98 & $3.46^{a}$ & 3.09 & $2.13^{a}$ & $2.07^{b}$ & 2.86 & 3.00 & $3.57^{a}$ & 2.85 & 3.25 & 3.05 & 2.93 \\
\hline Fama-French & 162 & $24 \%$ & $4 \%$ & 0.36 & 0.43 & 0.40 & $0.19^{b}$ & 0.33 & 0.32 & 0.26 & 0.67 & 0.40 & 0.33 & $0.49^{c}$ & $0.27^{c}$ \\
\hline Other multif. mod. & 161 & $29 \%$ & $8 \%$ & 0.55 & 0.48 & 0.61 & 0.58 & 0.58 & 0.43 & 0.83 & 0.50 & 0.56 & 0.46 & 0.48 & 0.59 \\
\hline Other & 84 & $24 \%$ & $11 \%$ & 0.58 & 0.64 & 0.48 & 0.52 & 1.00 & 0.82 & $0.00^{a}$ & 0.33 & $0.33^{c}$ & $1.42^{c}$ & 0.41 & 0.72 \\
\hline \multicolumn{16}{|c|}{ Panel C: Cost of equity: risk-free rate } \\
\hline 3m T-bill & 136 & $35 \%$ & $16 \%$ & 0.80 & 0.69 & 0.92 & 0.70 & 1.33 & 0.52 & 0.91 & 1.33 & 0.88 & 0.67 & $1.02^{c}$ & $0.64^{c}$ \\
\hline LIBOR & 138 & $44 \%$ & $25 \%$ & 1.08 & 1.05 & 0.95 & 1.35 & 0.88 & 1.20 & 1.05 & 1.38 & 1.15 & $0.62^{c}$ & 1.18 & 1.00 \\
\hline Swap rate & 128 & $34 \%$ & $15 \%$ & 0.79 & 0.68 & $0.46^{b}$ & 0.96 & $2.71^{b}$ & 0.74 & $0.22^{a}$ & $0.13^{a}$ & 0.91 & $1.32^{c}$ & 0.91 & 0.70 \\
\hline Longer term T-sec. & 163 & $85 \%$ & $70 \%$ & 2.74 & 2.70 & $3.31^{a}$ & $1.93^{a}$ & 2.64 & 2.70 & 2.82 & $3.27^{b}$ & 2.51 & 3.07 & 2.59 & 2.84 \\
\hline CFmatch & 137 & $48 \%$ & $28 \%$ & 1.33 & 1.55 & 1.22 & 1.04 & 1.00 & 1.04 & 1.15 & 1.44 & 1.44 & 1.52 & 1.15 & 1.45 \\
\hline Other & 73 & $22 \%$ & $16 \%$ & 0.73 & $1.35^{c}$ & 0.68 & 0.35 & $0.00^{a}$ & $0.17^{b}$ & 2.00 & $0.00^{a}$ & 0.83 & 0.33 & 0.50 & 0.95 \\
\hline \multicolumn{16}{|c|}{ Panel D: Cost of equity: market risk premium (in\%) } \\
\hline & 120 & - & - & 5.41 & 5.52 & 5.28 & 5.69 & $4.58^{a}$ & 5.31 & 5.69 & 5.72 & 5.50 & $5.10^{c}$ & $5.69^{c}$ & $5.22^{c}$ \\
\hline \multicolumn{16}{|c|}{ Panel E: Regressions. Significant coefficients. Stat. significant coefficients ( $\leq 10 \%)$ out of 14 : } \\
\hline Specification 1 & & & & & 1 & - & 2 & 3 & - & - & - & 0 & - & - & 2 \\
\hline Specification 2 & & & & & 1 & - & 2 & 3 & 0 & 0 & 2 & - & 2 & - & 3 \\
\hline
\end{tabular}

Table 9: DCF. Cost of capital.

Description: This table reports results from the third part of the questionnaire (Multiperiod models). The general structure is the same as for Table 2. Panels A - C correspond to sets of questions 26 - 27a, Panel D corresponds to question 29a. Three blocks of columns, "Profession," "Education," and "Experience" provide the mean (on the 0 - 4 scale) of the respective responses for the indicated subpopulation (e.g., Consulting, Investment Banking, etc.). Within each panel, the highest number in each column is indicated in bold. Within each panel-block, we check whether the mean of each subpopulation is statistically different from that of the complement population (e.g., Cons. vs. IB, PE, and AM together) and indicate statistical significance at the $1 \%, 5 \%$, and $10 \%$ level by $\boldsymbol{a}, \boldsymbol{b}$, and $\boldsymbol{c}$, respectively. Panel E reports the number of statistically significant coefficients at the $10 \%$ level or less from running the following regressions for each question in all preceding panels (except "Other")

Specification 1: $y_{i j}=\beta_{0 j}+\beta_{1 j}$ Cons $_{i}+\beta_{2 j} P E_{i}+\beta_{3 j} A M_{i}+\beta_{4 j} M B A_{i}+\beta_{5 j} H E x p_{i}+\beta_{6 j} L S_{i}+\varepsilon_{i j}$,

Specification 2: $y_{i j}=\beta_{0} j+\beta_{1 j}$ Cons $_{i}+\beta_{2 j} P E_{i}+\beta_{3 j} A M_{i}+\beta_{4 j} B A_{i}+\beta_{5 j} M A_{i}+\beta_{6 j} P h D_{i}+\beta_{7 j} C F A_{i}+\beta_{8 j} H E x p_{i}+\beta_{9 j} L S_{i}+\varepsilon_{i j}$,

where $y_{i j}$ is respondent $i$ 's answer to question $j$. The RHS variables in the regression are defined in the text after equations $(1,2)$. The numbers of statistically significant coefficients for the variable $L S$ are not provided in the table, but can be found as a summary for all regressions in Tables 2, 3, 5-7, 9-11 in Table 12. All significance tests are two-tailed.

"Cons.," "IB," "PE," and "AM" denote "Consulting," "Investment Banking," "Private Equity," and "Asset Management" respectively. "BA," "MA," "PhD," "MBA," and "CFA" denote "Bachelor," "Master," "Doctoral degree," "Master of Business Administration," and "Chartered Financial Analyst" respectively.

Interpretation: The cost of debt is typically calculated as the riskfree rate plus a spread. The vast majority of respondents calculate the cost of equity using the CAPM with a riskfree rate equal to the yield on a longer term treasury security. Multifactor models are rarely used. The number of statistically significant response differences are similar across professional subgroups and educational levels. 


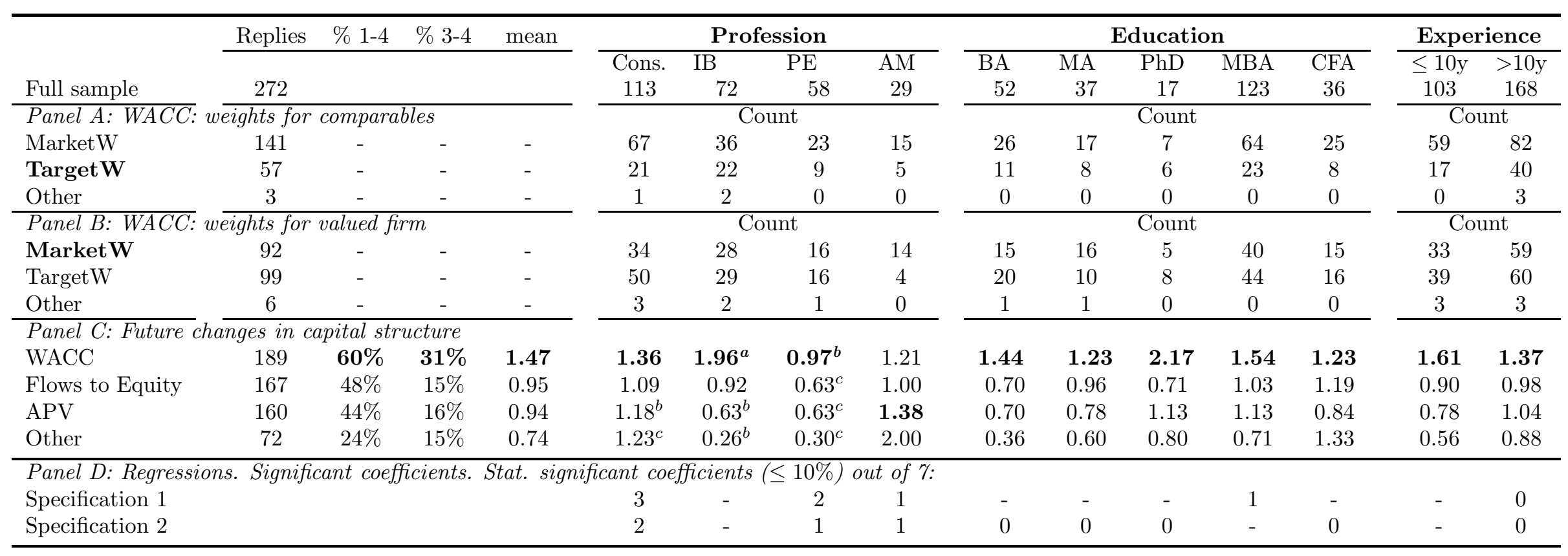

Table 10: WACC. Implementation and confusion.

Description: This table reports results from the third part of the questionnaire (Multiperiod models). Panels A - C correspond to sets of questions $22 \mathrm{a}$ - 23. Panels A and B report the number of responses ("Counts") to each question within the panel. The general structure in Panel C is the same as for Table 2. Three blocks of columns, "Profession," "Education," and "Experience" provide the mean (on the 0 - 4 scale) of the respective responses for the indicated subpopulation (e.g., Consulting, Investment Banking, etc.). Within Panel C, the highest number in each column is indicated in bold. In Panels A and B questions in bold indicate the wrong answer. Within each panel-block in Panel C, we check whether the mean of each subpopulation is statistically different from that of the complement population (e.g., Cons. vs. IB, PE, and AM together) and indicate statistical significance at the $1 \%$, $5 \%$, and $10 \%$ level by $\boldsymbol{a}, \boldsymbol{b}$, and $\boldsymbol{c}$, respectively. Panel D reports the number of statistically significant coefficients at the $10 \%$ level or less from running the following regressions for each question in all preceding panels (except "Other")

Specification 1: $y_{i j}=\beta_{0 j}+\beta_{1 j}$ Cons $_{i}+\beta_{2 j} P E_{i}+\beta_{3 j} A M_{i}+\beta_{4 j} M B A_{i}+\beta_{5 j} H \operatorname{Exp}_{i}+\beta_{6 j} L S_{i}+\varepsilon_{i j}$,

Specification 2: $y_{i j}=\beta_{0 j}+\beta_{1 j}$ Cons $_{i}+\beta_{2 j} P E_{i}+\beta_{3 j} A M_{i}+\beta_{4 j} B A_{i}+\beta_{5 j} M A_{i}+\beta_{6 j} P h D_{i}+\beta_{7 j} C F A_{i}+\beta_{8 j} H E p_{i}+\beta_{9 j} L S_{i}+\varepsilon_{i j}$,

where $y_{i j}$ is respondent $i$ 's answer to question $j$. The RHS variables in the regression are defined in the text after equations $(1,2)$. The numbers of statistically significant coefficients for the variable $L S$ are not provided in the table, but can be found as a summary for all regressions in Tables $2,3,5-7$, 9-11 in Table 12. All significance tests are two-tailed.

"Cons.," "IB," "PE," and "AM" denote "Consulting," "Investment Banking," "Private Equity," and "Asset Management" respectively. "BA," "MA," "PhD," "MBA," and "CFA" denote "Bachelor," "Master," "Doctoral degree," "Master of Business Administration," and "Chartered Financial Analyst" respectively.

Interpretation: Respondents seem to be confused with respect to the fact that the WACC is sensitive to leverage - and, therefore, need to be adjusted for leverage and debt policy. There are more statistically significant response differences across the professional subgroups than across educational levels. 


\begin{tabular}{|c|c|c|c|c|c|c|c|c|c|c|c|c|c|c|c|}
\hline \multirow[b]{3}{*}{ Sample } & \multirow[t]{2}{*}{ Replies } & \multirow[t]{2}{*}{$\% 1-4$} & \multirow[t]{2}{*}{$\% 3-4$} & \multirow[t]{3}{*}{ mean } & \multicolumn{4}{|c|}{ Profession } & \multicolumn{5}{|c|}{ Education } & \multicolumn{2}{|c|}{ Experience } \\
\hline & & & & & Cons. & $\mathrm{IB}$ & $\mathrm{PE}$ & $\mathrm{AM}$ & $\mathrm{BA}$ & $\mathrm{MA}$ & $\mathrm{PhD}$ & MBA & CFA & $\leq 10 \mathrm{y}$ & $>10 \mathrm{y}$ \\
\hline & 272 & & & & 113 & 72 & 58 & 29 & 52 & 37 & 17 & 123 & 36 & 103 & 168 \\
\hline \multicolumn{16}{|c|}{ Panel A: AP $V: \overline{P V T S \text { calculation. Discount at: }}$} \\
\hline $\mathrm{R}_{\mathrm{u}}$ & 128 & $48 \%$ & $25 \%$ & 1.18 & $1.46^{c}$ & 1.05 & $0.58^{a}$ & 1.86 & 0.96 & 0.81 & 0.75 & $1.50^{b}$ & 1.24 & 1.12 & 1.23 \\
\hline $\mathrm{R}_{\mathrm{d}}$ & 130 & $43 \%$ & $14 \%$ & 0.95 & 1.14 & 0.87 & $0.46^{a}$ & 1.30 & 0.68 & 1.14 & 1.67 & 0.85 & 0.95 & 0.80 & 1.05 \\
\hline $\mathrm{R}($ DebtPol $)$ & 127 & $42 \%$ & $14 \%$ & 0.93 & $1.24^{b}$ & 0.68 & $0.44^{b}$ & 1.40 & 0.79 & 0.71 & 1.13 & 0.91 & 1.44 & 1.06 & 0.84 \\
\hline $\mathrm{R}(\mathrm{CF})$ & 128 & $45 \%$ & $17 \%$ & 1.04 & $1.34^{b}$ & 0.78 & $0.68^{c}$ & 1.20 & 0.87 & 1.00 & 1.67 & 0.98 & 1.26 & 0.96 & 1.09 \\
\hline Other & 68 & $21 \%$ & $7 \%$ & 0.49 & $0.95^{c}$ & 0.23 & 0.37 & 0.33 & 0.79 & 0.50 & 0.17 & 0.53 & $0.00^{a}$ & 0.47 & 0.50 \\
\hline \multicolumn{16}{|c|}{ Panel B: Do you consider personal taxes in PVTS? } \\
\hline Yes & 189 & $25 \%$ & $5 \%$ & 0.42 & 0.48 & $0.21^{b}$ & 0.64 & 0.31 & 0.41 & $0.76^{c}$ & 0.33 & 0.42 & 0.21 & 0.46 & 0.40 \\
\hline \multicolumn{16}{|c|}{ Panel C: Regressions. Significant coefficients. Stat. significant coefficients ( $\leq 10 \%)$ out of 5 : } \\
\hline Specification & & & & & 2 & - & 1 & 0 & - & - & - & 1 & - & - & 0 \\
\hline Specification & & & & & 2 & - & 1 & 0 & 0 & 0 & 1 & - & 0 & - & 0 \\
\hline
\end{tabular}

Table 11: Present value of tax shield (PVTS).

Description: This table reports results from the third part of the questionnaire (Multiperiod models). The general structure is the same as for Table 2. Panels A, B correspond to sets of questions 24, 25. Three blocks of columns, "Profession," "Education," and "Experience" provide the mean (on the 0 - 4 scale) of the respective responses for the indicated subpopulation (e.g., Consultants, Investment Bankers, etc.). Within each panel, the highest number in each column is indicated in bold. Within each panel-block, we check whether the mean of each subpopulation is statistically different from that of the complement population (e.g., Cons. vs. IB, PE, and AM together) and indicate statistical significance at the $1 \%, 5 \%$, and $10 \%$ level by $\boldsymbol{a}, \boldsymbol{b}$, and $\boldsymbol{c}$, respectively. Panel C reports the number of statistically significant coefficients at the $10 \%$ level or less from running the following regressions for each question in all preceding panels (except "Other")

Specification 1: $y_{i j}=\beta_{0 j}+\beta_{1 j}$ Cons $_{i}+\beta_{2 j} P E_{i}+\beta_{3 j} A M_{i}+\beta_{4 j} M B A_{i}+\beta_{5 j} H \operatorname{Exp}_{i}+\beta_{6 j} L S_{i}+\varepsilon_{i j}$,

Specification 2: $y_{i j}=\beta_{0} j+\beta_{1 j}$ Cons $_{i}+\beta_{2 j} P E_{i}+\beta_{3 j} A M_{i}+\beta_{4 j} B A_{i}+\beta_{5 j} M A_{i}+\beta_{6 j} P h D_{i}+\beta_{7 j} C F A_{i}+\beta_{8 j} H E_{x p}+\beta_{9 j} L S_{i}+\varepsilon_{i j}$,

where $y_{i j}$ is respondent $i$ 's answer to question $j$. The RHS variables in the regression are defined in the text after equations $(1,2)$. The numbers of statistically significant coefficients for the variable $L S$ are not provided in the table, but can be found as a summary for all regressions in Tables 2 , 3, 5-7, 9-11 in Table 12. All significance tests are two-tailed.

"Cons.," "IB," "PE," and "AM" denote "Consulting," "Investment Banking," "Private Equity," and "Asset Management" respectively. "BA," "MA," "PhD," "MBA," and "CFA" denote "Bachelor," "Master," "Doctoral degree," "Master of Business Administration," and "Chartered Financial Analyst" respectively. $\mathrm{R}_{\mathrm{u}}$ denotes "unlevered cost of equity," $\mathrm{R}_{\mathrm{d}}$ denotes "cost of debt." R(DebtPol) and $\mathrm{R}(\mathrm{CF})$ mean "it depends on debt policy of the firm" and "it depends on how stable the forecasted cash flows are," respectively.

Interpretation: Respondents rarely take personal taxes into account. There are more statistically significant response differences across the professional subgroups than across educational levels. 


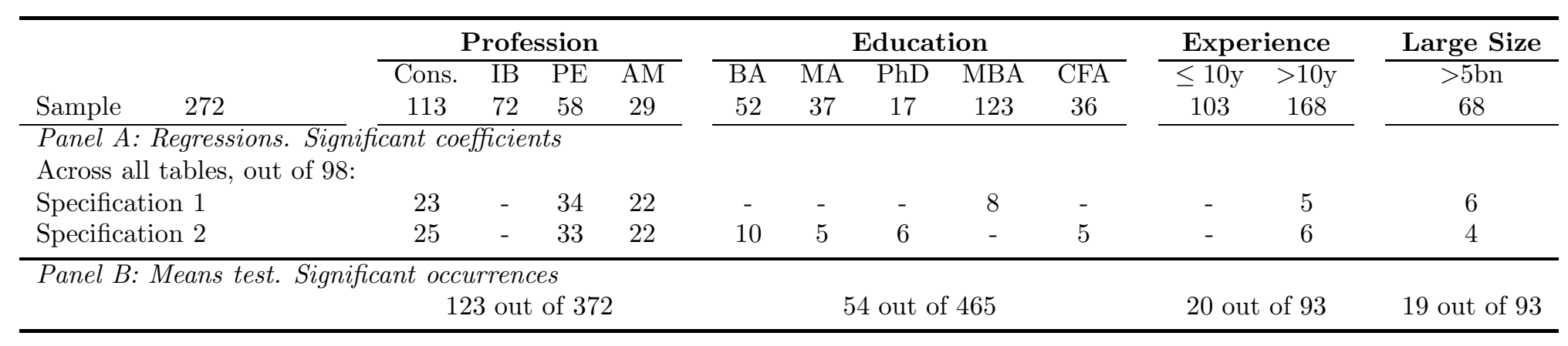

Table 12: Summary of Education versus Profession: Significant means tests and regression coefficients

Description: Panel A sums up all statistically significant regression coefficients (10\% or less) across all 98 questions in all tables (2, 3, 5-7, 9-11). Panel B reports the number of times, across all tables, the means test gives a statistically significant result (10\% or less). All significance tests are two-tailed.

Specification 1: $y_{i j}=\beta_{0 j}+\beta_{1 j}$ Cons $_{i}+\beta_{2 j} P E_{i}+\beta_{3 j} A M_{i}+\beta_{4 j} M B A_{i}+\beta_{5 j} H \operatorname{Exp}_{i}+\beta_{6 j} L S_{i}+\varepsilon_{i j}$,

Specification 2: $y_{i j}=\beta_{0} j+\beta_{1 j}$ Cons $_{i}+\beta_{2 j} P E_{i}+\beta_{3 j} A M_{i}+\beta_{4 j} B A_{i}+\beta_{5 j} M A_{i}+\beta_{6 j} P h D_{i}+\beta_{7 j} C F A_{i}+\beta_{8 j} H E x p_{i}+\beta_{9 j} L S_{i}+\varepsilon_{i j}$,

where $y_{i j}$ is respondent $i$ 's answer to question $j$. The RHS variables in the regression are defined in the text after equations $(1,2)$.

"Cons.," "IB," "PE," and "AM" denote "Consulting," "Investment Banking," "Private Equity," and "Asset Management" respectively. "BA," "MA," "PhD," "MBA," and "CFA" denote "Bachelor," "Master," "Doctoral degree," "Master of Business Administration," and "Chartered Financial Analyst" respectively.

Interpretation: There are more statistically significant differences across professional subgroups than across educational levels. Experience and size focus are largely unimportant. 


\begin{tabular}{|c|c|c|c|c|c|c|c|c|}
\hline \multirow[b]{2}{*}{ Full sample } & \multirow{2}{*}{$\begin{array}{c}\text { Replies } \\
272\end{array}$} & \multirow{2}{*}{$\% 1-4$} & \multirow[t]{2}{*}{$\% 3-4$} & \multirow{2}{*}{ mean } & \multicolumn{4}{|c|}{ Profession } \\
\hline & & & & & $\begin{array}{c}\text { Cons. } \\
113\end{array}$ & $\begin{array}{l}\text { IB } \\
\quad 72\end{array}$ & $\begin{array}{l}\mathrm{PE} \\
58\end{array}$ & $\begin{array}{c}\mathrm{AM} \\
29\end{array}$ \\
\hline \multicolumn{9}{|l|}{ Panel A: Type of investment } \\
\hline Project finance & 211 & $46 \%$ & $9 \%$ & 0.79 & $1.17^{a}$ & 0.63 & $0.33^{a}$ & 0.50 \\
\hline Listed firms & 256 & $88 \%$ & $61 \%$ & 2.66 & $2.23^{a}$ & $3.96^{a}$ & $1.38^{a}$ & $3.31^{b}$ \\
\hline Unlisted firms & 246 & $92 \%$ & $68 \%$ & 2.83 & $3.38^{a}$ & $1.47^{a}$ & $3.67^{a}$ & $1.52^{a}$ \\
\hline Real estate & 213 & $39 \%$ & $10 \%$ & 0.72 & $1.03^{a}$ & $0.35^{a}$ & 0.59 & 0.57 \\
\hline Other & 173 & $37 \%$ & $11 \%$ & 0.77 & $1.19^{a}$ & $0.30^{a}$ & 0.56 & 0.77 \\
\hline \multicolumn{9}{|l|}{ Panel B: Type of transaction } \\
\hline Merger or acquisition & 229 & $85 \%$ & $56 \%$ & 2.44 & $3.27^{a}$ & $1.29^{a}$ & 2.33 & $0.95^{a}$ \\
\hline Investment decisions & 255 & $95 \%$ & $77 \%$ & 3.12 & $2.30^{a}$ & $3.85^{a}$ & $3.43^{b}$ & $3.62^{a}$ \\
\hline Going public & 212 & $69 \%$ & $19 \%$ & 1.33 & $1.12^{b}$ & $1.83^{a}$ & $1.02^{c}$ & 1.24 \\
\hline Going private & 204 & $61 \%$ & $24 \%$ & 1.26 & $1.56^{a}$ & $0.65^{a}$ & 1.51 & $0.75^{b}$ \\
\hline Other & 134 & $31 \%$ & $21 \%$ & 0.85 & $1.50^{a}$ & $0.03^{a}$ & 0.88 & 0.75 \\
\hline \multicolumn{9}{|l|}{ Panel C: Role } \\
\hline Buy-side & 222 & $81 \%$ & $48 \%$ & 2.22 & $1.93^{a}$ & $0.39^{a}$ & $3.33^{a}$ & $3.71^{a}$ \\
\hline Sell-side & 242 & $83 \%$ & $58 \%$ & 2.52 & $2.30^{b}$ & $3.99^{a}$ & $1.72^{a}$ & $0.57^{a}$ \\
\hline Advisory role & 208 & $72 \%$ & $45 \%$ & 2.10 & $3.09^{a}$ & $1.21^{a}$ & $0.54^{a}$ & 1.57 \\
\hline Other & 105 & $11 \%$ & $6 \%$ & 0.29 & $0.86^{a}$ & $0.06^{b}$ & 0.13 & $0.00^{a}$ \\
\hline
\end{tabular}

Table 13: Purpose of valuation across professions.

Description: This table reports results from the first part of the questionnaire (Preliminary and personal questions). The general structure is similar to that of Table 2. Panels A - C correspond to sets of questions 1 - 3. The block of columns "Profession" provides the mean (on the $0-4$ scale) of the respective responses for the indicated subpopulation (e.g., Consultants, Investment Bankers, etc.). Within each panel, the highest number in each column is indicated in bold. Within each "Profession" panel-block, we check whether the mean of each subpopulation is statistically different from that of the complement population (e.g., Cons. vs. IB, PE, and AM together) and indicate statistical significance at the $1 \%, 5 \%$, and $10 \%$ level by $\boldsymbol{a}, \boldsymbol{b}$, and $\boldsymbol{c}$, respectively. All significance tests are two-tailed.

"Cons.," "IB," "PE," and "AM" denote "Consulting," "Investment Banking," "Private Equity," and "Asset Management" respectively.

Interpretation: The different professional subgroups have different overall valuation-purpose characteristics. 


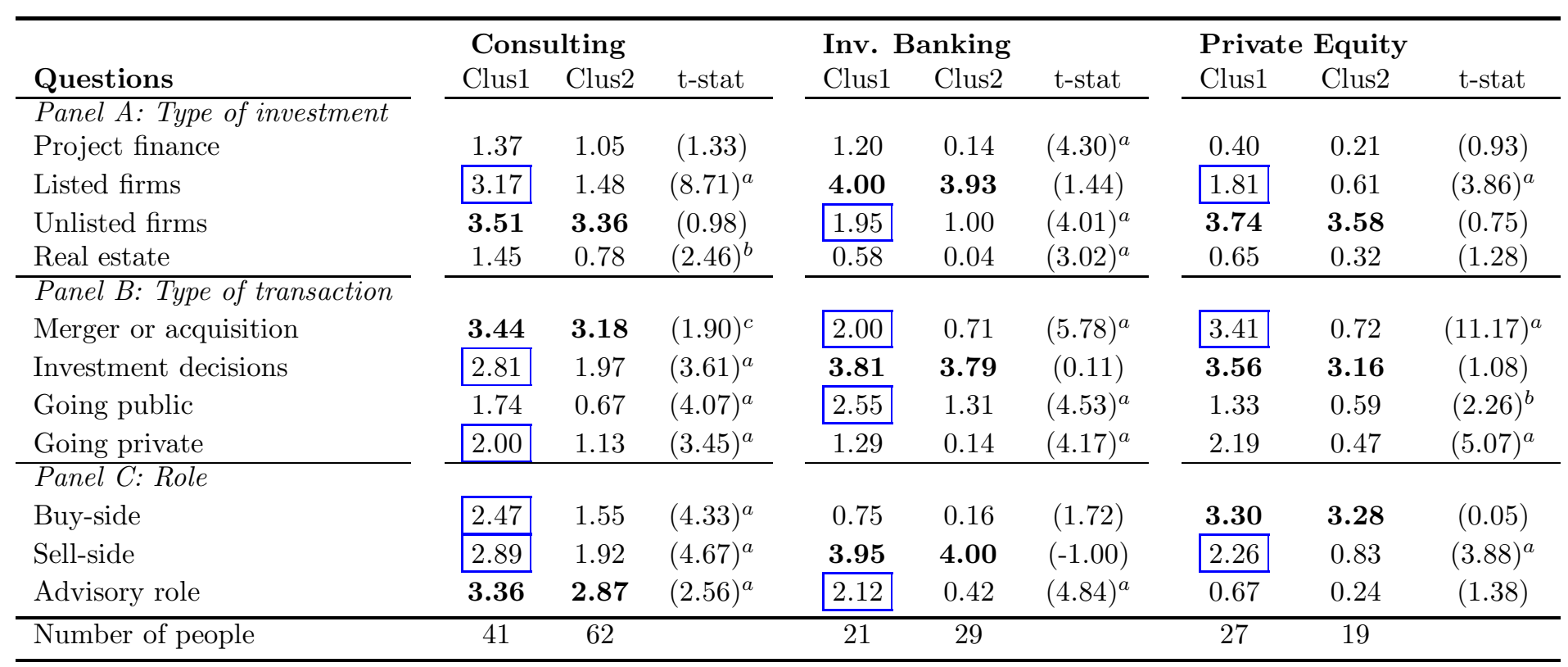

Table 14: Within-profession valuation-purpose clusters.

Description: This table reports results from the first part of the questionnaire (Preliminary and personal questions). Panels A - C correspond to sets of questions 1 - 3. Three blocks of columns provide the means (on the $0-4$ scale) of the respective responses for two clusters within the three indicated subpopulations: Consulting, Investment Banking, Private Equity. For each profession, the two clusters are created by running a cluster analysis on the respective sample of respondents, using the same procedure as in Figure 1. Within each panel, the highest number in each column is indicated in bold. Within each profession for each question we check whether the means of the two clusters are significantly different from each other and indicate statistical significance at the $1 \%, 5 \%$, and $10 \%$ level by $\boldsymbol{a}, \boldsymbol{b}$, and $\boldsymbol{c}$, respectively. All significance tests are two-tailed. Squares around numbers in the Clus1 columns are used to indicate numbers that are high relative to the corresponding Clus2 numbers.

Interpretation: Within the professional subgroups, there are clusters of specialists and generalists. 


\begin{tabular}{|c|c|c|c|c|c|c|c|c|c|c|c|c|c|}
\hline & \multirow{2}{*}{$\begin{array}{c}\text { N of } \\
\text { Questions }\end{array}$} & \multicolumn{4}{|c|}{ Consultants } & \multicolumn{4}{|c|}{ Investment Bankers } & \multicolumn{4}{|c|}{ Private Equity } \\
\hline & & Clus1 & MBA & HExp & LS & Clus1 & MBA & HExp & LS & Clus1 & MBA & HExp & LS \\
\hline Choice of valuation approach (Tab.2) & 13 & 0 & 1 & 0 & 0 & 1 & 0 & 0 & 1 & 2 & 5 & 0 & 0 \\
\hline Multiples (Tab.3) & 20 & 2 & 5 & 0 & 1 & 4 & 1 & 0 & 1 & 3 & 0 & 2 & 1 \\
\hline Multiples. Comparables selection (Tab.5) & 9 & 0 & 2 & 0 & 0 & 2 & 0 & 0 & 0 & 2 & 0 & 1 & 1 \\
\hline Multi-period models (Tab.6) & 14 & 2 & 4 & 3 & 1 & 5 & 2 & 3 & 0 & 1 & 0 & 3 & 0 \\
\hline DCF. Forecast. horizon and term. val. (Tab.7) & 16 & 2 & 0 & 0 & 0 & 1 & 0 & 0 & 0 & 0 & 4 & 3 & 1 \\
\hline DCF. Cost of Capital (Tab.9) & 14 & 3 & 0 & 2 & 0 & 1 & 0 & 2 & 1 & 1 & 1 & 0 & 0 \\
\hline WACC. Implem. and confusion (Tab.10) & 7 & 0 & 1 & 1 & 0 & 1 & 0 & 1 & 0 & 0 & 1 & 1 & 0 \\
\hline PVTS Calculation (Tab.11) & 5 & 1 & 0 & 1 & 1 & 1 & 0 & 0 & 1 & 0 & 1 & 1 & 0 \\
\hline Total & 98 & 10 & 13 & 7 & 3 & 16 & 3 & 6 & 4 & 9 & 12 & 11 & 3 \\
\hline
\end{tabular}

Table 15: Within-profession regressions.

Description: The table sums up all statistically significant regression coefficients (10\% or less) across all 98 questions in all tables (2, 3, 5-7, 9-11) 기 within each profession. All significance tests are two-tailed.

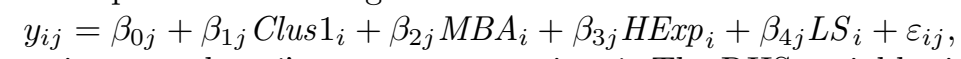

where $y_{i}$ is respondent $i$ 's answer to question $j$. The RHS variables in the regression are defined in the text after equation (9). The table provides the number of statistically significant coefficients ( $10 \%$ or less) for each variable within each profession, summed over all questions. The row labeled "Total" provides the number of statistically significant coefficients across all questions.

"Clus1," "MBA," "HExp," and "LS" denote "Cluster1," "Master of Business Administration," "High Experience," and "Large Size" respectively.

Interpretation: Within profession, the purpose of the valuation is only of marginal importance with respect to the choice of valuation technique. 


\begin{tabular}{|c|c|c|c|c|c|c|c|c|c|c|c|c|c|c|c|}
\hline & \multicolumn{7}{|c|}{ Profession and valuation purpose clusters } & \multicolumn{5}{|c|}{ Education } & \multicolumn{2}{|c|}{ Experience } & \multirow{2}{*}{$\begin{array}{c}\text { Large Size } \\
\quad>5 \mathrm{bn}\end{array}$} \\
\hline & Cons. & $\begin{array}{l}\text { Consult. } \\
\text { Cluster } 2\end{array}$ & IB & $\begin{array}{c}\text { IB } \\
\text { Cluster } 2 \\
\end{array}$ & $\mathrm{PE}$ & $\begin{array}{c}\text { PE } \\
\text { Cluster } 2 \\
\end{array}$ & $\mathrm{AM}$ & $\mathrm{BA}$ & MA & $\mathrm{PhD}$ & MBA & CFA & $\leq 10 \mathrm{y}$ & $>10 \mathrm{y}$ & \\
\hline \multirow[t]{3}{*}{ Specification 1} & 18 & 10 & 21 & - & 26 & - & - & - & - & - & 7 & - & - & 5 & 4 \\
\hline & 21 & - & 15 & 5 & 26 & - & - & - & - & - & 6 & - & - & 6 & 5 \\
\hline & 21 & - & 23 & - & 22 & 6 & - & - & - & - & 7 & - & - & 5 & 4 \\
\hline \multirow[t]{3}{*}{ Specification 2} & 19 & 8 & 22 & - & 22 & - & - & 10 & 4 & 6 & - & 6 & - & 6 & 3 \\
\hline & 20 & - & 13 & 5 & 21 & - & - & 10 & 3 & 5 & - & 6 & - & 7 & 4 \\
\hline & 120 & - & 23 & - & 20 & 5 & - & 9 & 4 & 6 & - & 6 & - & 5 & 3 \\
\hline
\end{tabular}

Table 16: Between-profession regressions with valuation-purpose controls. Significant coefficients.

Description: The table sums up all statistically significant regression coefficients (10\% or less) across all 98 questions in all tables (2, 3, 5-7, 9-11). All significance tests are two-tailed.

Specification 1: $y_{i j}=\beta_{0 j}+\beta_{1 j}$ Cons $_{i}+\beta_{2 j} I B_{i}+\beta_{3 j} P E_{i}+\beta_{4 j} M B A_{i}+\beta_{5 j} H \operatorname{Exp}_{i}+\beta_{6 j} L S_{i}+\beta_{7 j} C_{l u s 2_{i}}+\varepsilon_{i j}$,

Specification 2: $y_{i j}=\beta_{0 j}+\beta_{1 j}$ Cons $_{i}+\beta_{2 j} I B_{i}+\beta_{3 j} P E_{i}+\beta_{4 j} B A_{i}+\beta_{5 j} M A_{i}+\beta_{6 j} P h D_{i}+\beta_{7 j} C F A_{i}+\beta_{8 j} H E x p_{i}+\beta_{9 j} L S_{i}+\beta_{10 j} C l u s 2_{i}+\varepsilon_{i j}$, $\Phi$ where $y_{i j}$ is respondent $i$ 's answer to question $j$. The RHS variables in the regression are defined in the text.

"Cons.," "IB," "PE," and "AM" denote "Consulting," "Investment Banking," "Private Equity," and "Asset Management" respectively. "BA," "MA," "PhD," "MBA," and "CFA" denote "Bachelor," "Master," "Doctoral degree," "Master of Business Administration," and "Chartered Financial Analyst" respectively. "Cluster 2" consists of specialists for each profession.

Interpretation: Between-profession regressions show that the purpose of the valuation is only of marginal importance with respect to the choice of valuation technique. 


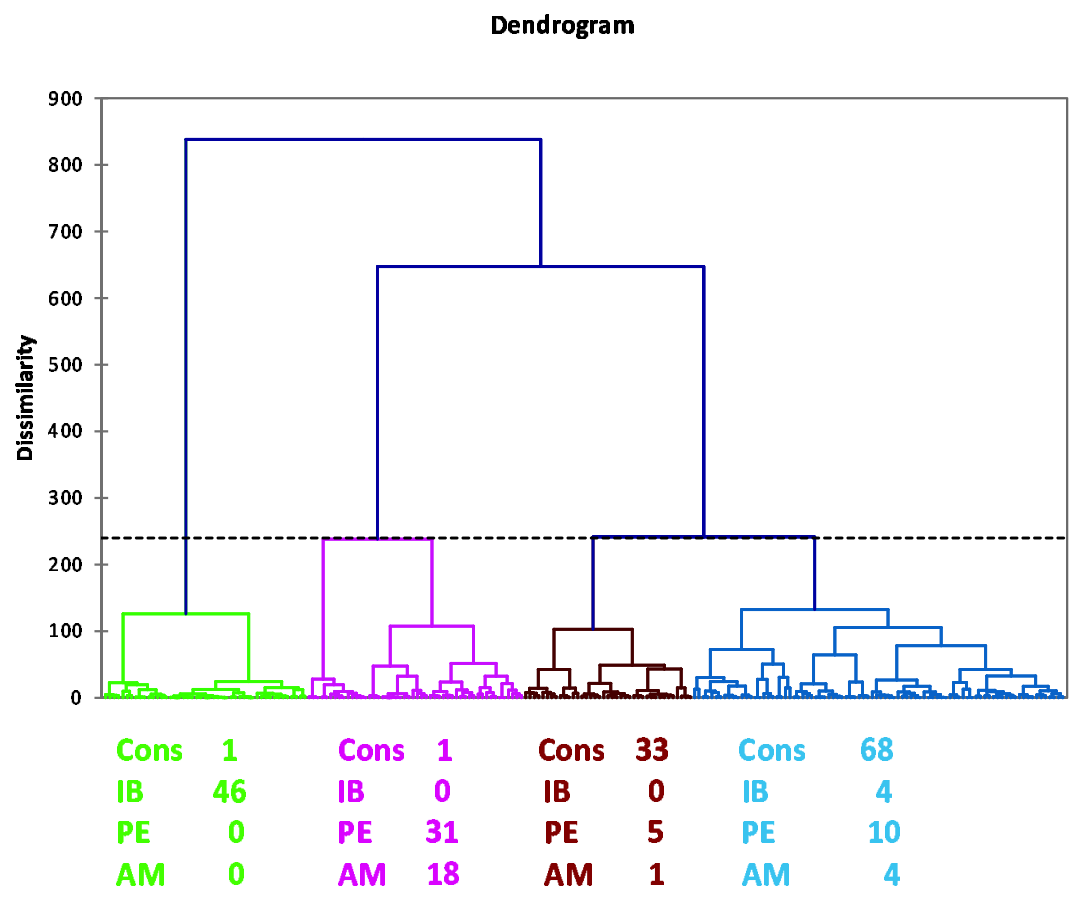

Figure 1: Clusters by valuation purpose.

Description: Dendrogram produced by cluster analysis (hierarchical, agglomerative, Ward's linkage, nearest-neighbor for missing values) set to give four clusters. Distances are calculated using the Euclidean metric based on eleven characteristics (Project Finance, Listed, Unlisted, Real Estate; M\&A, Investment Decisions, Going Public, Going Private; Buy side, Sell side, Advisory), on a scale from 0 to 4, for each of the 222 respondents in the sample. The numbers below the dendrogram provide the number of people, by profession, in each of the four clusters. Dissimilarity is the increase in the sum of squared distances from the mean cluster vectors from joining two clusters, as given by equation (8) in the text. "Cons.," "IB," "PE," and "AM" denote "Consulting," "Investment Banking," "Private Equity," and "Asset Management," respectively.

Interpretation: Respondents' valuation-purpose characteristics cluster largely along professionalsubgroup lines. The figure should be read from the bottom up; clusters grow larger as dissimilarity (based on Euclidean distance in eleven dimensions) is allowed to be larger. The algorithm is set to produce four clusters. 


\section{Survey on investment valuation practice and policy}

Boxes: $\quad$ Only one answer possible $\square$ Choose all that apply

\section{Preliminary and Personal questions}

1. What kind of investments are you usually valuing?

Never $\quad 0 \quad 1 \quad 2 \quad 3 \quad 4 \quad$ Always
a. Project finance
b. Listed firms or divisions
c. Unlisted firms or divisions
d. Real estate
e. Other, please specify ...

2. What is the usual purpose of your valuations?

Never $\quad 0 \quad 1 \quad 2 \quad 3 \quad 4 \quad$ Always
a. Merger or acquisition
b. Investment decision
c. Going public (Initial Public Offerings, IPOs)
d. Going private
e. Other, please specify ...

3. What side of the investment are you usually on?

Never $\quad 0 \quad 1 \quad 2 \quad 3 \quad 4 \quad$ Always
a. I am on the buy-side
b. I am on the sell-side
c. Advisory role
d. Other, please specify ...
4. Age
5. Education
6. Years of Work Experience
○ $20-25$
Bachelor Degree
○ $0-3$
○ $25-30$
$\square$ Master Degree
○ $4-10$
○ $30-40$
$\square \mathrm{MBA}$
$\bigcirc 10+$
○ $40-50$
$\square \mathrm{PhD}$
$\bigcirc 50+$
$\square$ CFA
$\square$ Other Professional Exam

7. Professional Title (e.g. Analyst, Associate, Investment Manager, Consultant, etc.)
8. Gender
Female
$\bigcirc$ Male

9. Sector focus

$\bigcirc$ No

Yes, which?

10. Firm size focus (in terms of enterprise value) 


\section{Regional Focus}

$\square$ Western Europe

$\square$ South and Middle America
Eastern Europe

Asia
North America

$\square$ Middle East
Africa

\section{Relative Valuation (Multiples)}

13. How important are the following types of multiples?

Not important $\quad 0 \quad 1 \quad 2 \quad 3 \quad 4 \quad$ Very important

a. Price-Earnings Ratio (P/E) b. Price/Earnings to Growth Ratio (PEG) c. Price-to-Book (P/B)

d. Price-to-Sales $(\mathrm{P} / \mathrm{S}) \quad$ e. Price-to-Cash Flow $(\mathrm{P} / \mathrm{CF}) \quad$ f. Enterprise Value-to-Sales $(\mathrm{EV} / \mathrm{S})$

g. Enterprise Value-to-EBITDA (EV/EBITDA) h. Enterprise Value-to-EBITA (EV/EBITA)

i. Enterprise Value-to-EBIT (EV/EBIT) j. Industry-specific multiples (e.g. EV to subscribers; $\mathrm{EV}$ to $m^{2}$ of sales area; EV to members)

14. How important are the following:

Not important $\quad 0 \quad 1 \quad 2 \quad 3 \quad 4 \quad$ Very important
a. Trailing multiples
b. 12-months forward multiples
c. 24-months forward multiples

15. What firm's or project's characteristics affect your choice on which multiples to use?

Not important $\quad 0 \quad 1 \quad 2 \quad 3 \quad 4 \quad$ Very important
a. Industry sector
b. Size
c. Type of transaction
d. Accounting policies and potential for manipulation
e. Earnings and margins stability
f. Capital intensity
g. Stock liquidity
h. Other, please specify ...

16. What factors affect the selection of comparable firms?

$\begin{array}{lllllll}\text { Not important } & 0 & 1 & 2 & 3 & 4 & \text { Very important }\end{array}$
a. Bloomberg default comparable firms
b. Industry sector
c. Size
d. Close competitors
e. Age

f. Expected Growth Rate

g. Return on Invested Capital (ROIC)

h. Stock liquidity

i. Other qualitative aspects j. Other, please specify ...

17. Please state the average number of comparable firms (number or range): ... 


\section{Multi-period models}

18. How important are the following approaches?

Not important $\quad 0 \quad 1 \quad 2 \quad 3 \quad 4 \quad$ Very important
a. Discounted Cash Flow (DCF)
b. Residual Income Model (RIM)
c. Economic Value Added (EVA)
d. Dividend Discount Model (DDM)
e. Internal Rate of Return (IRR)

19. Within DCF valuation, how frequently do you use the following approaches?

$\begin{array}{lllllll}\text { Never } & 0 & 1 & 2 & 3 & 4 & \text { Always }\end{array}$
a. Net Present Value (NPV)
b. Adjusted Present Value (APV)
c. Capital Cash Flow (CCF)
d. Flows-to-Equity
e. Weighted Average Cost of Capital (WACC)

19a. What factors affect your choice in (19.)?

Not important $\quad 0 \quad 1 \quad 2 \quad 3 \quad 4 \quad$ Very important

a. Debt policy of firm or project to be valued (i.e. whether the firm has a target debt ratio)

b. Riskiness of Tax Shield c. Firm's credit rating d. Type of transaction

e. Other, please specify ...

19b. How do the above mentioned factors affect your choice? ...

20. Over how many years do you forecast cash flows in your valuation model?

$\bigcirc$ About 5 years $\bigcirc$ About 8 years $\bigcirc$ About 10 years $\bigcirc$ Other, please specify $\ldots$

21. Terminal value: which of the following approaches do you rely more on?

Never $\quad 0 \quad 1 \quad 2 \quad 3 \quad 4 \quad$ Always
a. Gordon growth model (i.e. $T V=\frac{F C F_{t+1}}{W A C C-g}$ )
b. Price-to-Book ratio
c. Other multiples
d. Liquidation value
e. Replacement costs
f. Invested capital
g. Other, please specify ...

21a. If you use growth in perpetuity (Gordon growth model) for terminal value, which growth rate do you typically use?

$\begin{array}{lllllll}\text { Never } & 0 & 1 & 2 & 3 & 4 & \text { Always }\end{array}$
a. $-2 \%$
b. $-1 \%$
c. $0 \%$
d. $1 \%$
f. $3 \%$
g. $4 \%$
h. Inflation rate
i. GDP growth rate

j. Other, please specify ... 
22a. When calculating Weighted Average Cost of Capital (WACC) of your comparables, do you typically use market weights of equity and debt, or do you typically use target weights?

$\bigcirc$ Market weights $\quad \bigcirc$ Target weights $\quad \bigcirc$ Other, please specify $\ldots$

22b. When calculating Weighted Average Cost of Capital (WACC) to apply to the project or firm you are valuing, do you typically use market weights of equity and debt, or do you typically use target weights?

$\bigcirc$ Market weights $\quad \bigcirc$ Target weights $\quad \bigcirc$ Other, please specify $\ldots$

23. How do you deal with expected future changes in capital structure?

Never $\quad 0 \quad 1 \quad 2 \quad 3 \quad 4 \quad$ Always

a. When using WACC: recalculating WACC for every forecasted year

b. When using Flow-to-Equity: recalculating cost of equity for every forecasted year

c. I use Adjusted Present Value (APV) if the capital structure is not fixed $\quad$ d. Other, please specify ...

24. When using Adjusted Present Value (APV), how do you compute Present Value of Tax Shield (PVTS) (arising from the tax deductibility of interest payments)?

Never $\quad 0 \quad 1 \quad 2 \quad 3 \quad 4 \quad$ Always

a. Discounted at unlevered cost of equity (i.e. cost of assets, or all-equity opportunity cost of capital)

b. Discounted at cost of debt $\quad$ c. It depends on debt policy of the firm

d. It depends on how stable the forecasted cash flows are $\quad$ e. Other, please specify ...

25. Do you ever consider personal taxes when calculating the present value of the tax shield?

$\begin{array}{lllllll}\text { Never } & 0 & 1 & 2 & 3 & 4 & \text { Always }\end{array}$

26. Which of the following approximations / approaches most resemble how you calculate the cost of debt?

No resemblance $\quad 0 \quad 1 \quad 2 \quad 3 \quad 4 \quad$ High resemblance

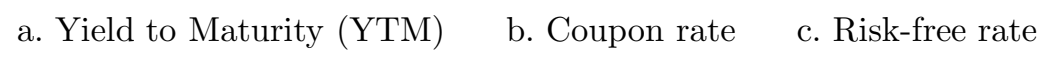

d. Risk-free rate plus spread (based on the rating and/or duration) e. Capital Asset Pricing Model (CAPM)

f. Other, please specify ... 
27. How frequently do you use the following approaches to calculate the cost of equity?

$\begin{array}{lllllll}\text { Never } & 0 & 1 & 2 & 3 & 4 & \text { Always }\end{array}$
a. Capital Asset Pricing Model (CAPM)
b. Fama-French three-factor model
c. Other multi-factor models
d. Other, please specify ...

27a. When calculating the cost of equity, which risk-free rate do you apply? Never $\quad \begin{array}{llllll}0 & 1 & 2 & 3 & 4 & \text { Always }\end{array}$
a. Three month T-bill
b. LIBOR
c. Swap rates
d. Longer term treasury rates
e. I try to match the risk-free rate to the duration of forecasted flows
f. Other, please specify ...

28. When using the CAPM, from where do you get Equity Betas?

$\bigcirc$ In-house calculation $\quad \bigcirc$ Published Equity Betas, please specify the source ...

If in-house calculation:

28a. Do you typically calculate the firm-specific Equity Betas or do you typically use industry Equity Betas?

$\bigcirc$ Firm-specififc Equity Beta $\bigcirc$ Industry-based Equity Beta

28b. You typically estimate Equity Beta using:
$\bigcirc$ Daily returns
$\bigcirc$ Weekly returns
$\bigcirc$ Monthly returns

28c. What time period do you typically use when calculating Equity Beta?
$\bigcirc 1$ year
$\bigcirc$ years
$\bigcirc 5$ years
$\bigcirc$ Other, please specify ...

28d. What do you typically use as the market portfolio?

$\bigcirc$ Regional Index $\bigcirc$ National Stock Index (e.g. S\&P500, DAX) $\bigcirc$ World Index (e.g. MSCI)

28e. Do you typically use Beta-Smoothing techniques?

$\bigcirc$ Yes $\quad \bigcirc$ No

29. When using the CAPM, from where do you get the Market Risk Premium (MRP)

$\bigcirc$ In-house calculation $\bigcirc$ Published sources, please specify the source $\ldots$

29a. What is your Market Risk Premium $\left(M R P=r_{\text {market }}-r_{\text {risk-free }}\right)$ ?

Value or range of values 
29b. Do you consider personal taxes when estimating MRP $M R P=r_{\text {market }}-r_{\text {risk-free }} \times\left(1-T_{p}\right)$ ?

$\bigcirc$ Yes $\quad \bigcirc$ No

\section{General questions on analysis approach}

30. If you are not using a multi-period model - why?

Does not apply at all $\quad 0 \begin{array}{llllll} & 0 & 2 & 3 & 4 & \text { Fully applies }\end{array}$

a. Too time consuming b. Too much uncertainty behind assumptions on CF forecasts

c. Too much uncertainty behind assumptions on Cost of Cap. $\quad$ d. Other, please specify ...

31. How frequently does your analysis include:

Never $\quad \begin{array}{llllll}0 & 1 & 2 & 3 & 4 & \text { Always }\end{array}$

a. Both Multiples and Discounted Cash Flow (DCF) b. Both Multiples and DCF, but Multiples primarily

c. Both Multiples and DCF, but DCF primarily d. Only Multiples e. Only DCF

f. Sensitivity analysis g. Scenario analysis h. Sum-of-parts valuation

32. Does your valuation approach differ across industries?

$\begin{array}{lllllll}\text { Not at all } & 0 & 1 & 2 & 3 & 4 & \text { Yes, it changes completely }\end{array}$

33. Does your valuation approach differ across transaction type?

$\begin{array}{lllllll}\text { Not at all } & 0 & 1 & 2 & 3 & 4 & \text { Yes, it changes completely }\end{array}$

Please use the space below to add any comments you might have: 


\title{
Supplementary Survey The Choice of Valuation Techniques in Practice: Education versus Profession*
}

\author{
Lilia Mukhlynina \\ Kjell G. Nyborg \\ University of Zurich \\ University of Zurich, \\ Swiss Finance Institute, \\ and CEPR
}

September 2018

\section{Introduction}

This short document reports on the results from a supplementary survey intended to examine the robustness of one of our conclusions from the original survey that "confusion reigns with respect to interest rate tax shields and the WACC." As such, the supplementary questionnaire, which is in Appendix B, is much shorter than the original. It is comprised of the same preliminary questions, a subset of the multiperiod model/DCF questions, and a new question, essentially a quiz, on the basics of implementing a valuation using the

\footnotetext{
${ }^{*}$ We are grateful to Ivo Welch for working with us to finalize the design of the supplementary survey. Nyborg (corresponding author): Department of Banking and Finance, University of Zurich, Plattenstrasse 14, CH-8032 Zurich, Switzerland; Swiss Finance Institute and CEPR. Email: kjell.nyborg@bf.uzh.ch. Mukhlynina: lilia.mukhlynina@bf.uzh.ch.
} 
WACC. Because the purpose is to check a part of the original survey, the supplementary survey was sent to a relatively small set of valuation professionals. In total, there are twenty-four respondents.

The results from the supplementary survey support our original conclusions. Valuation professionals' preferred multiperiod approach is DCF and they discount cash flows using the WACC. However, their answers to questions designed to test the depth of their understanding suggest that they are confused with respect to interest tax shields and the WACC, just as in the original survey. Their answers on the quiz confirm this. The quiz examines comprehension on three dimensions: (i) adjusting the WACC for leverage, (ii) avoiding double counting the tax shield, (iii) which cash flows to discount. Respondents are uniformly confused about how to adjust the WACC for leverage. In addition, approximately one third of the respondents double count tax shields, failing to recognize that the WACC is a tax-adjusted discount rate. However, there is little confusion with respect to the basic cash flows that should be discounted.

\section{The supplementary survey}

There are three parts to the questionnaire. The first part asks a series of background and personal questions that relate to the purpose of valuation, educational level achieved, experience, gender, regional focus, and so on (15 questions, including subquestions). These are the same as in the original survey. The second part focuses on multi-period models and is also taken from the original survey ( 8 questions). The third part contains the new question on WACC implementation - the quiz (3 questions).

The supplementary survey was conducted online with the help of the LimeSurvey tool. ${ }^{1}$ Email invitations with the link to the survey were sent to 432 investment professionals on July 6 and a reminder on July 31, 2018. None of these participated in the first survey. We have 13 complete and 11 partly complete responses, for an overall response rate of 5.6\%. This is similar to the response rate of $6.0 \%$ for the original survey. We define a survey response as "complete" if the respondent has answered at least one question in all three parts of the survey. Partly complete responses, apart from having some missing questions throughout the survey, all stop before part 3. Evidently, the exam-like nature of this

\footnotetext{
${ }^{1}$ LimeSurvey is a free software for conducting online surveys. See www.limesurvey.org.
} 
part served to discourage some respondents from attempting it. Given the low number of respondents, we have not subdivided them into subprofessions or educational levels in the tables below.

The twenty-four respondents are almost equally divided between those who have a bachelor or master as the highest basic degree. Roughly half of them also have CFA, MBA, or $\mathrm{PhD}$ degrees. Most respondents are middle-aged (30-40 years). Complete responses are tilted towards relatively younger professionals. The majority of respondents are highly experienced (10+ years). On the whole, respondents do not have a sector focus and their firm size focus is smaller than EUR 500 mill. They do both national and cross-border deals and have a regional focus on Western Europe. All subprofessions are represented and there are no two respondents from the same firm.

As in the original survey, respondents have several valuation purposes. As seen in Table 1, for type of investment, the strength of response is highest for unlisted firms for both the complete and partly complete groups (3.58 and 3.64, respectively). Merger and acquisitions and investment decisions are the top two choices for type of transaction. Respondents in the complete group are mostly in an advisory role (3.45), while the partly complete group are mostly buy-side (3.00).

\section{Insert Table 1 here.}

\section{$3 \quad$ Findings}

This section summarizes the answers to Part 2 (multiperiod models and WACC, questions 13 to 16 ) and Part 3 (the quiz) of the questionnaire.

\subsection{Multi-period models and WACC}

Table 2 summarizes the responses to questions 13, 14, and 16. As seen, DCF is the favored multiperiod approach, with a strength of response of 3.62 and 3.14 for the complete and partly complete groups, respectively. IRR is in second place (2.23 and 2.71 , respectively).

Insert Table 2 here.

When using DCF, $85 \%$ and $86 \%$ of respondents use the WACC almost always or always 
in the complete and partly complete groups, respectively. As in the original survey, APV is rarely used. Most respondents in either group also report that they use NPV almost always or always. The choice of DCF approach may depend on the transaction type and debt policy. Forty-six (thirty-three) percent of respondents in the complete (partly complete) group report that they recalculate the WACC in their projections if capital structure changes. This suggests a relatively low level of appreciation of the result that the WACC is sensitive to leverage. On the whole, responses are similar across the two groups and concordant with the results from the original survey.

To further examine how respondents' deal with changes in leverage when using the WACC, Question 15 asks how they would go about estimating the WACC for a project given data on comparables. We first ask whether respondents use market or target weights when estimating the WACC of the comparables and then repeat the question for the WACC of the project. As seen in Table 3, with respect to the WACC for comparables, $58 \%$ in the complete group and $71 \%$ in the partly complete group correctly answer that they use market weights. For the to-be-valued project, $38 \%$ and $71 \%$, respectively, incorrectly use

market weights. As in the original survey, these numbers suggest confusion among the respondents regarding how to adjust the WACC for leverage.

\section{Insert Table 3 here.}

\subsection{The quiz on WACC implementation}

In Part 3 of the supplementary survey, respondents are tested on three tasks:

A. Estimating the WACC of a project given complete information for a comparable and incomplete information (missing cost of equity) for the project. The project supports a different leverage ratio than what the comparable operates with. The challenge is thus to re-leverage the WACC.

B1. Using the WACC in valuation. The main challenge here is to avoid double counting the tax shield (which is implicit in the WACC - the WACC is a tax-adjusted discount rate).

B2. Choosing the correct basic cash flows to discount. 
The questions are posed as multiple choice (see Appendix B). For simplicity, there is only one comparable and the cost of debt is the same for the comparable as for the project. The setup gives a maximum tax advantage to debt (there are no personal taxes) and assumes leverage ratios are fixed so that discounting unlevered after-tax cash flows at the WACC is correct (Miles and Ezzell, 1980). ${ }^{2}$ The thirteen respondents' answers are laid out on a person-by-person basis in Table 4. The table also includes individual answers to Question 15.

\section{Insert Table 4 here.}

The first two columns in Table 4 show the responses to Questions $15 \mathrm{a}$ and b (in Part 2). ${ }^{3}$ For either question, seven individuals have the right answer ("market" and "target," respectively). However, only three respondents have both correct.

Confusion among the respondents is also apparent when we look at their answers on the quiz. With respect Question A, none of the respondents picked the correct answer. Only one respondent picked an answer that involves re-leveraging the WACC, but this respondent picked the answer that reverses the leverage ratios of the comparable and the project. The most common response (refer to Table 4) is to use the standard WACC formula,

$$
\mathrm{WACC}=\frac{E}{V} r_{e}+\frac{D}{V} r_{d}\left(1-T_{c}\right),
$$

with the target weights applied to the cost of equity of the comparable and the common cost of debt. In contrast, the correct approach would be to use the market weights of the comparable to calculate its WACC and then re-leverage this to reflect the different leverage ratio of the project. The most common response reveals confusion about how to re-leverage WACCs, but also includes another, more fundamental, mistake; it ignores that the cost of equity is a function of leverage. In short, the responses to Question A in Part 3 support the conclusion from the original survey that there is widespread confusion about tax shields and the WACC. For some professionals, the confusion may be even deeper.

\footnotetext{
${ }^{2}$ Ignoring issues relating to default (see Cooper and Nyborg, 2008). Personal taxes are ignored for simplicity and also because the original survey shows that valuation professionals rarely consider them.

${ }^{3}$ One individual (respondent 1) answered "other" to both questions as well as to all questions in Part 3. The respondent explained this by saying he/she does not use the WACC.
} 
Question B1 asks about using the WACC to value a non-growing perpetuity. Forty-five percent correctly chose to discount cash flows at the WACC without any further adjustment

for the tax shield. However, about a third of the respondents picked procedures that double count the tax shield, either by adding it to the cash flow or by adding the term $T_{c} D$ to the final answer. One respondent did not include the tax shield at all. This individual (respondent 10) discounted at a WACC (from part A) that used the pre-tax cost of debt (so an estimate of the unlevered cost of capital). The responses to Question B1 show that the respondents are less confused about how to use the WACC, once it is given, than they are with respect to how to adjust it for leverage in the first place. Still, some confusion remains.

In Question B2, the respondents are asked to state which basic cash flows they are discounting. Various incorrect answers are available in the multiple-choice set, but eighty percent correctly picked the after-tax unlevered cash flows.

\section{Conclusion}

To summarize, the evidence from the supplementary survey supports our original conclusion that valuation professionals are confused with respect to tax shields and the WACC. They find it especially difficult to deal with the WACC being sensitive to leverage. This is seen in their confusion about when and whether to use market or target leverage ratios when estimating the WACC and in their answers on the quiz. A few valuation professionals are also prone to double counting tax shields. In general, one might say that professionals have a less than perfect understanding of the WACC as a tax-adjusted discount rate. However, on the bright side, almost all of the respondents choose the correct cash flows to discount.

\section{References}

Cooper, I.A. and K.G. Nyborg (2008). Tax-adjusted discount rates with investor taxes and risky debt. Financial Management 37, 365-379.

Miles, J. and J.R.Ezzell (1980). The weighted average cost of capital, perfect capital markets and project life: A clarification. Journal of Financial and Quantitative Analysis 15, 719-730. 


\section{Appendix A: Supplementary Survey Tables}

\begin{tabular}{|c|c|c|c|c|c|c|c|c|}
\hline & \multicolumn{4}{|c|}{ Complete } & \multicolumn{4}{|c|}{ Partly complete } \\
\hline & Replies & $\% 1-4$ & $\% 3-4$ & mean & Replies & $\% 1-4$ & $\% 3-4$ & mean \\
\hline \multicolumn{9}{|c|}{ Panel A: Type of investment } \\
\hline Project finance & 12 & $75 \%$ & $8 \%$ & 1.17 & 10 & $70 \%$ & $30 \%$ & 1.40 \\
\hline Listed firms & 13 & $69 \%$ & $31 \%$ & 1.69 & 9 & $78 \%$ & $22 \%$ & 1.44 \\
\hline Unlisted firms & 12 & $100 \%$ & $100 \%$ & 3.58 & 11 & $100 \%$ & $100 \%$ & 3.64 \\
\hline Real estate & 12 & $67 \%$ & $25 \%$ & 1.50 & 9 & $11 \%$ & $0 \%$ & 0.11 \\
\hline Other & 2 & & & & 0 & & & \\
\hline \multicolumn{9}{|c|}{$\overline{\text { Panel B: Type of transaction }}$} \\
\hline Merger or acquisition & 13 & $92 \%$ & $85 \%$ & 3.15 & 10 & $100 \%$ & $90 \%$ & 3.50 \\
\hline Investment decisions & 13 & $85 \%$ & $54 \%$ & 2.38 & 11 & $100 \%$ & $91 \%$ & 3.27 \\
\hline Going public & 12 & $42 \%$ & $8 \%$ & 0.58 & 9 & $56 \%$ & $11 \%$ & 1.11 \\
\hline Going private & 11 & $18 \%$ & $18 \%$ & 0.64 & 9 & $44 \%$ & $0 \%$ & 0.56 \\
\hline Other & 1 & & & & 0 & & & \\
\hline \multicolumn{9}{|l|}{ Panel C: Role } \\
\hline Buy-side & 10 & $80 \%$ & $30 \%$ & 1.90 & 10 & $100 \%$ & $80 \%$ & 3.00 \\
\hline Sell-side & 11 & $82 \%$ & $36 \%$ & 1.82 & 10 & $80 \%$ & $60 \%$ & 2.30 \\
\hline Advisory role & 11 & $100 \%$ & $82 \%$ & 3.45 & 10 & $70 \%$ & $60 \%$ & 2.20 \\
\hline Other & 0 & & & & 0 & & & \\
\hline
\end{tabular}

Table 1: Purpose of valuation across the complete and partly complete responses.

Description: This table reports on valuation purpose characteristics of the complete and partly complete responses.

Interpretation: The two groups have similar valuation purpose characteristics. 


\begin{tabular}{|c|c|c|c|c|c|c|c|c|}
\hline & \multicolumn{4}{|c|}{ Complete } & \multicolumn{4}{|c|}{ Partly complete } \\
\hline & Replies & $\% 1-4$ & $\% 3-4$ & mean & Replies & $\% 1-4$ & $\% 3-4$ & mean \\
\hline \multicolumn{9}{|c|}{ Panel A: Different models } \\
\hline DCF & 13 & $100 \%$ & $85 \%$ & 3.62 & 7 & $100 \%$ & $71 \%$ & 3.14 \\
\hline RIM & 13 & $31 \%$ & $0 \%$ & 0.38 & 7 & $43 \%$ & $14 \%$ & 0.86 \\
\hline EVA & 13 & $31 \%$ & $8 \%$ & 0.54 & 7 & $57 \%$ & $14 \%$ & 1.00 \\
\hline DDM & 13 & $38 \%$ & $15 \%$ & 0.85 & 7 & $71 \%$ & $29 \%$ & 1.43 \\
\hline IRR & 13 & $92 \%$ & $46 \%$ & 2.23 & 7 & $100 \%$ & $71 \%$ & 2.71 \\
\hline \multicolumn{9}{|c|}{$\overline{\text { Panel B: Approaches within DCF }}$} \\
\hline NPV & 13 & $92 \%$ & $62 \%$ & 2.69 & 7 & $86 \%$ & $57 \%$ & 2.57 \\
\hline APV & 13 & $31 \%$ & $0 \%$ & 0.46 & 6 & $50 \%$ & $0 \%$ & 1.50 \\
\hline $\mathrm{CCF}$ & 13 & $38 \%$ & $15 \%$ & 0.92 & 7 & $57 \%$ & $29 \%$ & 1.29 \\
\hline Flows to Equity & 13 & $46 \%$ & $23 \%$ & 1.25 & 7 & $57 \%$ & $43 \%$ & 1.57 \\
\hline WACC & 13 & $92 \%$ & $85 \%$ & 3.38 & 7 & $100 \%$ & $86 \%$ & 3.43 \\
\hline \multicolumn{9}{|c|}{ Panel C: Factors affecting choice of (B) } \\
\hline Debt policy & 13 & $77 \%$ & $46 \%$ & 2.17 & 7 & $71 \%$ & $57 \%$ & 2.14 \\
\hline Tax shield risk & 13 & $54 \%$ & $8 \%$ & 0.92 & 7 & $86 \%$ & $0 \%$ & 1.29 \\
\hline Credit rating & 13 & $62 \%$ & $23 \%$ & 1.25 & 6 & $67 \%$ & $17 \%$ & 1.50 \\
\hline Transaction type & 13 & $77 \%$ & $69 \%$ & 2.62 & 7 & $71 \%$ & $43 \%$ & 1.86 \\
\hline Other & 0 & & & & 0 & & & \\
\hline \multicolumn{9}{|c|}{ Panel D: Future changes in capital structure } \\
\hline WACC & 13 & $62 \%$ & $46 \%$ & 1.77 & 6 & $83 \%$ & $33 \%$ & 2.00 \\
\hline Flows to Equity & 13 & $31 \%$ & $8 \%$ & 0.54 & 6 & $50 \%$ & $17 \%$ & 1.17 \\
\hline APV & 13 & $46 \%$ & $0 \%$ & 0.85 & 6 & $50 \%$ & $17 \%$ & 1.00 \\
\hline Other & 1 & & & & 0 & & & \\
\hline
\end{tabular}

Table 2: Multi-period models.

Description: This table reports on the results from the multiperiod and DCF questions for the complete and partly complete responses.

Interpretation: For both groups, DCF is the preferred multiperiod model and respondents discount cash flows using the WACC. Respondents typically do not recalculate the WACC in response to projected changes in leverage. 


\begin{tabular}{|c|c|c|c|c|}
\hline & \multicolumn{2}{|r|}{ Complete } & \multicolumn{2}{|c|}{ Partly complete } \\
\hline & Replies & $\%$ of total answered & Replies & $\%$ of total answered \\
\hline \multicolumn{5}{|c|}{ Panel A: WA $A \overline{C \text { : weights for comparables }}$} \\
\hline MarketW & 7 & $58 \%$ & 5 & $71 \%$ \\
\hline TargetW & 3 & $25 \%$ & 1 & $14 \%$ \\
\hline Other & 2 & $17 \%$ & 1 & $14 \%$ \\
\hline \multicolumn{5}{|c|}{ Panel B: WA $C \overline{C: \text { weights for valued firm/project }}$} \\
\hline MarketW & 5 & $38 \%$ & 5 & $71 \%$ \\
\hline TargetW & 7 & $54 \%$ & 1 & $14 \%$ \\
\hline Other & 1 & $8 \%$ & 1 & $14 \%$ \\
\hline
\end{tabular}

Note: Incorrect answers are in bold.

Table 3: WACC. Implementation and confusion.

Description: This table reports on respondents' choices of market or target weights (leverage ratios) when calculating WACCs for comparables and the to-be-valued firm or project.

Interpretation: Many respondents incorrectly use target weights to calculate WACCs for comparables and market weights for the project. This indicates confusion regarding the sensitivity of WACC to leverage. 


\begin{tabular}{|c|c|c|c|c|c|}
\hline \multirow{3}{*}{ Respondent } & \multirow{2}{*}{\multicolumn{2}{|c|}{$\frac{\text { PART 2: Q15 }}{\text { WACC weights }}$}} & \multicolumn{3}{|c|}{ PART 3} \\
\hline & & & \multirow{2}{*}{$\begin{array}{c}\text { Question A } \\
\text { Calculating WACC }\end{array}$} & \multirow{2}{*}{$\begin{array}{l}\text { Question B1 } \\
\text { Using WACC }\end{array}$} & \multirow{2}{*}{$\begin{array}{c}\text { Question B2 } \\
\text { Cash Flows }\end{array}$} \\
\hline & (a) Comparables & (b) Project & & & \\
\hline 1 & other & other & other & other & other \\
\hline 2 & target & target & e & b & $\mathrm{b}$ \\
\hline 3 & market & target & c & $\mathrm{a}$ & $\mathrm{b}$ \\
\hline 4 & market & target & c & b & $\mathbf{a}$ \\
\hline 5 & other & target & other & $\mathrm{a}$ & $\mathrm{b}$ \\
\hline 6 & target & target & c & $\mathrm{a}$ & $\mathrm{b}$ \\
\hline 7 & market & market & c & c & $\mathrm{b}$ \\
\hline 8 & market & market & - & - & - \\
\hline 9 & target & target & $\mathbf{a}$ & other & $\mathrm{b}$ \\
\hline 10 & market & target & $\mathbf{b}$ & $\mathrm{a}$ & - \\
\hline 11 & market & market & other & $\mathrm{a}$ & $\mathrm{b}$ \\
\hline 12 & - & market & - & - & - \\
\hline 13 & market & market & c & $\mathrm{b}$ & $\mathrm{b}$ \\
\hline Total correct & $58.33 \%$ & $53.85 \%$ & $0 \%$ & $45.45 \%$ & $80 \%$ \\
\hline
\end{tabular}

\section{Table 4: Implementation of WACC, "Quiz."}

Description: This table reports responses on an individual level for respondents in the "complete" group for Questions $15 \mathrm{a}$ and b (Part 2) and Questions A, B1, and B2 (Part 3). Wrong answers are highlighted red and are in bold. Correct answers are in green. Missing responses are indicated by a dash and not included when calculating correct-answer percentages.

Interpretation: Respondents have a less than perfect understanding of the WACC as a taxadjusted discount rate. They do not understand how to adjust the WACC for changes in leverage and about a third of them double-count tax-shields. 
Appendix B: Supplementary Survey Questionnaire 


\section{Survey on investment valuation practice and policy}

The survey is part of a research project. This part of the survey focuses on multi-period models, especially the technique of dicounted cash flows (DCF).

We estimate that the survey will take you about 10 minutes.

Responses will be used only in aggregate and remain anonymous.

Thank you for taking the time to complete the survey.

Instructions: fill in one box per line: $\bigcirc$ Only one answer possible

$\square$ Choose all that apply

\section{Preliminary and Personal questions}

1. What kind of investments are you usually valuing?

$\begin{array}{lllllll}\text { Never } & 0 & 1 & 2 & 3 & 4 & \text { Always }\end{array}$
a. Project finance
b. Listed firms or divisions
c. Unlisted firms or divisions
d. Real estate
e. Other, please specify ...

2. What is the usual purpose of your valuations?
$\begin{array}{lllllll}\text { Never } & 0 & 1 & 2 & 3 & 4 & \text { Always }\end{array}$
a. Merger or acquisition
b. Investment decision
c. Going public (Initial Public Offerings, IPOs)
d. Going private
e. Other, please specify ...

3. What side of the investment are you usually on?
$\begin{array}{lllllll}\text { Never } & 0 & 1 & 2 & 3 & 4 & \text { Always }\end{array}$
a. I am on the buy-side
b. I am on the sell-side
c. Advisory role
d. Other, please specify ... 

4. Age
5. Education
6. Years of Work Experience
- $20-25$
$\square$ Bachelor Degree
○ $0-3$
○ $25-30$
$\square$ Master Degree
○ $4-10$
○ $30-40$
$\square$ MBA
$10+$
○ $40-50$
$\square \mathrm{PhD}$
○ $50+$
$\square$ CFA
$\square$ Other Professional Exam

7. Professional Title (e.g. Analyst, Associate, Investment Manager, Consultant, etc.)
8. Gender
$\bigcirc$ Female
$\bigcirc$ Male

9. Sector focus

$\bigcirc$ No

Yes, which?

10. Firm size focus (in terms of enterprise value)

$\square$ More than $€ 5$ billion $\quad \square$ Between $€ 500$ million and $€ 5$ billion $\quad \square$ Less than $€ 500$ million
11. Transaction Focus
$\square$ National Deals
$\square$ Cross-Border Deals

\section{Regional Focus}

$\begin{array}{lll}\square \text { Western Europe } & \square \text { Eastern Europe } & \square \text { North America } \\ \square \text { South and Middle America } & \square \text { Asia } & \square \text { Middle East }\end{array}$




\section{Multi-period models}

13. How important are the following approaches?

Not important $\quad 0 \quad 1 \quad 2 \quad 3 \quad 4 \quad$ Very important
a. Discounted Cash Flow (DCF)
b. Residual Income Model (RIM)
c. Economic Value Added (EVA)
d. Dividend Discount Model (DDM)
e. Internal Rate of Return (IRR)

14. Within DCF valuation, how frequently do you use the following approaches?
$\begin{array}{lllllll}\text { Never } & 0 & 1 & 2 & 3 & 4 & \text { Always }\end{array}$
a. Net Present Value (NPV)
b. Adjusted Present Value (APV)
c. Capital Cash Flow (CCF)
d. Flows-to-Equity
e. Weighted Average Cost of Capital (WACC)

14a. What factors affect your choice in (14.)?
$\begin{array}{lllllll}\text { Not important } & 0 & 1 & 2 & 3 & 4 & \text { Very important }\end{array}$
a. Debt policy of firm or project to be valued (i.e. whether the firm has a target debt ratio)
b. Riskiness of Tax Shield
c. Firm's credit rating
d. Type of transaction
e. Other, please specify ...


15a. When calculating Weighted Average Cost of Capital (WACC) of your comparables, do you typically use market weights of equity and debt, or do you typically use target weights?

$\bigcirc$ Market weights $\quad \bigcirc$ Target weights $\quad \bigcirc$ Other, please specify ...

15b. When calculating Weighted Average Cost of Capital (WACC) to apply to the project or firm you are valuing, do you typically use market weights of equity and debt, or do you typically use target weights?

$\bigcirc$ Market weights $\quad \bigcirc$ Target weights $\quad \bigcirc$ Other, please specify $\ldots$

16. How do you deal with expected future changes in capital structure?

Never $\quad \begin{array}{llllll}0 & 1 & 2 & 3 & 4 & \text { Always }\end{array}$
a. When using WACC: recalculating WACC for every forecasted year
b. When using Flow-to-Equity: recalculating cost of equity for every forecasted year
c. I use Adjusted Present Value (APV) if the capital structure is not fixed
d. Other, please specify ... 


\section{WACC implementation: Practical examples}

Suppose you want to value AAA Corp by discounting cash flows at the appropriate weighted average cost of capital (WACC), and that:

- The corporate tax rate, $T_{c}$, is $30 \%$. (There are no personal taxes).

- The target debt-to-value ratio is $20 \%$ (maintained in perpetuity)

- The cost of debt is $5 \%$

- The cost of equity of AAA Corp is unknown, but BBB Corp is an excellent comparable with similar assets, operating strategy, etc, but less equity in its capital structure. BBB Corp maintains a constant leverage ratio over time.

\begin{tabular}{|c|c|c|c|c|}
\hline & $E / V$ & $\begin{array}{c}\text { Cost of equity, } \\
r_{e}\end{array}$ & $D / V$ & $\begin{array}{c}\text { Cost of debt, } \\
r_{d}\end{array}$ \\
\hline AAA Corp & Target: 0.8 & no information available & Target: 0.2 & $5 \%$ \\
\hline BBB Corp & Actual: 0.4 & $10 \%$ & Actual: 0.6 & $5 \%$ \\
\hline
\end{tabular}

$E$ : Equity value; $D$ : Debt value; $V=E+D$

\section{Questions:}

A. WACC: Which is most close to your best estimate of the WACC of AAA Corp?

Select one of the below:

a. $(E / V) r_{e}+(D / V) r_{d}=0.8 \times 10 \%+0.2 \times 5 \%=9.0 \%$

b. $(E / V) r_{e}+(D / V) r_{d}=0.4 \times 10 \%+0.6 \times 5 \%=7.0 \%$

c. $(E / V) r_{e}+(D / V) r_{d}\left(1-T_{c}\right)=0.8 \times 10 \%+0.2 \times 5 \% \times(1-0.3)=8.7 \%$

d. $(E / V) r_{e}+(D / V) r_{d}\left(1-T_{c}\right)=0.4 \times 10 \%+0.6 \times 5 \% \times(1-0.3)=6.1 \%$

e. $9.0 \%-(D / V) r_{d} T_{c}=9.0 \%-0.6 \times 5 \% \times 0.3=8.1 \%$

f. $7.0 \%-(D / V) r_{d} T_{c}=7.0 \%-0.2 \times 5 \% \times 0.3=6.7 \%$

g. None of the above. (Please explain.) 
B. VALUE: Using the WACC in part A, which is most close to your best estimate of the value of AAA Corp given that the expected cash flows per year in perpetuity are as follows:

- Pre-tax, under 100\% equity financing: USD 2.0 mill

- After-tax, under $100 \%$ equity financing: USD 1.4 mill

The formula I would use to estimate AAA Corp's value is: Select one of the below:
a. $\mathrm{CF} / \mathrm{WACC}$
b. $\left(\mathrm{CF}+T_{c} r_{d} D\right) / \mathrm{WACC}$
c. $(\mathrm{CF} / \mathrm{WACC})+T_{c} D$
d. $\left(\mathrm{CF}+T_{c} r_{d} D\right) / \mathrm{WACC}+T_{c} D$
e. None of the above. (Please explain.)

With the cash flow, CF, in the formula above being: Select one of the below:
a. $\mathrm{CF}=\mathrm{USD} 2.0$ mill
b. $\mathrm{CF}=\mathrm{USD} 1.4$ mill
a. $\mathrm{CF}=\mathrm{USD} 2.0$ mill $\times 0.8=\mathrm{USD} 1.6$ mill
c. $\mathrm{CF}=\mathrm{USD} 1.4 \mathrm{mill} \times 0.8=\mathrm{USD} 1.12 \mathrm{mill}$
d. None of the above. (Please explain.) 